\title{
S2k-Leitlinie Gastrointestinale Infektionen und Morbus Whipple ${ }^{1}$
}

\section{S2k-guideline gastrointestinal infectious diseases and Whipple's disease}

Autoren:

Institute

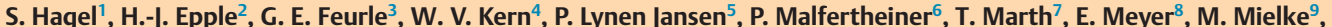
V. Moos $^{10}$, L. von Müller ${ }^{11}$, J. Nattermann ${ }^{12}$, M. Nothacker ${ }^{13}$, C. Pox ${ }^{14}$, E. Reisinger ${ }^{15}$, B. Salzberger ${ }^{16}$, H. J. F. Salzer ${ }^{17}$, M. Weber ${ }^{18}$, T. Weinke ${ }^{19}$, S. Suerbaum ${ }^{20}$, A. W. Lohse ${ }^{* 17}$, A. Stallmach ${ }^{* 11}$

Die Institutsangaben sind am Ende des Beitrags gelistet.

Weitere Mitglieder der Leitlinienkommission sind am Ende des Beitrags gelistet. eingereicht 20.2.2015

akzeptiert $\quad 8.3 .2015$

Bibliografie

DOI http://dx.doi.org/

$10.1055 / \mathrm{s}-0034-1399337$

Z Gastroenterol 2015; 53:

418-459 @ Georg Thieme

Verlag KG Stuttgart · New York · ISSN 0044-2771

Korrespondenzadresse

Prof. Dr. med. Andreas

Stallmach

Klinik für Innere Medizin IV

Gastroenterologie, Hepatologie, Infektiologie

Universitätsklinikum Jena

Erlanger Allee 101

107740 Jena

Germany

Tel. $++49 / 3641 / 9324221$

Fax: ++49/36 41/9324222

Andreas.Stallmach@med.uni-

jena.de

\begin{tabular}{|c|c|c|}
\hline \multicolumn{3}{|c|}{ Inhaltsverzeichnis } \\
\hline \multicolumn{2}{|c|}{ Einleitung } & 418 \\
\hline $\mathrm{E}-1$ & Hintergrund & 418 \\
\hline & Ziele der Leitlinie & 419 \\
\hline \multicolumn{2}{|c|}{ Methodik } & 419 \\
\hline M-1 & Versorgungsbereich und Zielgruppen & 419 \\
\hline M-2 & $\begin{array}{l}\text { Zusammensetzung der Leitliniengruppe: } \\
\text { Beteiligung von Interessengruppen }\end{array}$ & 420 \\
\hline$M-3$ & $\begin{array}{l}\text { Beteiligte Gruppierungen und Fachgesell- } \\
\text { schaften }\end{array}$ & 420 \\
\hline M-4 & $\begin{array}{l}\text { Umgang mit potenziellen Interessens- } \\
\text { konflikten }\end{array}$ & 420 \\
\hline \multirow[t]{3}{*}{ M-5 } & Durchführung & 420 \\
\hline & $\begin{array}{l}\text { a) Recherche, Auswahl und Bewertung } \\
\text { wissenschaftlicher Belege (Evidenz- } \\
\text { basierung) }\end{array}$ & 420 \\
\hline & $\begin{array}{l}\text { b) Formulierung der Empfehlungen und } \\
\text { strukturierte Konsensfindung }\end{array}$ & 420 \\
\hline \multicolumn{2}{|c|}{ Kapitel } & 421 \\
\hline $\mathrm{K}-1$ & $\begin{array}{l}\text { Diagnostik der ambulant erworbenen Gas- } \\
\text { troenteritis (AG 1) }\end{array}$ & 421 \\
\hline $\mathrm{K}-2$ & $\begin{array}{l}\text { Klinisches Bild und Therapie der ambulant } \\
\text { erworbenen Gastroenteritis (AG 2) }\end{array}$ & 427 \\
\hline $\mathrm{K}-3$ & $\begin{array}{l}\text { Nosokomiale Diarrhö und Clostridium difficile } \\
\text { (AG 3) }\end{array}$ & 433 \\
\hline $\mathrm{K}-4$ & Diarrhö bei Immundefizienz (AG 4) & 439 \\
\hline K-5 & $\begin{array}{l}\text { Akute Gastroenteritis bei Reiserückkehrern } \\
\text { (AG 5) }\end{array}$ & 442 \\
\hline K-6 & Morbus Whipple (AG 6) & 448 \\
\hline \multicolumn{2}{|c|}{ Literatur } & 454 \\
\hline
\end{tabular}

\section{Einleitung und Methodik \\ $\nabla$}

\section{E-1 Hintergrund}

Akute gastrointestinale Infektionen werden durch eine tbVielzahl bakterieller, viraler und parasitärer Erreger hervorgerufen. Der Krankheitsverlauf wird durch die Virulenz des jeweiligen Erregers, die Wirtsantwort, durch den Ernährungs- und Immunstatus des Wirtes sowie mögliche Begleiterkrankungen beeinflusst. Meist ist eine infektiöse Gastroenteritis selbstlimitierend, eine symptomatische Behandlung ausreichend und eine ätiologische Abklärung aus klinischen Erwägungen nicht notwendig [1] .

Akute gastrointestinale Infektionen sind häufig. Im Rahmen einer epidemiologischen Studie, bei der über 12 Monate 21262 Erwachsene nach Symptomen einer gastrointestinalen Infektion in den vergangenen 4 Wochen telefonisch befragt wurden, wurde für Deutschland eine Inzidenz von 0,95 Episoden/Personenjahr ermittelt. Hochgerechnet bedeutet dies für Deutschland rund 65 Mio. Episoden einer akuten gastrointestinalen Erkrankung pro Jahr, von denen die überwiegende Mehrzahl infektiöser Genese ist. 78\% der Erkrankten gaben an, eine Diarrhö gehabt zu haben, $12 \%$ der Erkrankten berichteten über Erbrechen, 10\% der Erkrankten wiesen beide Symptome auf. Die durchschnittliche Erkrankungsdauer betrug 3,7 Tage. Mehr als ein Drittel (37,8\%) der Erkrankten begaben sich in eine ambulante ärztliche Betreuung, weniger als $1-3 \%$ der Patienten wurden hospitalisiert [2]. Die bei Weitem größte Gruppe der Patienten mit aku-

\footnotetext{
${ }^{1}$ Ergebnisse einer S2k-Konsensuskonferenz der Deutschen Gesellschaft für Gastroenterologie, Verdauungs- und Stoffwechselerkrankungen (DGVS) gemeinsam mit der Deutschen Gesellschaft für Innere Medizin (DGIM), der Deutschen Gesellschaft für Hygiene und Mikrobiologie (DGHM), der Deutschen Gesellschaft für Infektiologie (DGI), der Deutschen Gesellschaft für Krankenhaushygiene e.V. (DGKH), der Deutschen Gesellschaft für Pathologie (DGP), der Deutschen Gesellschaft für Tropenmedizin und Internationale Gesundheit (DTG), dem Robert Koch-Institut (RKI) und der Paul-Ehrlich Gesellschaft für Chemotherapie e.V. (PEG).

* Gleichberechtigte durch die DGVS mandatierte Koordinatoren der Leitlinie

\# für die Mitglieder der Leitlinienkommission „Gastrointestinale Infektion und Morbus Whipple“
} 
Tab. 1 Definitionen für den Leitlinientext

\begin{tabular}{|c|c|}
\hline \multicolumn{2}{|l|}{ Definition } \\
\hline akute Diarrhö & $\begin{array}{l}\geq 3 \text { Stuhlentleerungen sowie ein Stuhlgewicht }>250 \mathrm{~g} \\
\text { pro Tag bei verminderter Stuhlkonsistenz }\end{array}$ \\
\hline Dysenterie & $\begin{array}{l}\text { Diarrhö einhergehend mit Blut- und Schleimbeimen- } \\
\text { gungen }\end{array}$ \\
\hline $\begin{array}{l}\text { chronische } \\
\text { Diarrhö }\end{array}$ & Diarrhö länger als 4 Wochen anhaltend \\
\hline Immundefizienz & $\begin{array}{l}\text { - angeborene Immundefizienz, z. B. im Rahmen von } \\
\text { T- und B-Zell-Defekten } \\
\text { - Patienten mit erworbener Immundefizienz, z. B. Z. n. } \\
\text { Organ- oder Knochenmarktransplantation; Chemo- } \\
\text { therapie solider oder hämatologischer Neoplasien mit } \\
\text { oder ohne Neutropenie; HIV-Infektion im Stadium } \\
\text { AIDS; Immunsuppressive oder immunmodulierende } \\
\text { Therapie bei Autoimmunopathien; Glukokortikoid- } \\
\text { therapie über einen Zeitraum von mindestens vier } \\
\text { Wochen mit einer Erhaltungsdosis } \geq 10 \text { mg/d. }\end{array}$ \\
\hline
\end{tabular}

ter Gastroenteritis wird somit ambulant betreut. Im Gegensatz zu diesen blanden, selbstlimitierenden Verläufen steht die Beobachtung, dass sich von 2001 - 2011 die Zahl der stationären Aufnahmen aufgrund einer akuten infektiösen Gastroenteritis von 127867 auf 282199 Fälle pro Jahr mehr als verdoppelt hat. Besonders stark war dieser Anstieg in der Gruppe der über 65-jährigen Patienten sowie bei Patienten mit Clostridium difficile-Infektionen (CDI) zu verzeichnen. Die Zahl der Sterbefälle aufgrund gastrointestinaler Infektionen stieg im gleichen Zeitraum um das 10fache an [3].

Entsprechend der nationalen und internationalen Literatur wurden - wie in 0 Tab. 1 angegeben - zentrale Bezeichnungen für den Leitlinientext definiert.

\section{E-2 Ziele der Leitlinie}

Vor dem Hintergrund der Häufigkeit, aber auch der Bandbreite vom blanden, selbstlimitierenden Verlauf, bis hin zur vital-bedrohlichen Infektion ist ein evidenzbasiertes Vorgehen in der Diagnostik und Therapie notwendig, um den Patientenbedürfnissen gerecht zu werden, aber auch um die zur Verfügung stehenden Ressourcen adäquat einzusetzen. Aufgrund dessen hat sich die Deutsche Gesellschaft für Gastroenterologie, Verdauungs- und Stoffwechselerkrankungen entschlossen, eine S2kLeitlinie zu erstellen, die diesem wachsenden Problem Rechnung trägt. Die methodische Erstellung der Leitlinie folgt dem Regelwerk der AWMF und dem Leitlinienprogramm der DGVS [4]. Um der Vielfältigkeit und den Besonderheiten gastrointestinaler Infektionen bei Patienten in unterschiedlichen Situationen gerecht zu werden, wurden insgesamt 6 Arbeitsgruppen gebildet:

- Diagnostik der ambulant erworbenen Gastroenteritis (AG 1)

- Klinisches Bild und Therapie der ambulant erworbenen Gastroenteritis (AG 2)

- Nosokomiale Diarrhö und Clostridium difficile (AG 3)

- Diarrhö bei Immundefizienz (AG 4)

- Akute Gastroenteritis bei Reiserückkehrern (AG 5)

- Morbus Whipple (AG 6)

Obgleich ausgesprochen selten, stellt auch die Infektion mit Tropheryma whipplei eine gastrointestinale Infektion dar, die in dieser Leitlinie in einem eigenen Kapitel dargestellt wird. In dieser Arbeitsgruppe gab es zur Empfehlung 6.4 keinen Konsens; hier fand eine sehr kontroverse Diskussion statt. Da Vertreter beider Positionen aufgrund ihrer klinischen Erfahrungen und wissenschaftlichen Expertise als nationale und internationale Experten gelten, sogenannte Kompromissformulierungen zu wenig inhaltliche Aussagen enthalten und deshalb für die Praxis als nicht hilfreich erachtet wurden, entschlossen sich die Koordinatoren in Abstimmung mit dem Vertreter der Arbeitsgemeinschaft der Wissenschaftlichen Medizinischen Fachgesellschaften e.V. (AWMF) (M. Nothacker), ein sog. Minderheitsvotum aufzunehmen. Ebenso wurde zur Empfehlung 1.4 eine Minderheitsmeinung der Vertreter des Robert Koch-Instituts aufgenommen, die auf eine regelhafte Diagnostik bez. Stx-Bildner bei Patienten mit blutigen Diarrhöen zum Ausschluss einer EHEC-Infektion hinwiesen.

Das Ziel der S2k-Leitlinie „Gastrointestinale Infektionen und Morbus Whipple“ ist es, den aktuellen Kenntnisstand zu klinischem Bild, Diagnostik und Therapie gastrointestinaler Infektionen bei Erwachsenen auf Basis der wissenschaftlichen Evidenz zusammenzufassen, im Expertenkonsens zu bewerten und daraus praxisrelevante Empfehlungen abzuleiten. Sie soll einen Handlungskorridor für häufige Entscheidungen liefern und der evidenzbasierten Fort- und Weiterbildung dienen, um somit eine Verbesserung der medizinischen Versorgung betroffener Personen zu erreichen. Für die Therapie und die Besonderheiten bei Kindern und Jugendlichen sei auf die AWMF-Leitlinie „Akute infektiöse Gastroenteritis“ der Gesellschaft für Pädiatrische Gastroenterologie und Ernährung (GPGE) hingewiesen (AWMF Leitlinien Register; Nr.068/003). Für die Diagnostik und Therapie der Helicobacter pylori-Infektion wird auf die entsprechende, aktuell in Revision befindliche, AWMF-Leitlinie „Helicobacter pylori und gastroduodenale Ulkuskrankheit” der Deutschen Gesellschaft für Gastroenterologie, Verdauungs- und Stoffwechselkrankheiten (DGVS) und auf die Mikrobiologisch-infektiologischen Qualitätsstandards (MIQ): Gastrointestinale Infektionen verwiesen [5, 6]. Da Besonderheiten hinsichtlich Diagnostik, Therapie und Verlauf bei immundefizienten Patienten beachtet werden müssen, widmet sich diesem Thema detailliert das Kapitel 4. In der Gruppe immundefizienter Patienten werden einerseits Patienten mit angeborener Immundefizienz z. B. im Rahmen von T- und B-ZellDefekten als auch Patienten mit erworbener Immundefizienz im Rahmen einer fortgeschrittenen HIV-Erkrankung, einer Immunsuppression bei Chemotherapie oder medikamentös bedingt nach Transplantationen oder unter der Therapie einer Autoimmunerkrankung verstanden. Auf Besonderheiten bei der Therapie älterer Patienten über 65 Jahre wird, sofern die Evidenz dies zulässt, in den entsprechenden Kapiteln zu Diagnostik und Therapie gesondert hingewiesen.

\section{Gültigkeit der Empfehlungen}

Die Diagnose- und Therapieempfehlungen gelten nicht für Säuglinge und Kleinkinder; hier sei auf die entsprechenden Leitlinien der Fachgesellschaften verwiesen.

Die Gültigkeit dieser Leitlinie beträgt 5 Jahre. Eine Revision ist für 2018/2019 geplant. Ansprechpartner für die Aktualisierung ist Frau PD. Dr. med. Petra Lynen Jansen, lynen@dgvs.de.

\section{Methodik}

$\nabla$

\section{M-1 Versorgungsbereich und Zielgruppen}

Die Empfehlungen richten sich an alle an der Diagnostik und Therapie beteiligten Berufsgruppen (insbesondere an Hausärzte, Allgemeinmediziner, Internisten, Gastroenterologen, Infektiologen, 
Reisemediziner, Laborärzte, Mikrobiologen sowie Krankenhaushygieniker) ebenso wie an alle betroffenen Personen.

\section{M-2 Zusammensetzung der Leitliniengruppe: Beteiligung von Interessengruppen}

Die Deutsche Gesellschaft für Gastroenterologie, Verdauungsund Stoffwechselkrankheiten (DGVS) beauftragte zunächst Martin Zeitz (Berlin) und Andreas Stallmach (Jena) mit der Leitung der Leitlinienerstellung. Mit dem Wechsel von M. Zeitz auf die Position des Ärztlichen Direktors am Universitätsklinikum Hamburg-Eppendorf legte dieser sein Mandat nieder. Durch die DGVS wurde anschließend Ansgar Lohse (Hamburg) mit der Funktion des Koordinators betraut. In Abstimmung mit der DGVS und AWMF wurden die Eckpunkte des Konsentierungsverfahrens festgelegt, andere Fachgesellschaften eingeladen und die Mitglieder der Arbeitsgruppen ausgewählt. Dabei erfolgte die Auswahl der AG-Mitglieder primär nach fachlicher Expertise. Da es sich um ein akutes Krankheitsbild handelt und eine Selbsthilfegruppe nicht existiert, war ein Patientenvertreter nicht beteiligt ( $\bullet$ Tab. 2 ).

Tab. 2 Mitarbeiter der Leitlinie.

\begin{tabular}{|c|c|c|}
\hline arbeiter der Leitlinie & & \\
\hline $\begin{array}{l}\text { AG } 1 \text { „Diagnostik der am- } \\
\text { bulant erworbenen Gastro- } \\
\text { enteritis“ }\end{array}$ & $\begin{array}{l}\text { A. Stallmach (DGVS, } \\
\text { DGIM, Jena) } \\
\text { M. Mielke (RKI, Berlin) } \\
\text { S. Suerbaum (DGHM, } \\
\text { Hannover) }\end{array}$ & $\begin{array}{l}\text { C. Berg (Tübingen) } \\
\text { S. Ebensberger (Jena) } \\
\text { A. Flieger (RKI, Berlin) } \\
\text { M. Höhne (RKI, Berlin) } \\
\text { C. Lübbert (Leipzig) } \\
\text { J. Richter (Düsseldorf) }\end{array}$ \\
\hline $\begin{array}{l}\text { AG } 2 \text { „Klinisches Bild u. } \\
\text { Therapie der ambulant er- } \\
\text { worbenen Gastroenteritis“ }\end{array}$ & $\begin{array}{l}\text { S. Hagel (Jena) } \\
\text { C. Pox (Bochum) } \\
\text { P. Malfertheiner } \\
\text { (Magdeburg) }\end{array}$ & $\begin{array}{l}\text { R. Vogelmann } \\
\text { (Mannheim) } \\
\text { M. Weber (Jena) } \\
\text { T. Frieling (Krefeld) } \\
\text { D. Jaspersen (Fulda) } \\
\text { I. Koop (Hamburg) }\end{array}$ \\
\hline $\begin{array}{l}\text { AG3 „Nosokomiale Diarrhö } \\
\text { und Clostridium difficile“ }\end{array}$ & $\begin{array}{l}\text { H.-J. Epple (Berlin) } \\
\text { E. Meyer (München) } \\
\text { L. von Müller } \\
\text { (Homburg) }\end{array}$ & $\begin{array}{l}\text { H. Matthes (Berlin) } \\
\text { C. Spinner (München) } \\
\text { P. Walger (DGKH, } \\
\text { Bonn) } \\
\text { B. Lembcke } \\
\text { (Gladbeck) }\end{array}$ \\
\hline $\begin{array}{l}\text { AG4 „Diarrhö bei Immun- } \\
\text { defizienz“ }\end{array}$ & $\begin{array}{l}\text { A. Lohse (DGVS, } \\
\text { DGIM, Hamburg) } \\
\text { J. Nattermann (Bonn) } \\
\text { B. Salzberger } \\
\text { (Regensburg) }\end{array}$ & $\begin{array}{l}\text { W. Heise (Berlin) } \\
\text { B. Jensen (Düsseldorf) } \\
\text { H. Salzer (Hamburg) } \\
\text { R. Duchmann (Frank- } \\
\text { furt) }\end{array}$ \\
\hline $\begin{array}{l}\text { AG5 „Akute Gastroenteritis } \\
\text { bei Reiserückkehrern“ }\end{array}$ & $\begin{array}{l}\text { W. V. Kern } \\
\text { (DGI, Freiburg) } \\
\text { E. Reisinger } \\
\text { (PEG, Rostock) } \\
\text { T. Weinke } \\
\text { (PEG, Potsdam) }\end{array}$ & $\begin{array}{l}\text { T. Andus (Stuttgart) } \\
\text { T. Feldt (Düsseldorf) } \\
\text { M. Menges (Schwä- } \\
\text { bisch Hall) } \\
\text { H. Sudeck (DTG, } \\
\text { Hamburg) }\end{array}$ \\
\hline AG6 „Morbus Whipple“ & $\begin{array}{l}\text { G. E. Feurle (Neuwied) } \\
\text { T. Marth (Daun) } \\
\text { V. Moos (Berlin) }\end{array}$ & $\begin{array}{l}\text { A. Jefremow } \\
\text { (Erlangen) } \\
\text { C. Loddenkemper } \\
\text { (DGP, Berlin) } \\
\text { H. Bläker (DGP, Berlin) }\end{array}$ \\
\hline AWMF & $\begin{array}{l}\text { M. Nothacker } \\
\text { (Marburg) }\end{array}$ & \\
\hline DGVS & $\begin{array}{l}\text { P. Lynen-Jansen } \\
\text { (Berlin) }\end{array}$ & \\
\hline
\end{tabular}

M-3 Beteiligte Gruppierungen und Fachgesellschaften Federführung und Koordination

Deutsche Gesellschaft für Gastroenterologie, Verdauungs- und Stoffwechselkrankheiten e.V. (DGVS)

\section{Mitarbeit}

Deutsche Gesellschaft für Innere Medizin e.V. (DGIM)

Deutsche Gesellschaft für Hygiene und Mikrobiologie (DGHM)

Deutsche Gesellschaft für Infektiologie (DGI)

Deutsche Gesellschaft für Krankenhaushygiene e.V. (DGKH)

Deutsche Gesellschaft für Tropenmedizin und Internationale Gesundheit (DTG)

Paul-Ehrlich Gesellschaft für Chemotherapie e.V. (PEG)

Deutsche Gesellschaft für Pathologie e.V. (DGP) und Bundesverband Deutscher Pathologen e.V. (BDP)

Robert Koch-Institut (RKI)

\section{M-4 Umgang mit potenziellen Interessenskonflikten}

Vor dem Hintergrund der zunehmenden Bedeutung von Leitlinien zur Diagnostik und Therapie von Erkrankungen werden potenzielle Interessenskonflikte der an der Leitlinie mitarbeitenden Personen immer wichtiger. Interessenskonflikte sind als Situationen definiert, die ein Risiko beinhalten, dass das professionelle Urteilsvermögen, welches sich auf ein primäres Interesse bezieht, durch sekundäre (persönliche) Interessen unangemessen beeinflusst wird. Sekundäre Interessen, die mit dem primären Interesse der evidenzbasierten Leitlinienerstellung in Konflikt geraten können, sind z. B. materielle Interessen, wie das Interesse an der Aufrechterhaltung einer Beziehung zu einem pharmazeutischen Unternehmen. Zu den immateriellen Interessen gehören ggf. die mandatierende Organisation (z. B. Fachgesellschaften), der Arbeitgeber und der wissenschaftliche Schwerpunkt der betroffenen Person. Ebenso können soziale oder intellektuelle Interessen als sekundäre Interessen zu einem Interessenkonflikt führen. Bezüglich potenzieller Interessenskonflikte bei den Teilnehmern der S2k-Leitlinienkonferenz "Gastrointestinale Infektionen und Morbus Whipple“ sei an dieser Stelle kurz zusammengefasst, dass vor Beginn der Leitlinienkonferenz alle Teilnehmer ihre potenziellen Interessenskonflikte offengelegt haben (siehe Tabelle Onlineversion (www.dgvs.de/leitlinien/gastrointestinale-infektionen-und-morbus-whipple/). Hierfür wurden Interessenkonflikte schriftlich mithilfe eines Formblattes der AWMF, das materielle und immaterielle Interessen umfasst, offengelegt. Diese Interessenskonflikte wurden auf der Leitlinienkonferenz unter Moderation der AWMF (vertreten durch M. Nothacker) offen diskutiert und es wurde einstimmig beschlossen, dass Personen mit potenziellen Interessenskonflikten (d.h. Patentbesitz, Mitgliedschaft in einem Advisory Board eines thematisch relevanten Medikaments und Aktienbesitz >10000€) sich bei der Abstimmung von Empfehlungen, die von diesen Interessenskonflikten berührt werden könnten, enthalten.

\section{M-5 Durchführung}

a) Recherche, Auswahl und Bewertung wissenschaftlicher Belege (Evidenzbasierung)

Eine systematische Literaturrecherche und -bewertung nach vorher festgelegten Regeln erfolgte nicht.

\section{b) Formulierung der Empfehlungen und strukturierte Konsensfindung}

Die Arbeitsgruppenleiter wurden gebeten, einen Fragenkatalog möglichst klinisch orientierter Fragen zu erstellen. Die Fragen der einzelnen Arbeitsgruppen wurden in einen gemeinsamen Fragenkatalog überführt. Im Sinne eines Delphi-Verfahrens wurden alle 
an der Erstellung der Leitlinie Beteiligten gebeten, die Fragen aller Arbeitsgruppen zu beantworten. Pro Frage gab es fünf Antwortmöglichkeiten (ja, eher ja, unentschieden, eher nein, nein). Bei Zustimmung konnte, bei Ablehnung musste ein erläuternder Kommentar geschrieben werde. Die Rückmeldungen wurden zentral gesammelt und die Gesamtergebnisse der Abstimmung und die dazugehörenden Kommentare an die Arbeitsgruppen übermittelt. Ziel war es, strittige Punkte bei der Erstellung der Leitlinie zu identifizieren, um diese in den Arbeitsgruppen vor Beginn der Leitlinienkonferenz zu klären. Auf der Basis der Antworten des DelphiVerfahrens und der Diskussion in den Arbeitsgruppen, erfolgte die Ausarbeitung der Empfehlungen durch die Arbeitsgruppenleiter. Im Rahmen einer zweitägigen Leitlinienkonferenz vom 7. - 8.11.2013 wurden diese Empfehlungen noch einmal innerhalb der Arbeitsgruppen im nominalen Gruppenprozess diskutiert und überarbeitet. In einer anschließenden Plenarsitzung wurden alle Empfehlungen diskutiert und anonym abgestimmt. Das Abstimmungsergebnis wurde digital protokolliert. Die Konsensstärken sind in $\bullet$ Tab. 3 dargestellt.

Tab. 3 Konsensusstärke.

\begin{tabular}{|ll}
\hline Konsensusstärke & \\
\hline starker Konsens & Zustimmung von $>95 \%$ der Teilnehmer \\
\hline Konsens & Zustimmung von $>75-95 \%$ der Teilnehmer \\
\hline $\begin{array}{l}\text { mehrheitliche } \\
\text { Zustimmung }\end{array}$ & Zustimmung von $>50-75 \%$ der Teilnehmer \\
\hline kein Konsens & Zustimmung von weniger als 50\% der Teilnehmer \\
\hline
\end{tabular}

Tab. 4 Empfehlungsstärken.

\begin{tabular}{|l|l|}
\hline Empfehlungsstärken & Formulierung \\
\hline starke Empfehlung & „soll“ \\
\hline Empfehlung & "sollte“ \\
\hline Empfehlung offen & "kann“ \\
\hline negative Empfehlungen werden entsprechend formuliert
\end{tabular}

Nach der Leitlinienkonferenz wurden die einzelnen Empfehlungen von den Arbeitsgruppenleitern mit Kommentaren und Literaturverweisen versehen. Bei allen Handlungsempfehlungen ist die Stärke der Empfehlung anhand der Formulierung ersichtlich. Die Formulierungen und Bedeutung der Empfehlungsstärken sind in 0 Tab. 4 dargelegt. In allen Kommentaren wurden die Empfehlungen mit der jeweils zugrunde liegenden Literatur verknüpft. Evidenzgrade wurden in dieser S2k-Leitlinie nicht vergeben ( $\bullet$ Tab. 5).

Tab.5 Zeitplan der Leitlinie.

\begin{tabular}{|c|c|}
\hline \multicolumn{2}{|l|}{ Zeitplan } \\
\hline bis Ende Juli 2012 & $\begin{array}{l}\text { Zusammenstellung der Arbeitsgruppen: Auswahl, } \\
\text { Anfragen, Zu-/Absagen (Gruppen und Teilnehmer } \\
\text { siehe Punkt M-2) und Anfrage bei den anderen un- } \\
\text { terstützenden Fachgesellschaften (siehe Punkt M-3) }\end{array}$ \\
\hline bis Januar 2013 & Entwurf der Statements \\
\hline bis August 2013 & $\begin{array}{l}\text { Sichtung und Kommentierung der Entwürfe über } \\
\text { Onlineplattform (Delphi) }\end{array}$ \\
\hline bis Oktober 2013 & Überarbeitung der Statements \\
\hline
\end{tabular}

Tab. 5 (Fortsetzung)

\begin{tabular}{ll|}
$\begin{array}{l}\text { Zeitplan } \\
\text { 07.-08. November } \\
2013\end{array}$ & 2-tägige Konsensuskonferenz in Berlin \\
\hline bis Juni 2014 & Erstellung aller Kommentare \\
\hline bis Oktober 2014 & $\begin{array}{l}\text { Fertigstellung des Manuskriptes durch Einarbeitung } \\
\text { der Literatur und Ergänzung des Methodenteils }\end{array}$ \\
\hline bis Januar 2015 & $\begin{array}{l}\text { Begutachtung durch die beteiligten Fachgesell- } \\
\text { schaften }\end{array}$ \\
\hline
\end{tabular}

\section{K-1 Diagnostik der ambulant erworbenen Gastroenteritis (AG 1) $\nabla$}

\section{Präambel}

Die Sinnhaftigkeit/Bedeutung einer ätiologischen Klärung und ggf. Therapie einer infektiösen Gastroenteritis ergibt sich neben individualmedizinischen Aspekten (Schwere des Krankheitsbildes, Komorbiditäten, Immunsuppression, etc.) auch aus dem Schutz Dritter, z. B. bei diarrhöbetroffenen Personen, die in Gemeinschaftseinrichtungen oder lebensmittelproduzierenden oder -handelnden Betrieben arbeiten. Wichtig ist der Hinweis, dass für bestimmte Erreger in Deutschland eine Meldepflicht an das Gesundheitsamt besteht. Namentlich hat diese bei gesicherten Infektionen durch Campylobacter sp., Salmonellen, Yersinia enterocolitica, EHEC sowie sonstige darmpathogene $E$. coli, Shigellen, Giardia lamblia, humanpathogene Cryptosporidium sp., Rotaund Noroviren zu erfolgen. Hingegen besteht bei Typhus, Paratyphus und Cholera schon beim Verdacht wie auch bei Erkrankung, Tod und Ausscheidung eine namentliche Meldepflicht.

Darüber hinaus ist nach $§ 6$ (1) des Infektionsschutzgesetzes (IfSG) der Verdacht auf und die Erkrankung an einer mikrobiell bedingten Lebensmittelvergiftung oder an einer akuten infektiösen Gastroenteritis namentlich zu melden, wenn a) eine Person betroffen ist, die eine Tätigkeit im Lebensmittelbereich im Sinne des $§ 42$ Abs. 1 ausübt oder b) zwei oder mehr gleichartige Erkrankungen auftreten, bei denen ein epidemiologischer Zusammenhang wahrscheinlich ist oder vermutet wird. Bei der Meldepflicht sind zusätzlich bundeslandspezifische Verordnungen (z. B. Labormeldepflicht für Entamoeba histolytica in Sachsen, Thüringen und Mecklenburg-Vorpommern) zu beachten. Eine Übersicht findet sich auf den Seiten des Robert Koch-Institut. (http://www.rki.de/ DE/Content/Infekt/IfSG/Meldepflichtige_Krankheiten/Melde-

pflichtige_Krankheiten_node.html) ( $\bullet$ Abb. 1 und 2)

Häufigere Ursachen für infektiöse Gastroenteritiden finden sich in $\bullet$ Tab. 6.

\section{Tätigkeits- und Beschäftigungsverbote}

Nach $\S 42$ (1) des Infektionsschutzgesetzes können durch das Gesundheitsamt für Personen, die

a) an Typhus abdominalis, Paratyphus, Cholera, Shigellenruhr, Salmonellose, einer anderen infektiösen Gastroenteritis oder Virushepatitis A oder E erkrankt oder dessen verdächtig sind oder b) die Krankheitserreger Shigellen, Salmonellen, enterohämorrhagische Escherichia coli oder Choleravibrionen ausscheiden, ein Tätigkeits- und Beschäftigungsverbot ausgesprochen werden, wenn sie beim Herstellen, Behandeln oder Inverkehrbringen der nachfolgend genannten Lebensmittel tätig oder in Küchen von Gaststätten und sonstigen Einrichtungen mit oder zur Gemeinschaftsverpflegung beschäftigt sind. Dies gilt entsprechend für Personen, die mit Bedarfsgegenständen, die für die dort genann- 


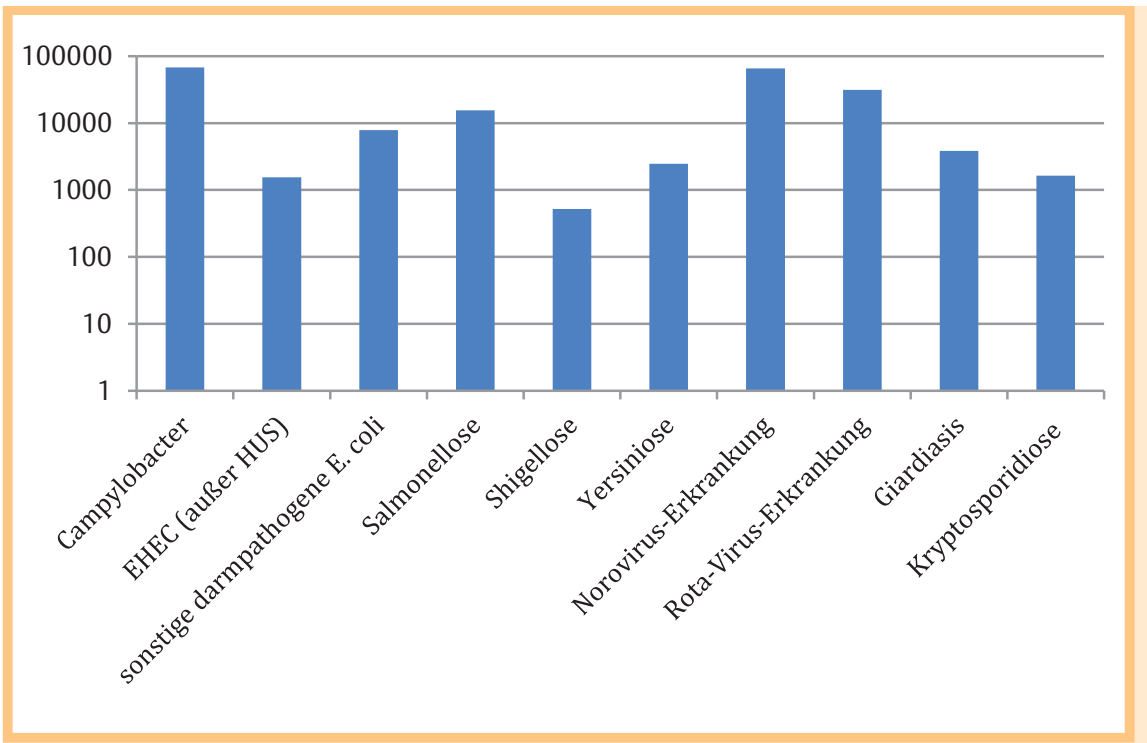

Abb. 1 Aktuelle Statistik meldepflichtiger infektiöser Gastroenteritiden; RKI, Epidemiologisches Bulletin Nr. 50, Stand 24.12.2014).

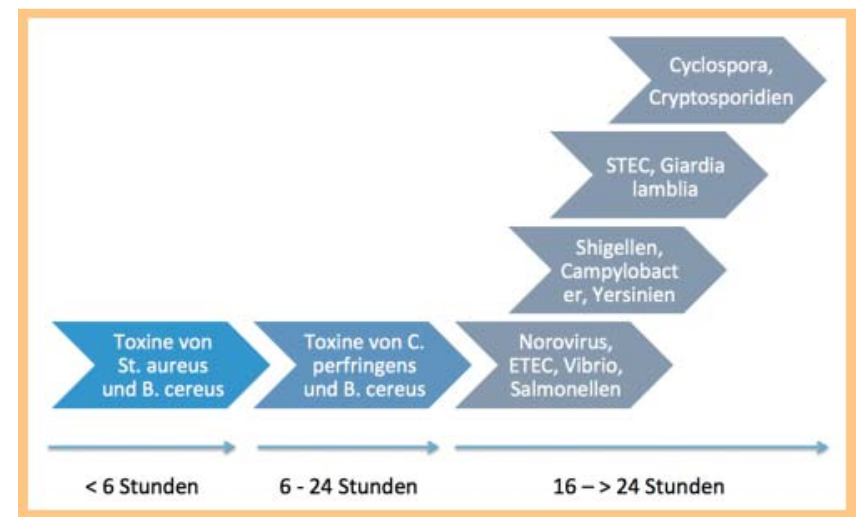

Abb. 2 Zusammenhang Inkubationszeit und Erreger infektiöser Gastroenteritiden (modifiziert nach [7]).

ten Tätigkeiten verwendet werden, so in Berührung kommen, dass eine Übertragung von Krankheitserregern auf die Lebensmittel zu befürchten ist.

Lebensmittel im Sinne des Absatzes 1 sind

1. Fleisch, Geflügelfleisch und Erzeugnisse daraus

2. Milch und Erzeugnisse auf Milchbasis

3. Fische, Krebse oder Weichtiere und Erzeugnisse daraus

4. Eiprodukte

5. Säuglings- und Kleinkindernahrung

6. Speiseeis und Speiseeishalberzeugnisse

7. Backwaren mit nicht durchgebackener oder durcherhitzter Füllung oder Auflage

8. Feinkost-, Rohkost- und Kartoffelsalate, Marinaden, Mayonnaisen, andere emulgierte Soßen, Nahrungshefen

9. Sprossen und Keimlinge zum Rohverzehr sowie Samen zur Herstellung von Sprossen und Keimlingen zum Rohverzehr.

Empfehlung 1.1: Keine routinemäßige Erregerdiagnostik

Eine routinemäßige Erregerdiagnostik bei allen Patienten, d.h. unabhängig von der Symptomatik, evtl. vorhandenen Komorbiditäten oder dem Umfeld, soll nicht erfolgen. [Konsensusstärke: starker Konsens, starke Empfehlung]

\section{Kommentar}

Eine sorgfältige Untersuchung des Patienten, einschließlich körperlicher Untersuchung und Anamneseerhebung (Fernreisen, Medikamenteneinnahme, Komorbiditäten, Erkrankungen im sozialen Umfeld), ist die Voraussetzung, um eine evidenzbasierte und kosteneffektive Diagnostik und ggf. Therapie durchführen zu können. Folgende Gesichtspunkte sind für die Beurteilung der Indikation zur diagnostischen Abklärung wichtig:

1. Die meisten Episoden einer infektiösen Gastroenteritis sind selbstlimitierend; eine Diagnostik mit Sicherung des Erregers hat in dieser Situation keine therapeutische Konsequenz.

2. Die diagnostische Ausbeute einer mikrobiologischen Untersuchung (Stuhluntersuchungen, serologische Untersuchungen) ist bei einer infektiösen Gastroenteritis niedrig, und nur in der Minderheit der Fälle lässt sich der Erreger sichern [8 - 10].

3. Das Erregerspektrum der infektiösen Gastroenteritis ist umfangreich ( $\bullet$ Tab. 6); die Untersuchung jedes Patienten auf jeden potenziellen Erreger ist medizinisch und ökonomisch von eingeschränktem Nutzen.

In der Regel suchen Patienten mit akuter Diarrhö im Mittel nach zwei Tagen einen Arzt auf [11]. Wenn keine Alarmsymptome/ Hinweise für einen schweren Verlauf oder Komorbiditäten vorliegen, wird ein Zuwarten ohne spezifische Diagnostik und Therapie empfohlen. Auch sistieren die Symptome bereits in den meisten Fällen, bevor überhaupt das finale Ergebnis der Stuhluntersuchung vorliegt [12]. Im Gegensatz zu diesem, den Spontanverlauf abwartenden Vorgehen, ist bei Patienten mit den nachfolgend in Empfehlung 1.2 aufgeführten Konstellationen eine zeitnahe diagnostische Abklärung notwendig.

\section{Empfehlung 1.2: Indizierte Erregerdiagnostik bei Subkollektiven von Patienten}

Bei Verdacht auf eine infektiöse Gastroenteritis sollte insbesondere in folgenden Situationen eine Erregerdiagnostik erfolgen:

> relevante Komorbiditäten

- Patienten mit Immunsuppression

- blutige Diarrhö

- schweres Krankheitsbild (z. B. Fieber, Dehydrierung, SIRS/ Sepsis)

- diarrhöbedingte Hospitalisierung 


\begin{tabular}{|c|c|c|c|c|}
\hline Bakterien & Toxinbildner & Viren & Protozoen & $\begin{array}{l}\text { Helminthen } \\
\text { (Würmer) }\end{array}$ \\
\hline $\begin{array}{l}\text { Escherichia coli (EC): } \\
\text { - Enterotoxinbildende EC } \\
\text { (ETEC) } \\
\text { - Enteroinvasive EC (EIEC) } \\
\text { - Enterohämorrhagische EC } \\
\text { (EHEC) } \\
\text { - Enteropathogene EC (EPEC) } \\
\text { - Enteroaggregative EC (EAEC) } \\
\text { Yersinia enterocolitica, Y. pseu- } \\
\text { dotuberculosis } \\
\text { Clostridium difficile } \\
\text { Campylobacter jejuni, Campy- } \\
\text { lobacter coli } \\
\text { Salmonellen } \\
\text { Shigellen } \\
\text { Vibrio cholerae }\end{array}$ & $\begin{array}{l}\text { Staphylococcus } \\
\text { aureus } \\
\text { Bacillus cereus } \\
\text { Clostridium perf- } \\
\text { ringens }\end{array}$ & $\begin{array}{l}\text { Rotaviren } \\
\text { Adenoviren } \\
\text { Noroviren } \\
\text { Sapoviren }\end{array}$ & $\begin{array}{l}\text { Giardia lamblia } \\
\text { Cryptosporidium } \\
\text { parvum } \\
\text { Entamoeba histoly- } \\
\text { tica } \\
\text { Cyclospora cayeta- } \\
\text { nensis } \\
\text { Isospora belli }\end{array}$ & $\begin{array}{l}\text { Plathelminthen } \\
\text { (Trematoden } \\
\text { (Schistosoma), } \\
\text { Zestoden) } \\
\text { Trichinellen } \\
\text { Strongyloides } \\
\text { stercoralis }\end{array}$ \\
\hline
\end{tabular}

Patienten, die in Gemeinschaftseinrichtungen oder lebensmittelverarbeitenden Institutionen arbeiten

- bei Personen mit stattgehabter Antibiotikaeinnahme innerhalb der letzten 3 Monate

- bei Verdacht auf eine Häufung, bei der ein epidemiologischer Zusammenhang vermutet werden kann

- nosokomiale Diarrhö

- vor Einleitung einer antibiotischen Therapie (siehe dazu Empfehlung 2.7)

[Konsensusstärke: Konsens, Empfehlung]

\section{Kommentar}

Wie oben ausgeführt, ergibt sich die Sinnhaftigkeit einer ätiologischen Klärung der infektiösen Gastroenteritis und ggf. der Therapie aufgrund individualmedizinischer Aspekte (Schwere des Krankheitsbildes, Komorbiditäten, Immunsuppression etc.) und auch aus dem Schutz Dritter, z. B. bei diarrhöbetroffenen Personen, die in Gemeinschaftseinrichtungen oder lebensmittelproduzierenden oder -handelnden Betrieben arbeiten. Die Diagnostik bei Patienten, die in Gemeinschaftseinrichtungen oder lebensmittelverarbeitenden Institutionen arbeiten, dient klassischen infektionspräventiven Maßnahmen und ist entsprechend dem Infektionsschutzgesetz (IfSG) durchzuführen. Ebenso ist eine Diagnostik beim Verdacht auf Ausbruchssituationen unerlässlich; die 2011 aufgetretene EHEC-Epidemie in Norddeutschland ist ein klassisches Beispiel für die Notwendigkeit der Diagnostik unter diesem Aspekt. Darüber hinaus ist es sinnvoll, vor Beginn einer kalkulierten Antibiotikatherapie eine Erregerdiagnostik durchzuführen, um diese später nach Kenntnis des Erregers anzupassen bzw. die Therapiedauer zu modifizieren.

Ob die empfohlene erregerorientierte Diagnostik bei Patienten, die aufgrund einer akuten Gastroenteritis hospitalisiert werden, notwendig ist, wurde kontrovers diskutiert. So gab es in der Minderheit Meinungsträger, die zwar auf die Sinnhaftigkeit einer Isolierung des Patienten, unabhängig eines potenziellen Erregernachweises, hinwiesen. Diese wird jedoch durch den klinischen Verdacht auf eine akute infektiöse Gastroenteritis bestimmt und hängt nicht vom Nachweis eines bestimmten Erregers ab.

Bezüglich Indikation und Umfang der Diagnostik bei Patienten mit nosokomialer Gastroenteritis wird auf das Kapitel 3 verwiesen.

\section{Empfehlung 1.3: Umfang der Erregerdiagnostik}

Die Basisdiagnostik bei ambulant erworbener Gastroenteritis sollte mikrobiologische Untersuchungen auf Campylobacter, Salmonellen, Shigellen und Noroviren umfassen.

[Konsensusstärke: Konsens, Empfehlung]

\section{Kommentar}

In einer prospektiven Studie aus Berlin vom August 2005 bis August 2007 zeigte sich, dass bei Patienten mit ambulant erworbener Gastroenteritis, die zur stationären Betreuung aufgenommen wurden, Campylobacter spp. gefolgt von Noroviren und Salmonella spp. die häufigsten Erreger sind [10]. Vor dem Hintergrund der begrenzten diagnostischen Sensitivität und klinischen Konsequenz sollte somit in der rationalen und rationellen Diagnostik zunächst nach diesen häufigsten Erregern gesucht werden. Die Shigellen-Infektion erscheint in Deutschland mit jährlich 300 1000 Erkrankungsfällen (Meldedaten des RKI) relativ selten; hier ist jedoch von einer größeren Dunkelziffer auszugehen, da Shigellen in nativen Stuhlproben nur wenige Stunden überleben können und somit bei längeren Transportwegen ins Labor dem kulturellen Nachweis entgehen [13, 14]. Unter diesem Gesichtspunkt ist auch die Bereitstellung spezieller Transport- bzw. Konservierungsmedien für diese Erreger von essenzieller Bedeutung; dieses Vorgehen ist jedoch nicht immer Bestandteil der gängigen Laborroutine. Auch vor dem Hintergrund der potenziell besonders schwer verlaufenden Erkrankung wurde dieser Erreger in die Basisdiagnostik mit aufgenommen. Finden sich in der Basisdiagnostik Salmonellen, sollte aus epidemiologischen Gründen (Aufdeckung von Infektionsquellen und Verfolgung von Infektionswegen und -ketten) eine komplette Serotypisierung durchgeführt werden. Grundsätzlich sind über 500 Serovare humanpathogen, jedoch wurden im Rahmen der Meldepflicht seit 2001 nur 24 Serovare mit durchschnittlich mehr als 50 Salmonelloseerkrankungen im Jahr übermittelt. Die beiden häufigsten Salmonellenserovare sind S. Enteritidis und S. Typhimurium.

In Deutschland sind Norovirus-Infektionen als häufigste Ursache von Gastroenteritisausbrüchen gesichert. Die Viren sind hochinfektiös und zeichnen sich durch eine hohe Umweltresistenz aus. Sie werden von infizierten Personen über den Stuhl und mit Erbrochenem ausgeschieden. Eine Übertragung kann durch Schmierinfektionen (von Mensch zu Mensch oder über kontaminierte Lebensmittel bzw. Wasser) oder auch durch virushaltige Aerosole nach Erbrechen erfolgen. Norovirus-Infektionen betref- 
fen alle Altersgruppen und führen besonders in den Wintermonaten zu größeren Gruppenerkrankungen in Gemeinschaftseinrichtungen wie z.B. Kindergärten, Schulen, Pflegeheimen und Krankenhäusern. Seit dem 1.1.2001 sind Infektionen mit Noroviren nach IfSG meldepflichtig ( $\S \S 6,7)$. Zum Nachweis einer Norovirus-Infektion werden molekularbiologische Methoden (i.d.R. PCR) wegen ihrer hohen Sensitivität bevorzugt [15], dennoch haben auch ELISA-basierte Antigennachweise ihre Vorteile [16]. Die Diagnostik ist insbesondere aus krankenhaushygienischen Gründen notwendig, da bei Verdacht auf Norovirus-Infektion bzw. bei bestätigtem Virusnachweis besondere Hygienemaßnahmen (z. B. Einzelzimmerunterbringung, Tragen eines Mundschutzes, viruzides Händedesinfektionsmittel) notwendig sind.

In der Konsensuskonferenz wurde kontrovers über die Aufnahme der Diagnostik zu „Rotaviren“ in das routinemäßige Panel diskutiert. Grundsätzlich gilt, dass die Rotavirus-bedingte Enteritis klinisch nicht von anderen infektionsbedingten Gastroenteritiden unterschieden werden kann. Die gastrointestinalen Symptome bestehen in der Regel zwei bis sechs Tage. Rotaviren werden fäkal-oral besonders durch Schmierinfektion, aber auch durch kontaminiertes Wasser und Lebensmittel übertragen. Das Virus ist sehr leicht übertragbar; bereits 10 Viruspartikel reichen aus, um z. B. ein Kind zu infizieren [17]. Die Übertragungsgefahr von Rotaviren auf andere Personen besteht während des akuten Krankheitsstadiums und solange das Virus mit dem Stuhl ausgeschieden wird. In der Regel erfolgt eine Virusausscheidung nicht länger als acht Tage, in Einzelfällen wurden jedoch auch längere Virusausscheidungen beobachtet. Rotaviren stehen nach den Meldedaten des RKI an 3. Stelle der häufigen Gastroenteritiden verursachenden Erreger ( $\bullet$ Abb. 1); dieses spricht für die Diagnostik bei Patienten mit Gastroenteritis. Gegen die Diagnostik sprechen die klinischen Einschätzungen, dass aus dem Nachweis einer Rotavirus-Infektion bei Patienten ohne weitere Risikofaktoren außerhalb von Ausbruchssituationen keine therapeutischen Konsequenzen gezogen werden; die Diagnostik ist somit ohne Wert für das weitere Management des Patienten. Dieses würde sich im Wesentlichen am klinischen Bild orientieren; bei stationärer Aufnahme wäre der Patient aufgrund der Diarrhö („Verdacht auf eine akute Gastroenteritis“) zu isolieren; ein positiver oder negativer Rotavirus-Befund würde grundsätzlich an dieser Maßnahme und der notwendigen Therapie nichts ändern. In Ausbruchssituationen hingegen könnte bei Nachweis von Rotaviren eine Kohortenisolierung durchgeführt werden. Insgesamt besteht somit wegen der fehlenden therapeutischen Konsequenzen keine klinische Indikation für die Diagnostik; aus krankenhaushygienischen Gründen kann sie im Einzelfall durchgeführt werden.

Ebenfalls wurde von Vertretern des RKI die Bedeutung der Yersinien- und EHEC-Diagnostik im Routinefall insbesondere bei Kindern betont. Da die EHEC-Infektion insgesamt relativ selten ist, konnte sich die Konsenuskonferenz dieser Meinung nicht anschließen, verweist aber auf die dringende Notwendigkeit der Diagnostik bei einer entsprechenden klinisch hinweisenden Konstellation (siehe Empfehlung 1.4). Für eine routinemäßige Diagnostik der Yersinien fand sich ebenfalls keine Mehrheit, da sich aus einem positiven Befund in der Regel keine therapeutischen Konsequenzen ergeben. Wenn auch diese Leitlinie nicht für Säuglinge, Kinder und Jugendliche gilt, sei an dieser Stelle trotzdem auf die große klinische und differenzialdiagnostische Bedeutung der Yersinien-Infektionen insbesondere im Kindes(Kinder unter 5 Jahren) und Jugendalter hingewiesen.
Empfehlung 1.4: Umfang der Erregerdiagnostik] EHEC-Verdacht

Eine EHEC-Infektion soll bei Patienten mit typischer/entsprechender Symptomatik ausgeschlossen werden.

[Konsensusstärke: Konsens, starke Empfehlung]

\section{Kommentar}

Die Zahl der EHEC-Infektionen befindet sich nach dem weltweit bislang größten Ausbruch in Norddeutschland im Jahr 2011 mit über 3800 Patienten wieder auf einem auch in Vorjahren ähnlich niedrigen Niveau. Der Ausbruch wurde durch einen Shigatoxinproduzierenden Stamm des Serovars 0104:H4, der auch Eigenschaften von EAEC aufwies und damit einen EHEC/EAEC Hybridstamm darstellt, hervorgerufen [18, 19]. In diesem Ausbruch wurde eine Letalität von 0,6\% bei EHEC-Patienten mit Gastroenteritis und $4,1 \%$ bei Patienten mit HUS beschrieben, die damit deutlich höher lagen, als die Daten für den bedeutendsten EHEC-Erreger 0157:H7 [20]. Aufgrund der Häufigkeit von Patienten mit blutigen Diarrhöen, aber der Seltenheit von EHEC-0104: H4-Infektionen, wird durch die Mehrheit der Konsensuskonferenzteilnehmer eine regelhafte Untersuchung des Stuhles bzw. in der Stuhlanreicherung auf Stx-Bildner nicht empfohlen. Besteht die klinische Trias „blutige Diarrhö, Hämolyse und Thrombozytenabfall“ oder handelt es sich um Personen, die im Lebensmittelbereich tätig sind oder Gemeinschaftseinrichtungen besuchen, ist jedoch dringend eine dementsprechende Diagnostik durchzuführen ( $§ 42$ IfSG). Vertreter des Robert Koch-Instituts haben in dieser Diskussion eine Minderheitsmeinung vertreten und wiesen auf die regelhaft indizierte Suche nach Stx-Bildnern bei Patienten mit blutigen Diarrhöen hin.

Die mikrobiologische Diagnostik von EHEC ist komplex; es gibt kein einfach nachzuweisendes phänotypisches Merkmal mit dem EHEC schnell und sicher aus einer Stuhlanreicherungskultur diagnostiziert werden kann. Mittel der Wahl sind molekulare Verfahren zur Detektion der Stx-Gene. Der Nachweis von EHEC mittels direkter PCR aus der Stuhlprobe hängt von der Erregerdichte $a b$; neuere Methoden erreichen eine Nachweisgrenze von $10^{2}-10^{3} / \mathrm{g}$ Stuhl und darunter (siehe auch MiQ: Qualitätsstandards in der mikrobiologischen Diagnostik, Gastrointestinale Infektionen [6]). In der Regel wird eine Anreicherung des Erregers durch geeignete Kulturen empfohlen. Direktuntersuchungen aus der Stuhlprobe mittels der im Handel erhältlichen ShigatoxinEIA-Nachweise sind zu unspezifisch und nicht sensitiv genug [21]. Zur notwendigen und sinnvollen Kombination der verschiedenen Testverfahren wird auf die Empfehlungen des RKI und BfR verwiesen [22].

\section{Empfehlung 1.5: Diagnostik bei Verdacht auf Clostridium} difficile

Bei Diarrhö mit Verdacht auf Clostridium difficile-Infektion soll zeitnah eine sensitive Diagnostik zum Nachweis der toxigenen C. difficile-Infektion erfolgen.

[Konsensusstärke: starker Konsens, starke Empfehlung]

\section{Kommentar}

Bei Patienten mit V.a. eine infektiöse Gastroenteritis (Diarrhö, abdominelle Schmerzen) soll bei jedem Patienten mit nosokomialer Diarrhö und bei ambulanten Patienten mit Risikofaktoren eine zeitnahe Diagnostik auf eine Infektion mit Clostridium difficille durchgeführt werden. Dabei sind die in $\bullet$ Tab. 7 aufgeführ- 
Tab. 7 Risikofaktoren für eine CDI [23 - 27].

aktuelle oder stattgehabte Antibiotikatherapie innerhalb der letzten
3 Monate
hohes Lebensalter (über 65 Jahre)
Hospitalisierung bzw. stattgehabte Hospitalisierung innerhalb der letz-
ten drei Monate bzw. Unterbringung in Gemeinschaftseinrichtungen
des Gesundheitssystems
zwei oder mehr Komorbiditäten
stattgehabte C. difficile-Infektion

ten Risikofaktoren für eine $C$. difficille-Infektion (CDI) besonders relevant:

Unzweifelhaft ist der Gebrauch von Antibiotika mit einem erhöhten Risiko für die Entwicklung einer CDI verbunden. Metaanalysen zeigen, dass das Risiko für verschiedene Antibiotika unterschiedlich ist [28]:

- Drittgenerations-Cephalosporine (OR 3,2, 95 \% KI 1,8 - 5,7)

- Clindamycin (OR 2,9, $95 \%$ KI 2,0 - 4,0),

- Zweitgenerations-Cephalosporine (OR 2,2, $95 \%$ KI 1,5 - 3,4),

- Viertgenerations-Cephalosporine (OR 2,1, $95 \%$ KI 1,3 - 3,5),

- Carbapeneme (OR 1,84, 95 \% KI 1,3 - 2,7),

- Trimethoprim/Sulfamethoxazol (OR 1,8, $95 \%$ KI 1,0 - 3,0),

- Fluorchinolone (OR 1,7, 95 \% KI 1,2 - 2,3),

- Penicillin-Kombinationen (OR 1,5, $95 \%$ KI 1,1 - 2,0).

Neben einer Medikation mit Antibiotika wird die Einnahme von Protonenpumpeninhibitoren (PPI) als Risikofaktor für die Entwicklung einer CDI postuliert. [29] Diese Annahme kann nicht zweifelsfrei durch Metaanalysen bestätigt werden; hier gibt es Studien, die PPI als Risikofaktor bestätigen [30]; andere, die dieses nicht nachweisen können [31]. Unzweifelhaft ist eine stattgehabte Hospitalisierung innerhalb der letzten 3 Monate, insbesondere wenn Patienten in Mehrbettzimmern untergebracht wurden, ein akzeptierter Risikofaktor für die Entwicklung einer CDI [32]. Eine aktuelle epidemiologische Studie aus Nordamerika zeigt aber bei Patienten, die wegen einer CDI hospitalisiert werden, eine Verschiebung von „Patienten mit stattgehabter Hospitalisierung“ zu „Patienten, die in Langzeitpflegeinrichtungen des Gesundheitssystems“ leben [33]. Inwieweit das Vorliegen von Immundefekten oder iatrogener Immunsuppression das Auftreten einer CDI beeinflusst, ist bislang noch unzureichend geklärt [34-36]. Eine retrospektive Beobachtungsstudie aus Deutschland konnte kürzlich zeigen, dass CDI-Rezidive bei immunsupprimierten Patienten häufiger auftreten (OR 2,75, 95 \% KI 1,365,54) [37].

Bei Verdacht auf eine CDI sollte frühzeitig und sensitiv der Nachweis von $C$. difficile geführt werden, um zeitnah eine spezifische Therapie einzuleiten. Hierfür reicht in der Regel eine breiig-flüssige Stuhlprobe; eine Diagnostik aus geformtem Stuhl ist nicht indiziert. In besonderen Situationen, $z$. B. bei Patienten mit einem Ileus, können Rektalabstriche verwandt werden. Ein allgemein akzeptierter labordiagnostischer Algorithmus existiert nicht. Grundsätzlich ist zwischen einem ein- und einem mehrstufigen Vorgehen zu unterscheiden. Aufgrund des notwendigen Zeitaufwands sind der direkte Antigennachweis im Stuhl (Glutamat-Dehydrogenase [GDH]), der direkte Nachweis der Toxine A/B (sogenannte Schnelltests) bzw. molekularbiologische Testverfahren zum Toxinnachweis geeignet. Die GDH ist ein „common antigen“ von $C$. difficile und kann sowohl bei toxigenen als auch nicht toxigenen Stämmen nachgewiesen werden. Der GDH-Nachweis ist aufgrund seiner Sensitivität in mehrstufigen Diagnosealgorithmen ein gut geeigneter kostengünstiger und „schneller“ Suchtest.
Zum Nachweis der GDH können enzymgekoppelte Immunadsorptionstests (EIA) im Mikrotiterplattenformat (hoher Probendurchsatz) oder als Point of Care-Membranschnelltest direkt am Patienten durchgeführt werden. Wichtig ist, dass die Ergebnisse der Diagnostik schnell verfügbar sind; lange Transportwege (z.B. zu auswärtigen Zentrallaboratorien) oder Lagerungszeiten sind unbedingt zu vermeiden. Da die GDH sowohl bei toxigenen wie auch nicht toxigenen Stämmen auftritt, ist eine zeitnahe Bestätigung (Toxinnachweis per EIA oder Nachweis toxinkodierender Gensequenzen und/oder Zytotoxizitätsnachweis in der Zellkultur) notwendig, andernfalls führt der alleinige GDH-Nachweis in der Praxis zur häufigeren Diagnosestellung einer vermeintlichen CDI und damit zu einer Übertherapie [38]. Mehrere kommerziell verfügbare, EIA-basierte Testsysteme erlauben die simultane Detektion des GDH-Antigens sowie der Toxine A und B. In mehrstufigen Algorithmen werden Bestätigungstests für die toxigene Infektion durchgeführt; die Kultur gilt dabei als Goldstandard. Sie ermöglicht außerdem die Resistenztestung und molekulare Typisierung („Toxinotyping“). Ein zweistufiges Vorgehen wird von der Europäischen Gesellschaft für Klinische Mikrobiologie und Infektionskrankheiten (ESCMID) favorisiert [39]. Alternativ hierzu kann in einer einstufigen Diagnostik direkt ein molekularbiologischer Nachweis toxinbildender Stämme geführt werden; dieses wird in der amerikanischen Leitlinie zur CDI-Diagnostik favorisiert [40]. Damit können toxinbildende C. difficile-Stämme detektiert werden, die mittels EIA-basierter Analytik GDH-positiv und toxinnegativ (also falsch negativ) getestet wurden [41].

Bei schweren, nach dem IfSG meldepflichtigen Infektionen, bei Patienten mit wiederholten Rezidiven und im Rahmen nosokomialer Ausbrüche sollte zusätzlich ein kultureller Nachweis angestrebt werden (anaerobe Kultur auf Selektivmedien, z. B. CCF Agar). Die Typisierung der Isolate erlaubt die Identifikation von Infektionsketten, den Nachweis epidemiologisch besonders bedeutsamer Stämme (z.B. Ribotyp 027) und die Antibiotikaresistenztestung $[42,43]$.

\section{Empfehlung 1.6: Erweiterung der Diagnostik}

In Abhängigkeit vom klinischen Bild (z. B. blutige Diarrhö, Fieber), Anamnese (Fernreise, Medikamente) etc. sollte abgestuft die Diagnostik unter Einbeziehung laborchemischer, mikrobiologischer und bildgebender Verfahren (z. B. Ultraschall, Endoskopie) erweitert werden.

[Konsensusstärke: Konsens, Empfehlung]

\section{Kommentar}

In Abhängigkeit vom klinischen Bild sollte die Diagnostik entsprechend erweitert werden. Laboruntersuchungen zur Erfassung des Schweregrades der Infektion (z. B. Blutbild einschließlich Differenzialblutbild, Elektrolyte (Natrium, Kalium), Kreatinin, C-reaktives Protein) sind sinnvoll. Auch wenn die Anmerkung propädeutisch scheint, soll hier auch auf die Notwendigkeit zur Abnahme von Blutkulturen bei Fieber hingewiesen werden. Ohne Zweifel besitzen bildgebende Verfahren wie die transabdominelle Sonografie (Frage nach dilatierten Darmschlingen, Peristaltik, freier Flüssigkeit, Lymphknotenvergrößerungen etc.) oder Computertomografieuntersuchungen (CT) (ggf. mit und ohne intravenöser bzw. gastrointestinaler Kontrastmittelgabe) insbesondere zur Abschätzung der Schwere des Krankheitsbildes einen wichtigen Stellenwert und sind im Einzelfall durchzuführen. Die Bedeutung der Endoskopie in der differenzialdiagnostischen Abklärung der akuten Gastroenteri- 
tis wird im allgemeinen überschätzt und besitzt nur bei Patienten mit einem besonderen Risikoprofil (angeborene oder erworbene Immundefekte, Fernreisende, V.a. M. Whipple oder Patienten mit chronischer Diarrhö) eine Bedeutung. [44-46]. Auch bei Verdacht auf eine CDI liefert die Endoskopie keine zuverlässige Entscheidungshilfe; so finden sich bei Patienten mit durch Stuhluntersuchungen gesicherter CDI in nur $40 \%$ typische Pseudomembranen [47]. Bei Patienten mit Immunsuppression oder einer CED ist der Nachweis von Pseudomembranen bei einer CDI noch seltener [48, 49]. Zur differenzialdiagnostischen Abklärung ist auch - wie in Kapitel 4 dargestellt - insbesondere bei Patienten mit Immundefekten oder iatrogener Immunsuppression bzw. schweren Komorbiditäten die mikrobiologische Diagnostik zu erweitern. Serologische Untersuchungen (z.B. Campylobacter spp.) haben bei der Abklärung der akuten Gastroenteritis in der Regel keinen Stellenwert; auch wenn sie zu epidemiologisch-relevanten Abklärungen einen Beitrag liefern können [10]. Untersuchungen auf Pilze im Stuhl sind nicht indiziert. Ebenso sind fäkale Entzündungsparameter in der Regel nicht hilfreich, da sie keine Bedeutung in der differenzialdiagnostischen Abklärung haben und nicht gut mit der Schwere des Krankheitsbildes korrelieren. Ihre Bedeutung liegt stattdessen in der Abgrenzung funktioneller Beschwerden von entzündlichen Erkrankungen [50].

\section{Empfehlung 1.7: Anzahl der Stuhlproben}

Zur ätiologischen Klärung bei akuter Gastroenteritis sollten 1-2 geeignete Stuhlproben zeitnah auf relevante Bakterien und Viren mikrobiologisch untersucht werden.

Bei Verdacht auf eine Parasitose sollten mindestens 3 Proben untersucht werden.

Für den mikrobiologischen Nachweis von Durchfallerregern sind Stuhlproben (3-5 ml) und in Ausnahmefällen Rektalabstriche in geeignetem Transportmedium geeignet.

[Konsensusstärke: Konsens, Empfehlung]

\section{Kommentar}

Die fäkale Ausscheidung der ursächlichen Erreger ist von der Schwere des Befalls und dem Zeitpunkt nach Infektion sowie des Immunstatus des Patienten abhängig. In der Regel nimmt die Erregerdichte im Stuhl mit Einsetzen einer spezifischen Immunantwort und dem Sistieren der Durchfälle deutlich ab. Dieses beeinflusst die Wahrscheinlichkeit des Erregernachweises. Auch ist die Transportzeit der Probe ein relevanter Faktor. Shigellen und Campylobacter spp. sind Beispiele für Bakterien, die durch eine lange Transportzeit und Temperaturschwankungen beim Transport der Probe so geschädigt werden können, dass ihr Nachweis erheblich beeinträchtigt wird. Eine wiederholte Probengewinnung erhöht somit die Wahrscheinlichkeit für einen Erregernachweis; andererseits ist diese mit einem deutlichen Mehraufwand und erhöhten Kosten verbunden. Es ist daher grundsätzlich anzustreben Proben für die Erregerdiagnostik im Stadium der akuten Symptomatik zu gewinnen, diese dem Labor so zeitnah wie möglich zuzuführen und ein sensitives und möglichst wenig störanfälliges Nachweisverfahren zu wählen. Dabei sind Transportzeiten unter 12 Stunden in jedem Falle anzustreben (Abnahmezeitpunkt dokumentieren) [51]. Angemerkt sei, dass ortsferne mikrobiologische Laborgemeinschaften mit längeren Transportwegen diese Forderungen wohl nicht immer erfüllen können. Bei adäquaten Prozessabläufen reicht für die Diagnostik von pathogenen Bakterien oder Viren eine Stuhlprobe aus. Der diagnostische Zusatznutzen weiterer Untersuchungs- proben zum Nachweis bakterieller oder viraler Durchfallursachen ist in der Regel gering. So zeigt eine systematische Auswertung von 59500 Stuhlproben bei 3808 (6,4\%) Proben einen pathologischen Befund. Dabei wurden $99 \%$ in der ersten oder zweiten Probe gefunden; der diagnostische Mehrgewinn der 3. Stuhlprobe ist somit sehr niedrig [52]. Auch für Patienten mit CDI gilt, dass sich aus der Untersuchung über die erste Stuhlprobe hinausgehender Proben nur mit niedriger Wahrscheinlichkeit positive Ergebnisse erheben lassen [53]. Diese Erläuterungen gelten jedoch nicht für den Nachweis von Erregern bei symptomlosen Dauerausscheidern. Hier werden aus epidemiologischen Gründen nach wie vor drei konsekutive Stuhluntersuchungen gefordert, um das Vorhandensein der Erreger mit höchster Wahrscheinlichkeit auszuschließen. Auch sind bei Patienten mit chronisch entzündlichen Darmerkrankungen zum Ausschluss einer CDI 3 Stuhlproben sinnvoll [54]. Offensichtlich reichen bei diesen Patienten niedrigere Toxinmengen, die einer Diagnostik entgehen können, aus, um eine symptomatische CDI zu verursachen. Bei Durchfällen durch Parasiten erfolgt die Erregerausscheidung abhängig vom Erreger (z. B. Protozoenzysten, Wurmeier) diskontinuierlich. Bei Verdacht auf eine parasitär verursachte (chronische) Diarrhö zeigt die Untersuchung von 2 bzw. 3 Proben, die an verschiedenen Tagen gewonnen wurden, daher eine relevant höhere Sensitivität [55].

\section{Empfehlung 1.9: Maßnahmen bei Entlassung aus dem \\ Krankenhaus}

Bei Patienten, die im Krankenhaus aufgrund einer infektiösen Gastroenteritis betreut wurden, sollte vor Entlassung, z. B. in Gemeinschaftseinrichtungen, eine ärztliche Einschätzung der Kontagiosität durchgeführt werden.

[Konsensusstärke: Konsens, Empfehlung]

\section{Kommentar}

Werden Patienten aufgrund einer infektiösen Gastroenteritis im Krankenhaus behandelt und besteht nach Besserung des klinischen Bildes die Möglichkeit zur Entlassung in Gemeinschaftseinrichtungen des Gesundheitssystems (Alten- und Pflegeheime, Kurzzeitpflegeinrichtungen etc.), ist die Frage der Kontagiösität bzw. die Übertragungsgefahr auf Mitbewohner und Beschäftige zu adressieren. Häufig werden „negative Stuhlkulturen“ gefordert, bevor eine Rückverlegung möglich ist. Da Erreger oder auch Toxine teilweise noch Wochen (bei immunsupprimierten Patienten unter Umständen sogar Monate) nach der akuten Erkrankung im Stuhl nachzuweisen sind, führt dieser Ansatz regelhaft zu Problemen. So wird z. B. bei Erkrankten mit Norovirus-Infektionen das Virus in der Regel noch 7-14 Tage, in Ausnahmefällen (z.B. bei Immunsuppresion) aber auch noch über Wochen nach einer akuten Erkrankung über den Stuhl ausgeschieden. Bei Patienten mit CDI bleibt selbst nach adäquater Therapie und Sistieren der Symptomatik bei bis zu 30\% der Patienten der Toxinnachweis positiv [56].

Nach Expertenmeinung gilt, dass 48 Stunden nach Sistieren der klinischen Symptomatik (Erbrechen, Diarrhö) die Kontagiosität des Patienten so stark reduziert ist, dass bei Einhaltung der üblichen hygienischen Maßnahmen (Basishygienemaßnahmen) weder für Familienangehörige, Mitbewohner und Pflegende, noch für andere Patienten ein erhöhtes Risiko besteht, und eine Unterbringung in Mehrbettzimmern in Krankenhäusern bzw. eine Entlassung in das häusliche Umfeld oder die Gemeinschaftseinrichtung möglich ist. An dieser Stelle sei auch auf die Empfehlung 
3.15 und den entsprechenden Kommentar verwiesen. Es gibt keine gute Evidenz für Maßnahmen, die über die in der Empfehlung 3.15 beschriebenen Empfehlungen hinausgehen, sodass hier ein Bedarf an infektionsepidemiologischen Studien besteht. Bei der Betreuung von Personen mit eingeschränktem Hygienebewusstsein (z. B. Personen mit Demenz) in Gemeinschaftseinrichtungen sind weitergehende hygienische Maßnahmen ggf. nach Maßgabe des im Einzelfall zuständigen und einbezogenen Gesundheitsamtes zu erwägen. Im Infektionsschutzgesetz ist geregelt, dass an Cholera-, Enteritis durch enterohämorrhagische E. coli (EHEC), Typhus abdominalis, Paratyphus oder Shigellose erkrankte Personen in Gemeinschaftseinrichtungen keine Tätigkeiten ausüben dürfen, bei denen sie Kontakt zu den dort betreuten Patienten haben, bis nach ärztlichem Urteil eine Weiterverbreitung der Krankheit ausgeschlossen werden kann. In der Regel werden hierfür von den Gesundheitsämtern 3 negative Stuhluntersuchungen gefordert.

\section{Empfehlung 1.10: Chronische Diarrhö}

Auch bei chronischer Diarrhö (länger als 4 Wochen) sollte eine infektiöse Ursache ausgeschlossen werden.

[Konsensusstärke: Konsens, Empfehlung]

\section{Kommentar}

Von einer chronischen Diarrhö wird gesprochen, wenn die Durchfallsymptomatik länger als 4 Wochen besteht. Die Ursachen der chronischen Diarrhö sind vielfältig und umfassen sowohl mikrobielle als auch nicht-mikrobielle Ursachen. Die meisten mikrobiell bedingten Durchfälle werden beim Immungesunden innerhalb von 1-2 Wochen (durch die spezifischen Immunreaktionen) überwunden. Chronische Durchfälle können insbesondere bei Patienten mit Immundefekten (z. B. angeborene Immundefekte oder AIDS) auftreten. Begleitsymptome (z. B. blutige Stühle bei Infektion mit E. histolytica; Flatulenz bei G. lamblia) und vorbestehende Erkrankungen (z. B. HIV-Infektion bei Infektion mit Isospora belli) sowie Auslandsaufenthalte beeinflussen das differenzialdiagnostische Spektrum. Zum Erregerspektrum und der entsprechenden Diagnostik sei auf die Empfehlung und Kommentare im Kapitel 4 „Diarrhö bei Immundefizienz“ verwiesen.

\section{K-2 Klinisches Bild und Therapie der ambulant erworbenen Gastroenteritis (AG 2) $\nabla$}

\section{Empfehlung 2.1: Flüssigkeitssubstitution}

Bei Verdacht auf eine infektiöse Gastroenteritis soll eine ausreichende Flüssigkeitssubstitution erfolgen.

[Konsensusstärke: starker Konsens, starke Empfehlung]

\section{Kommentar}

Abhängig von dem Ausmaß der Diarrhö kann eine infektiöse Gastroenteritis mit einem starken Flüssigkeits- und Elektrolytverlust einhergehen, wobei insbesondere ältere Patienten gefährdet sind. Zeichen der Exsikkose und hierdurch bedingte Komplikationen bei älteren Patienten sind:

- stehende Hautfalten

- orthostatische Dysregulation und Stürze

- Bewusstseinsstörungen, Delir
- Nierenfunktionsstörungen bis hin zu einem akuten Nierenversagen

- Obstipation

- Rhabdomyolyse

- Verschlechterung der Rheologie mit in der Folge erhöhter Gefahr eines akuten Myokardinfarktes oder apoplektischen Insults

- erhöhtes Dekubitusrisiko

Die wichtigste therapeutische Maßnahme bei allen Patienten mit infektiöser Gastroenteritis besteht somit in erster Linie in einer ausreichenden Flüssigkeits- und Elektrolytsubstitution. Diese sollte primär in Form einer oralen Rehydrierung mithilfe einer speziellen glukosebasierten Elektrolytlösung erfolgen. Die Weltgesundheitsorganisation WHO empfiehlt eine Salz- und Glukosetrinklösung (orale Rehydratationslösung, „WHO-Trinklösung“) mit einer Osmolarität von $245 \mathrm{mOsm} / \mathrm{L}$ und folgender Zusammensetzung: Glucose 13,5 g/L, Natriumchlorid 2,6 g/L, Kaliumchlorid $1,5 \mathrm{~g} / \mathrm{L}$ und Natriumcitrat $2,9 \mathrm{~g} / \mathrm{L}$. Die physiologische Grundlage für dieses Therapieprinzip ist mit dem in den Enterozyten vorhandenen, gekoppelten Kotransport von Natrium und Glucose verbunden. Natrium wird über den sGLT-1-Transporter effektiver aus dem Darmlumen aufgenommen, wenn es mit Glucose oder Galactose transportiert werden kann. Wasser folgt dem gerichteten Natriumstrom passiv nach. In der oralen Rehydratationslösung ist das Verhältnis von Natrium zu Glucose so optimiert, dass eine maximale Natriumresorption und damit Wasseraufnahme erreicht wird. Daher sollte die Rehydratationslösung in der vorgeschriebenen Verdünnung in Wasser und nicht zusammen mit anderen Getränken (z. B. Milch, Limonade) verabreicht werden [57]. Aufgrund der optimierten Zusammensetzung und durch wissenschaftliche Studien belegten Wirksamkeit ist diese standardisierte orale Rehydratationslösung anderen Zubereitungen (z.B. gesüßter Tee in Kombination mit Salzgebäck oder mit Zucker und Salz angereicherte Fruchtsaftverdünnung) vorzuziehen. Ungeeignet zur oralen Rehydrierung sind reine Fruchtsäfte, Leitungswasser oder Limonade (z.B. Cola). Sie enthalten entweder zu viel Zucker, was die Diarrhösymptomatik verstärken kann, oder zu wenig bzw. im falschen Verhältnis Elektrolyte. Die Anwendung oraler Rehydratationslösung ist nahezu ausschließlich in der Pädiatrie wissenschaftlich untersucht worden. Die Ergebnisse und ihre praktische Umsetzung können jedoch ohne Einschränkungen auf erwachsene Patienten übertragen werden $[58,59]$. Eine Cochrane-Analyse von 17 randomisierten kontrollierten Studien bei Kindern mit infektiöser Gastroenteritis $(n=1811)$ zeigte keinen relevanten Unterschied zwischen einer oralen und einer intravenösen Rehydrierung. Bei oraler Rehydrierung war die Durchfalldauer im Vergleich zur intravenösen Rehydrierung sogar im Schnitt fast sechs Stunden kürzer und der Krankenhausaufenthalt verkürzte sich signifikant um 1,2 Tage [60]. Obwohl primär eine orale Rehydrierung durchgeführt werden sollte, wird diese in Industrienationen, sowohl in der Pädiatrie als auch bei Erwachsenen, nicht regelmäßig angewendet [61]. Ein Grund hierfür ist die häufig von Ärzten und Pflegepersonal geäußerte Meinung, dass eine orale Rehydrierung in vielen Fällen nicht möglich bzw. eine intravenöse Therapie der oralen Rehydrierung überlegen sei. Beide Postulate sind wissenschaftlich klar widerlegt worden [57]. Möglicherweise sind diese Ansichten auch durch den niedrigeren Personal- bzw. Pflegeaufwand, der mit der Zubereitung von Infusionen im Vergleich zum regelmäßigen Anbieten von Trinklösungen verbunden ist, zu erklären. Im Gegensatz dazu muss in schweren Fällen (schwere Dehydrierung $\geq 10 \%$ Körpergewicht, Kreislaufschock oder Be- 
wusstseinsstörung) oder bei trotz antiemetischer Therapie fortbestehend schwerem Erbrechen die Rehydratation mit einer Infusionsbehandlung erfolgen [62]. Die klassische „Durchfalldiät“ mit Bananen, Reis, Apfelmus und Toast unter Vermeidung von Milchprodukten (möglicher transienter Laktasemangel) wird häufig empfohlen, eine wissenschaftliche Evidenz hierfür liegt aber nicht vor [63].

\section{Empfehlung 2.2: Symptomatische Therapie}

Eine kurzdauernde symptomatische Therapie mit motilitätshemmenden Substanzen (z. B. Loperamid) kann bei unkompliziertem Krankheitsbild durchgeführt werden.

[Konsensusstärke: starker Konsens, Empfehlung offen].

Bei schwerem Krankheitsbild (z.B. blutige Diarrhö, Fieber, Megakolon) soll keine motilitätshemmende Therapie durchgeführt werden.

[Konsensusstärke: starker Konsens, starke Empfehlung]

\section{Kommentar}

Loperamid ist ein stark wirksames synthetisches Antidiarrhoikum für den oralen Gebrauch und kann zur symptomatischen Therapie bei unkompliziertem Krankheitsbild angewendet werden. Es bindet an die $\mu$-Opiatrezeptoren in der Darmwand und zeichnet sich durch einen raschen Wirkungseintritt aus. Loperamid blockiert die Freisetzung von Acetylcholin und Prostaglandin, wodurch die propulsive Peristaltik gehemmt und die intestinale Transitzeit verlängert wird. Zusätzlich wird der Tonus des Analsphinkters erhöht, was eine Inkontinenzsymptomatik reduziert und den Stuhldrang herabsetzt. Obwohl ein Großteil des eingenommenen Loperamids über den Darm absorbiert wird, liegt die systemische Verfügbarkeit aufgrund eines ausgeprägten First-Pass-Effekts nur bei rund 0,3\%. Studien zur Anwendung von Loperamid wurden in der Mehrzahl der Fälle in Kombination mit einem Antibiotikum (Rifaximin, Trimethoprim-Sulfamethoxazol, Fluorchinolone, Azithromycin) bei Patienten mit Reisediarrhö durchgeführt [64-69]. Nur wenige Studien untersuchten Loperamid in einem placebokontrollierten Design [70]. Die Ergebnisse der Studien sind heterogen, zeigen jedoch eine statistisch signifikante Abnahme der Stuhlfrequenz um 1-2 Stuhlentleerungen/ 24 Stunden und Verkürzung der Symptomdauer je nach Studie um bis zu 48 Stunden [66]. Bei Dysenterie (Diarrhö mit blutigem Stuhl und/oder Fieber) und bei Patienten mit einer Enterocolitis durch Salmonellen, Shigellen, Campylobacter, Entamoeba spp. oder Clostridium difficile soll keine motilitätshemmende Therapie durchgeführt werden. Diese Empfehlung basiert auf Fallberichten, in denen das Auftreten eines toxischen Megakolons unter einer Therapie mit Loperamid beschrieben wurde [71 - 77]. In einer doppelblinden placebokontrollierten Studie aus Thailand bei 88 Patienten mit akuter Dysenterie konnten diese Befürchtungen jedoch nicht bestätigt werden. Alle Patienten wurden mit Ciprofloxacin behandelt und bekamen in der Studiengruppe zusätzlich Loperamid (max. $16 \mathrm{mg} / \mathrm{Tag}$ ) verabreicht. In rund $50 \%$ der Fälle konnten Shigellen und enteroinvasive E. coli, in $16 \% \mathrm{Vi}$ brio parahaemolyticus und in $7 \%$ Salmonellen nachgewiesen werden. In keinem Fall kam es unter der Therapie mit Loperamid zu einer Komplikation [65]. Auch wenn sich somit die Negativempfehlung nur auf Fallberichte stützt, soll eine motilitätshemmende Therapie in Fällen mit schwerem Krankeitsbild (z. B. blutige Diarrhö, Fieber, Megakolon) nicht eingesetzt werden, zumal dieses auch in der Fachinformation von Loperamid explizit als Kontraindikation genannt wird. Darüber hinaus konnte für Kin- der mit einer enterohämorrhagischen Escherichia coli-Infektion und Loperamidtherapie ein erhöhtes Risiko für ein hämolytischurämisches Syndrom gezeigt werden [78]. Racecadotril, welches nach oraler Gabe und hydrolytischer Spaltung zum Metaboliten Thiorphan aktiviert wird, ist ein Enkephalinasehemmer, der den Abbau körpereigener Enkephaline hemmt und eine Alternative zu Loperamid darstellt. Enkephaline hemmen über $\delta$-Opiatrezeptoren die Sekretion von Wasser und Elektrolyten in das Darmlumen. In Studien war die klinische Wirksamkeit vergleichbar zu Loperamid, das Präparat wird in Deutschland derzeit aber nur selten eingesetzt [79 - 81]. Für die anderen erhältlichen Antidiarrhoika wie z.B. pflanzliche Substanzen (Uzara, getrocknetes Apfelpulver) oder Siliciumdioxid, Tannin, Kohle oder Myrrhe liegen keine kontrollierten Studien vor.

Empfehlung 2.3: Analgetische/spasmolytische Therapie

Eine symptomatische analgetische/spasmolytische Therapie kann gemäß des Stufenschema der WHO mit Paracetamol, Metamizol, Opioiden sowie Butylscopolamin durchgeführt werden. Vermieden werden sollten Acetylsalicylsäure, nicht steroidale Antiphlogistika (NSAIDs) und Coxibe.

[Konsensusstärke: starker Konsens, Empfehlung]

\section{Kommentar}

Systematische Studien zur symptomatischen analgetischen/spasmolytischen Therapie bei infektiöser Gastroenteritis liegen nicht vor. Empfehlungen zur symptomatischen Schmerztherapie gründen sich daher auf klinische Erfahrungen und auf Extrapolationen von Therapieprinzipien anderer akuter Schmerzsyndrome. Bei der Therapie mit Opioiden sind relative Kontraindikationen (z.B. Ileussymptomatik, toxisches Megakolon) sowie Nebenwirkungen (Sedierung, missbräuchliche Verwendung) zu beachten. Es gibt Berichte, dass bei Einnahme von nicht steroidalen Antiphlogistika (NSAIDs) oder Coxiben gastrointestinale Nebenwirkungen auftreten, sodass diese Präparate nicht primär eingesetzt werden sollten $[82,83]$.

\section{Empfehlung 2.4: Antiemetische Therapie}

Bei Erbrechen kann eine antiemetische Therapie erfolgen. [Konsensusstärke: starker Konsens, Empfehlung offen]

\section{Kommentar}

Obwohl kontrollierte Studien zur antiemetischen Therapie bei akuter infektiöser Gastroenteritis bei erwachsenen Patienten nicht vorliegen, kann bei Patienten, bei denen eine orale Rehydrierung aufgrund rezidivierenden Erbrechens nicht möglich ist, eine antiemetische Therapie erfolgen. Studien aus dem Bereich der Pädiatrie zeigen, dass eine orale oder parenterale antiemetische Therapie die Symptomatik erfolgreich reduziert und Krankenhausaufenthalte reduziert [84].

\section{Empfehlung 2.5: Probiotika}

Eine generelle Empfehlung für den Einsatz von Probiotika zur Therapie der akuten infektiösen Enteritis von Erwachsenen kann derzeit nicht gegeben werden.

[Konsensusstärke: starker Konsens, Empfehlung offen] 


\section{Kommentar}

Probiotika werden entweder als Nahrungsmittel oder Nahrungsergänzungsmittel, einzelne Probiotika mit definierter Spezies auch als Arzneimittel angeboten [85]. Sie stellen eine extrem heterogene Gruppe mit unterschiedlichen Mikroorganismen (Bakterien, Hefen etc.) dar, die miteinander kaum vergleichbar sind. In einem Cochrane-Review von 2010, in dem 63 RCTs mit insgesamt 8014 behandelten Patienten analysiert wurde, zeigte sich, dass der Verlauf einer akuten infektiösen Gastroenteritis durch die Gabe von Probiotika positiv beeinflusst werden kann und ohne relevante Nebenwirkungen einhergeht. Patienten hatten 48 Stunden nach dem Beginn der Probiotikaeinnahme im Schnitt eine Stuhlentleerung weniger am Tag und einen insgesamt um circa 25 Stunden kürzeren Verlauf der Erkrankung. Von den insgesamt 8014 eingeschlossenen Studienpatienten waren jedoch nur 352 Patienten sicher älter als 18 Jahre. In 3 Studien mit insgesamt 1173 Patienten war das exakte Alter der eingeschlossenen Patienten nicht valide eruierbar. Aufgrund der geringen Anzahl von erwachsenen Patienten ist somit eine Aussage für diese Patientengruppe nicht möglich. Weiterhin stellten die Autoren eine hohe Heterogenität der Studien, u. a. bei den Studienendpunkten und verwendeten Substanzen (u.a. Bifidobakterien, Lactobacillus spp., E. coli Nissle 1917, Saccharomyces boulardii) fest. Aufgrund dieser Limitationen kann aktuell eine generelle Empfehlung für den Einsatz von Probiotika zur Therapie der akuten infektiösen Gastroenteritis bei Erwachsenen nicht gegeben werden $[86,87]$.

\section{Empfehlung 2.6: Empirische antimikrobielle Therapie}

Bei Verdacht auf eine infektiöse Gastroenteritis sollte primär keine empirische antimikrobielle Therapie erfolgen [Konsensususstärke: starker Konsens, Empfehlung].

Eine empirische antimikrobielle Therapie kann bei folgenden Konstellationen durchgeführt werden [Konsensususstärke: starker Konsens, Empfehlung offen]:

- bei Immunsuppression (medikamentös oder durch Grunderkrankung bedingt)

- bei Zeichen einer systemischen Infektion (z. B. Fieber $>38,5^{\circ} \mathrm{C}$ )

- bei blutiger Diarrhö

\section{Empfehlung 2.7: Empirische antimikrobielle Therapie}

Die initiale empirische antimikrobielle Therapie sollte - nach Durchführung einer Erregerdiagnostik - mit einer der folgenden Substanzen erfolgen: Azithromycin ( $500 \mathrm{mg} / \mathrm{d}$ p.o.) für 3 Tage oder Ciprofloxacin ( $1 \mathrm{~g} /$ Tag p.o. oder $800 \mathrm{mg} / \mathrm{Tag}$ i.v.) für 3 - 5 Tage oder Ceftriaxon ( $2 \mathrm{~g} /$ Tag i. v.) für 3 - 5 Tage. [Konsensusstärke: Konsens, Empfehlung]

\section{Kommentar}

Bei der Erwägung einer Antibiotikatherapie gilt grundsätzlich, dass die meisten Fälle einer infektiösen Gastroenteritis selbstlimitierend sind und ausreichend mit Flüssigkeitsersatz und supportiven Maßnahmen behandelt werden können. Nur wenige Studien haben die empirische Antibiotikatherapie bei infektiöser Gastroenteritis ohne Reiseanamnese untersucht [88 - 91]. In diesen Studien führte der empirische Einsatz von Antibiotika, vorwiegend Ciprofloxacin, zu einer Verkürzung der Diarrhö um 24-48 Stunden und Verkürzung der Erregerausscheidung im Stuhl. Die empirische Gabe eines Antibiotikums sollte jedoch in
Hinblick auf mögliche Nebenwirkungen (inkl. Clostridium difficile assoziierte Diarrhö) und der Zunahme von Antibiotikaresistenzen nur mit Zurückhaltung eingesetzt werden und individuell bei jedem Patienten kritisch hinterfragt werden.

Bei Immunsuppression, Anzeichen für eine systemische Infektion (z. B. Fieber $>38,5^{\circ} \mathrm{C}$ ) oder Vorliegen einer Dysenterie (blutige Diarrhö) kann eine empirische Antibiotikatherapie durchgeführt werden - unter der Vorstellung, dass eine frühzeitige empirische Antibiotikatherapie eine weitere Progression zu einem schweren Verlauf abwenden kann [90]. In solchen Fällen sollte nach Durchführung einer Erregerdiagnostik inkl. Abnahme von Blutkulturen eine Therapie mit Azithromycin (500 mg/Tag p.o.) für 3 Tage oder Ciprofloxacin ( $1 \mathrm{~g} / \mathrm{Tag}$ p. o. oder $800 \mathrm{mg} / \mathrm{Tag}$ i.v.) für 3-5 Tage oder Ceftriaxon ( $2 \mathrm{~g} /$ Tag i.v.) für 3-5 Tage durchgeführt werden. $\mathrm{Zu}$ beachten sind die in der Fachinformation genannten Gegenanzeigen und Warnhinweise für die genannten Substanzen. Ergibt sich aus einer durchgeführten mikrobiologischen Untersuchung ein spezifischer Erregernachweis einschließlich der Resistenzbestimmung, sind in Abhängigkeit von bestimmten Konstellationen beim Patienten und des Erregers spezifische Therapie- bzw. Nichttherapieindikationen gegeben, die im folgenden diskutiert werden sollen.

\section{Nicht typhoidale Salmonellen}

\section{Empfehlung 2.8: Antimikrobielle Therapie}

Bei akuter nicht typhoidaler Salmonelleninfektion ohne Hinweis auf eine systemische Infektion sollte in der Regel keine antimikrobielle Therapie durchgeführt werden.

[Konsensusstärke: starker Konsens, Empfehlung]

\section{Empfehlung 2.9: Antimikrobielle Therapie}

Eine antimikrobielle Therapie soll bei akuter nicht typhoidaler Salmonelleninfektion in folgenden Fällen erfolgen [Konsensusstärke: starker Konsens, starke Empfehlung]:

- bei Bakteriämie

- bei Zeichen systemischer Infektion (z. B. Fieber $>38,5^{\circ} \mathrm{C}$ )

Eine antimikrobielle Therapie sollte bei akuter nicht typhoidaler Salmonelleninfektion in folgenden Fällen erfolgen [Konsensususstärke: starker Konsens, Empfehlung]:

- bei Immunsuppression (medikamentös oder durch Grunderkrankung bedingt)

- bei Hämodialysepatienten

Eine antimikrobielle Therapie kann bei akuter nicht typhoidaler Salmonelleninfektion in folgenden Fällen erfolgen [Konsensusstärke: starker Konsens, Empfehlung offen]:

- bei Vorliegen von Gefäßprothesen

- bei Vorliegen von Gefäßaneurysmen

- bei Vorliegen von Fremdmaterial (z. B. Gelenkprothesen)

\section{Kommentar}

Nicht typhoidale Salmonellen verursachen beim Menschen in der Regel unkomplizierte Gastroenteritiden. Die beiden häufigsten Salmonellenserovare, die im Rahmen der IfSG-Meldepflicht an das Robert Koch-Institut gemeldet werden, sind S. Enteritidis (ca. 35\%) und S. Typhimurium (ca. 40\%) [92]. S. Typhi und S. Paratyphi hingegen rufen systemische Infektionen mit meist sekundärer Darmbeteiligung hervor. Beide Infektionen kommen endemisch in Afrika, Mittel- und Südamerika, im indischen Subkontinent und in Südostasien vor und sind nicht Gegenstand 
dieser Empfehlung. Nicht typhoidale Salmonellen führen dagegen primär zu einer Lokalinfektion des Darmes. Die Infektion erfolgt durch orale Erregeraufnahme und gilt als klassische Lebensmittelinfektion (Eier bzw. eihaltige Speisen, rohes Fleisch bzw. nicht oder nicht ausreichend erhitzte Fleischerzeugnisse). Auch primär nicht mit nicht typhoidalen Salmonellen kontaminierte Lebensmittel können durch die Verarbeitung durch infizierte Menschen, Kontakt mit kontaminierten Oberflächen oder anderen kontaminierten Lebensmitteln ein Infektionsrisiko darstellen (sogenannte „Kreuzkontamination“). Selten ist die Übertragung durch direkten Kontakt mit nicht typhoidale Salmonellen ausscheidenden Tieren, z. B. in Streichelzoos. Dieser Übertragungsweg ist bei Haustieren häufiger, insbesondere bei der Haltung von Reptilien [93]. Eine direkte oder indirekte Übertragung von Mensch zu Mensch ist ggf. als nosokomiale Infektion bei besonders disponierten Personen oder unter hygienisch mangelhaften Bedingungen möglich, dies ist jedoch sehr selten [94]. Die Inkubationszeit der Salmonellenenteritis beträgt 6-72 Stunden, in der Regel 12 - 36 Stunden. Sie ist abhängig von der Infektionsdosis und dem Serovar [93]. Die Ausscheidung von Enteritissalmonellen dauert bei Erwachsenen im Durchschnitt einen Monat, bei Kindern unter 5 Jahren meist länger [95]. Die Salmonellose manifestiert sich meist als akute Darmentzündung mit plötzlich einsetzendem Durchfall, Kopf- und Bauchschmerzen, Unwohlsein und manchmal Erbrechen. Häufig tritt leichtes Fieber auf. In den meisten Fällen handelt es sich um einen selbstlimitierenden Verlauf, wobei die Körpertemperatur sich nach 48 - 72 Stunden normalisiert, und die Diarrhö innerhalb von 4-10 Tagen sistiert. In seltenen Fällen $(<5 \%)$ kann es zu einer Bakteriämie mit fokalen Absiedlungen der Erreger (Abszesse, Osteomyelitis, septische Arthritis, Cholezystitis, Endokarditis, Meningitis, Perikarditis, Pneumonie, Pyodermie oder Pyelonephritis) kommen, insbesondere bei älteren und abwehrgeschwächten Patienten [96, 97]. Die Entscheidung zur Einleitung einer antibiotischen Therapie nach Anzucht von nicht typhoidalen Salmonellen im Stuhl richtet sich nach dem klinischen Verlauf und patientenspezifischen Risikofaktoren. Eine Cochrane-Analyse mit 767 ansonsten gesunden Patienten mit gesicherter Salmonellenenteritis kam zu dem Ergebnis, dass eine antibiotische Therapie keinen Einfluss auf den Verlauf der Erkrankung hat. In der Auswertung der 12 placebokontrollierten Studien fanden sich zwischen Placebo- und Verumgruppe keine Unterschiede in der Dauer der Diarrhö, Dauer des Fiebers oder Schwere des Krankheitsverlaufs. Allerdings konnten bei Patienten, die mit einem Antibiotikum behandelt wurden, einen Monat nach Beendigung der Therapie signifikant häufiger Salmonellen im Stuhl nachgewiesen werden (RR 1,96, $95 \%$ KI 1,29 - 2,98) [98]. Somit sollte bei akuter Salmonellenenteritis ohne Hinweis auf systemische Infektion keine antimikrobielle Therapie durchgeführt werden. Im Gegensatz dazu soll bei Patienten mit Zeichen einer systemischen Infektion (z. B. Fieber über $38,5^{\circ} \mathrm{C}$ ) und bei Nachweis der Erreger in Blutkulturen eine antimikrobielle Therapie erfolgen, um schwere systemische Verläufe sowie septische fokale Absiedlungen zu verhindern. In mehreren Studien konnte gezeigt werden, dass es bei bis zu $25 \%$ der Patienten, die älter als 50 Jahre sind, und eine Salmonellenbakteriämie aufwiesen, zu einer sekundären Arteriitis vor allem der großen Gefäße (abdominelle und thorakale Aorta) oder einer Endokarditis kommen kann. Gefährdet sind hierbei insbesondere Patienten mit einer Arteriosklerose, Diabetes mellitus, angeborenen oder erworbenen Immundefekten [99]. Darüber hinaus sollte bei Patienten mit Risikofaktoren, die für einen schweren Verlauf prädisponiert sind (z. B. angeborene oder erworbene Im- mundefekte, Hämodialyse), unabhängig von dem Vorliegen einer Bakteriämie oder der Schwere der Salmonellenenteritis, ebenfalls eine Antibiotikatherapie durchgeführt werden. Bei Patienten mit Gefäßprothesen, Gefäßaneurysmen oder Vorliegen von Fremdmaterial (z. B. Gelenkprothesen) kann eine Therapie erwogen werden. Hintergrund für die beiden letztgenannten Empfehlungen ist die Tatsache, dass diese Patientengruppen ein erhöhtes Risiko für schwere systemische Verläufe und septische fokale Absiedlungen aufweisen und eine präemptive Therapie diese Komplikationen verhindern kann [100]. Die Leitlinie der Infectious Diseases Society of America (IDSA) zur Therapie gastrointestinaler Infektionen empfiehlt eine Antibiotikatherapie bei allen Patienten über 50 Jahre und bei Patienten mit einer Herzklappenerkrankung, unabhängig vom Schweregrad der Salmonelleninfektion [101].

\section{Empfehlung 2.10: Antimikrobielle Therapie}

Die antimikrobielle Therapie sollte mit folgenden Substanzen durchgeführt werden (unter Beachtung der Resistenztestung) Ciprofloxacin ( $1 \mathrm{~g} /$ Tag p. o. oder $800 \mathrm{mg} /$ Tag i. v.) für 5 - 7 Tage oder Ceftriaxon ( $2 \mathrm{~g} /$ Tag i. v.) für 5 - 7 Tage.

[Konsensusstärke: starker Konsens, Empfehlung]

\section{Kommentar}

Die antimikrobielle Therapie sollte mit Ciprofloxacin ( $1 \mathrm{~g} / \mathrm{Tag}$ p. o. oder $800 \mathrm{mg} /$ Tag i. v.) oder Ceftriaxon ( 2 g/Tag i. v.) durchgeführt werden und muss ggf. in Abhängigkeit von den Ergebnissen der Resistenztestung angepasst werden. Bei Patienten ohne angeborene oder erworbene Immundefekte sollte die Therapiedauer 5 - 7 Tage betragen, bei Patienten mit einem angeborenen oder erworbenen Immundefekten mindestens 14 Tage. Für beide Empfehlungen liegen keine kontrollierten Studien vor; sie stützen sich auf Expertenmeinungen [102]. In Fällen von fokalen Absiedlungen (Abszesse, Osteomyelitis, septische Arthritis, Cholezystitis, Endokarditis, Meningitis, Perikarditis, Pneumonie, Pyodermie oder Pyelonephritis) muss die Therapiedauer individuell festgelegt werden.

\section{Empfehlung 2.11: Dauerausscheider}

Bei Nachweis von Salmonellen im Stuhl länger als 3 Monate kann ein Therapieversuch mit Ciprofloxacin für 4 Wochen durchgeführt werden.

[Konsensusstärke: Konsens, Empfehlung offen]

\section{Kommentar}

Die Ausscheidung von Enteritissalmonellen dauert bei Erwachsenen im Durchschnitt 4 Wochen ab Beginn der Infektion. In weniger als $1 \%$ der Fälle beträgt die Ausscheidungsdauer länger als ein Jahr (sogenannte Dauerausscheider) [95]. Es gibt keine kontrollierten Studien zur Therapie von Dauerausscheidern nicht typhoidalen Salmonellen. In Analogie zu den Empfehlungen bei Dauerausscheidern von S. Typhi kann im Einzelfall eine 4-wöchige Therapie mit Fluorchinolonen (z.B. Ciprofloxacin) erwogen werden, wobei in den Studien eine Eradikation bei 75 -93\% der Patienten gelang [103, 104]. In der Literatur wird ein häufigeres Auftreten von S.Typhi-Dauerausscheidern bei Patienten mit Gallensteinen beschrieben, und die Vermutung besteht, dass diese als Reservoir dienen können [105]. Studien, welche die Empfehlung zur Durchführung einer Cholezystektomie zur verbesserten Ausscheidersanierung stützen, liegen jedoch nicht vor. 


\section{Shigellen}

\section{Empfehlung 2.12: Antimikrobielle Therapie}

Bei akuter Shigellen-Infektion soll eine antimikrobielle Therapie durchgeführt werden.

[Konsensusstärke: Konsens, starke Empfehlung]

\section{Empfehlung 2.13: antimikrobielle Therapie}

Die antimikrobielle Therapie sollte mit folgenden Substanzen durchgeführt werden (unter Beachtung der Resistenztestung) Azithromycin (500 mg/Tag p. o.) für 3 Tage oder Ciprofloxacin ( $1 \mathrm{~g} /$ Tag p. o. oder $800 \mathrm{mg} /$ Tag i. v.) für 3 - 5 Tage.

[Konsensusstärke: starker Konsens, Empfehlung]

\section{Kommentar}

Shigellen sind unbewegliche gramnegative Bakterien und Verursacher der Shigellose (Shigellenruhr, Shigellen-Dysenterie). Sie werden nach biochemischen Merkmalen und spezifischen O-Antigenen in vier Serogruppen unterteilt: Shigella dysenteriae, Shigella flexneri, Shigella boydii und Shigella sonnei. In Deutschland sind hauptsächlich Infektionen durch S. sonnei (70\%) und S. flexneri (20\%) von Bedeutung, welche häufig von Reisenden aus Ägypten, Indien, Marokko, Tunesien und der Türkei importiert werden (2011: 53\% der Fälle). Diese beiden Spezies führen überwiegend zu leichteren Erkrankungen, die aber hoch akut beginnen (Inkubationszeit 12 - 96 Stunden) und sehr infektiös (Infektionsdosis 10-200 Keime) sein können [106]. Der Mensch ist das einzige relevante Reservoir für Shigellen. Die Übertragung erfolgt fäkal-oral, überwiegend durch direkten Kontakt von Mensch zu Mensch. Daneben kann eine Infektion durch kontaminiertes Trinkwasser, Lebensmittel, Badegewässer oder durch Fliegen als mechanische Vektoren erfolgen. Eine Ansteckungsfähigkeit besteht während der akuten Infektion und solange der Erreger mit dem Stuhl ausgeschieden wird, dies kann 1 - 4 Wochen nach der akuten Krankheitsphase der Fall sein. Eine Ausscheidung über einen längeren Zeitraum ist sehr selten. Die Krankheit variiert zwischen leichten Verlaufsformen mit geringer wässriger Diarrhö und schweren Erkrankungen mit Fieber, Koliken, Tenesmen, blutiger und eitriger Diarrhö (Shigellenruhr, Bakterienruhr) [107]. Im weiteren Verlauf kann es zu fokalen Ulzerationen, vorwiegend im distalen Kolon, im Extremfall bis hin zur Kolonperforation kommen [106]. In seltenen Fällen kann es zu einem hämolytisch-urämischen Syndrom (HUS) kommen, welches durch ein Zytotoxin (Shiga-Toxin), das von S. dysenteriae Serovar 1 gebildet und mit dem Shiga-Toxin 1 (Verotoxin 1) enterohämorrhagischer E. coli (EHEC) nahezu identisch ist, verursacht wird [108]. Weitere mögliche Komplikationen sind eine reaktive Arthritis und das Reitersyndrom [109].

Obwohl die Shigellose in vielen Fällen eine selbstlimitierende Erkrankung mit einer mittleren Dauer von 7 Tagen darstellt, wird aufgrund der hohen Infektiosität und der gelegentlich sehr schweren Krankheitsverläufe eine Antibiotikabehandlung empfohlen. Bakterienausscheidung und somit Ansteckungsfähigkeit werden hierdurch reduziert, und die Krankheitsdauer wird um etwa 2 Tage verkürzt $[110,111]$. Aufgrund der zunehmenden Resistenzproblematik bei Shigellen ist die Durchführung einer Resistenztestung obligat [107]. Vor allem Isolate von Reiserückkehrern aus Asien und Afrika und von homosexuellen Patienten können vermehrte Resistenzen zeigen. In Deutschland besteht bei homosexuellen Patienten mit einer S.sonnei-Infektion in über $66 \%$ der Fälle eine Ciprofloxacinresistenz bei HIV-positiven und in $24 \%$ bei HIV-negativen Patienten [112]. Bei Patienten außerhalb dieser Risikogruppen betrug die Ciprofloxacinresistenz den europäischen Resistenzdaten bis 2009 nach weniger als $1 \%$ [113].

In Abhängigkeit von den Ergebnissen der Resistenztestung soll die antimikrobielle Therapie mit folgenden Substanzen durchgeführt werden: Ciprofloxacin ( $1 \mathrm{~g} / \mathrm{Tag}$ p. o. oder $800 \mathrm{mg} / \mathrm{Tag}$ i.v.) für 3 - 5 Tage oder Azithromycin ( $500 \mathrm{mg} / \mathrm{Tag}$ p.o.) für 3 Tage [114-116]. Bei Patienten mit einem angeborenen oder erworbenen Immundefekt sollte eine längere Therapiedauer erwogen werden (5 - 7 Tage), auch wenn für diese Empfehlung keine kontrollierten Studien vorliegen.

\section{Campylobacter}

\section{Empfehlung 2.14: Antimikrobielle Therapie}

Bei akuter Campylobacter-Infektion sollte keine antimikrobielle Therapie durchgeführt werden, wenn es bis zum Erhalt des mikrobiologischen Nachweises bereits zu einer Besserung der klinischen Symptome gekommen ist.

[Konsensusstärke: starker Konsens, Empfehlung]

\section{Empfehlung 2.15: Antimikrobielle Therapie}

Bei schwerem Krankheitsbild oder fehlender klinischer Besserung sollte eine antimikrobielle Therapie mit folgenden Substanzen durchgeführt werden (unter Beachtung der Resistenztestung) 1. Wahl: Azithromycin (500 mg/Tag p.o. für 3 Tage oder $1000 \mathrm{mg}$ p. o. einmalig), Alternativ: Ciprofloxacin ( $1 \mathrm{~g} /$ Tag p. o. für 3 Tage).

[Konsensusstärke: starker Konsens, Empfehlung]

\section{Kommentar}

Campylobacter ist ein gramnegatives Bakterium mit stäbchenförmiger, spiraliger Gestalt. In Deutschland gehören Campylobacter (v. a. C. jejuni und C. coli) zusammen mit den Salmonellen zu den häufigsten gemeldeten bakteriellen Enteritiserregern. Campylobacter-Infektionen des Menschen sind fast immer lebensmittelbedingt. Unzureichend erhitztes oder kontaminiertes Geflügelfleisch und -produkte (nicht aber Eier) stellen die Hauptinfektionsquelle dar. Weitere Infektionsquellen sind nicht pasteurisierte Milch, kontaminiertes Trinkwasser oder Oberflächengewässer, Haustiere sowie rohes Hackfleisch. Eine direkte Übertragung von Mensch zu Mensch ist wegen der geringen krankheitsauslösenden Infektionsdosis von $\geq 500$ Keimen insbesondere bei Kindern möglich [117]. Die Inkubationszeit beträgt in der Regel 2-5 Tage, in Einzelfällen 1-10 Tage. Die mittlere Ausscheidungsdauer beträgt 2-5 Wochen, in dieser Zeit gelten Patienten als potenziell infektiös [118].

Die Krankheit variiert zwischen asymptomatischen Verläufen und schweren Erkrankungen mit Fieber, Bauchschmerzen und schwerer, breiig bis massiv wässriger Diarrhö, die nicht selten auch blutig sein kann. Bis zu einem Drittel der Patienten berichten 12-24 Stunden vor Auftreten der enteritischen Symptome über Prodromi mit Fieber, Kopfschmerzen, Myalgien, Arthralgien und Müdigkeit. Die Krankheit dauert in der Regel wenige Tage bis eine Woche. Bei immungeschwächten Personen, z. B. bei AIDSPatienten, kann es zu protrahierten oder chronischen Verläufen kommen [119]. In weniger als $1 \%$ der Fälle kommt es zu einer Bakteriämie, dies v. a. bei Patienten mit einer Immunsuppression 
oder schweren Begleiterkrankungen [120, 121]. Als seltene Komplikation können im Verlauf ein Guillain-Barré-Syndrom, eine reaktive Arthritis oder eine Myokarditis auftreten. Ob eine antibiotische Therapie geeignet ist, die Häufigkeit solcher Komplikationen zu beeinflussen, ist nicht bekannt. Eine Metaanalyse aus 11 placebokontrollierten Studien konnte zwar zeigen, dass eine Antibiotikatherapie den Verlauf der Erkrankung um 1,3 Tage verkürzt, aufgrund des selbstlimitierenden Charakters der Krankheit und dem Problem der zunehmenden Antibiotikaresistenz durch den häufigen Antibiotikaeinsatz wird eine Antibiotikatherapie jedoch nur bei ausgewählten Patientengruppen empfohlen. Zu diesen gehören Patienten mit einem schweren Krankheitsbild, fehlender klinischer Besserung oder Immunsuppression, wobei die Entscheidung zur Therapie auf individueller Basis getroffen werden muss. So gilt nicht generell, dass jeder Patient mit z. B. blutiger Diarrhö oder Fieber über $38,5^{\circ} \mathrm{C}$ eine Therapie benötigt. In Abhängigkeit von den Ergebnissen der Resistenztestung sollte die antimikrobielle Therapie mit folgenden Substanzen durchgeführt werden: Azithromycin (500 mg/Tag p.o.) für 3 Tage oder Azithromycin 1000 mg einmalig p.o. oder Ciprofloxacin $1 \mathrm{~g} / \mathrm{Tag}$ p. o. für 3 Tage. Eine Therapie mit Erythromycin wird aufgrund des Nebenwirkungsspektrums, inkl. erhöhter Darmmotilität, und Interaktionspotenzials nicht mehr als Mittel der Wahl gesehen, zumal in einer pädiatrischen Studie sich die Substanz einer Therapie mit Azithromycin unterlegen zeigte [122]. Vor allem bei Reiserückkehrern mit Shigelleninfektionen wird in vielen Fällen eine Resistenz gegenüber Ciprofloxacin, bei Rückkehrern aus Indien aber auch bereits gegenüber Azithromycin beschrieben. Eine Beachtung der Resistenztestung ist notwendig, wobei es kaum klinische Erfahrungen mit alternativen Substanzen gibt. Cephalosporine zeigen eine unzureichende Aktivität gegenüber Campylobacter und sind daher nicht zur Therapie geeignet [123].

\section{Yersinien}

\section{Empfehlung 2.16: Antimikrobielle Therapie}

Bei akuter Yersinien-Infektion sollte in der Regel keine antimikrobielle Therapie durchgeführt werden. [Konsensusstärke: Konsens, Empfehlung]

\section{Empfehlung 2.17: Antimikrobielle Therapie}

Bei schwerem Krankheitsbild oder fehlender klinischer Besserung sollte, abhängig vom Krankheitsbild, eine antimikrobielle Therapie mit folgenden Substanzen durchgeführt werden (unter Beachtung der Resistenztestung).

Enterokolitis: Ciprofloxacin (1 g/Tag p. o. oder $800 \mathrm{mg} /$ Tag i.v. für 5 - 7 Tage) oder Cotrimoxazol (1920 mg/Tag p.o. oder i.v. für 5 - 7 Tage).

Bakteriämie: Ceftriaxon ( $2 \mathrm{~g} / \mathrm{Tag}$ i.v. für 7 - 14 Tage) oder Ciprofloxacin ( $1 \mathrm{~g} /$ Tag p. o. oder $800 \mathrm{mg} /$ Tag i. v. für 7 - 14 Tage). [Konsensusstärke: starker Konsens, Empfehlung]

\section{Kommentar}

Die Yersiniose ist eine gastrointestinale Erkrankung, die durch eine Infektion mit dem Bakterium Yersinia enterocolitica oder (seltener) Y. pseudotuberculosis verursacht wird. Typische Symptome sind Durchfall, Bauchschmerzen, schmerzhafter Stuhldrang, Fieber, Rachenringinfektion und Erbrechen. Im Gegensatz zu infektiösen Gastroenteritiden mit anderen Erregern treten die Symptome häufig subakut auf [124]. Die Inkubationszeit beträgt etwa 5 Tage (Zeitspanne 1-11 Tage). Bei Jugendlichen können die Symptome mit Schmerzen im rechten Unterbauch denen einer Appendizitis ähneln („Pseudoappendizitis“). In seltenen Fällen können Folgeerkrankungen wie eine reaktive Arthritis oder ein Erythema nodosum auftreten [125]. Das natürliche Reservoir des Erregers Y. enterocolitica sind Tiere unterschiedlicher Arten, wobei Schweine als Hauptreservoir für humanpathogene $Y$. enterocolitica-Serotypen gelten [126]. Die Übertragung erfolgt hauptsächlich über Lebensmittel, in Deutschland ist der Verzehr von rohem Schweinehackfleisch (Mett oder „Hackepeter“) der wichtigste Risikofaktor [125]. Die Symptome klingen in der Regel nach 12 - 22 Tagen ab, somit später als bei anderen infektiösen Gastroenteritiden. Solange Erreger mit dem Stuhl ausgeschieden werden, besteht Ansteckungsgefahr. Die mittlere Ausscheidungsdauer beträgt 40 Tage (17 - 116 Tage) [124].

Bei akuter Yersinien-Infektion ohne schweren Krankheitsverlauf sollte keine antimikrobielle Therapie durchgeführt werden, da der Verlauf nicht wesentlich beeinflusst werden kann - nur die Ausscheidungsdauer reduziert sich unter einer antibiotischen Therapie. Bei einem nur geringen Risiko einer Übertragung zwischen Menschen kann dieses jedoch nicht als Argument für die Durchführung einer Antibiotikatherapie herangezogen werden [124]. Darüber hinaus gibt es keine Evidenz, dass eine frühzeitige Antibiotikatherapie Folgeerkrankungen, wie reaktive Arthritis oder Erythema nodosum, verhindern kann [127]. Bei schwerem Krankheitsbild oder fehlender klinischer Besserung sollte eine antimikrobielle Therapie durchgeführt werden. In Abhängigkeit von den Ergebnissen der Resistenztestung wird für die Therapie einer Enterokolitis Ciprofloxacin ( $1 \mathrm{~g} / \mathrm{Tag}$ p.o. oder $800 \mathrm{mg} / \mathrm{Tag}$ i. v.) oder Cotrimoxazol (1920 mg/Tag p.o. oder i. v.) empfohlen. Bei einer Bakteriämie wird eine Therapie mit Ceftriaxon ( $2 \mathrm{~g} / \mathrm{Tag}$ i. v.) oder Ciprofloxacin ( $1 \mathrm{~g} / \mathrm{Tag}$ p. o. oder $800 \mathrm{mg} / \mathrm{Tag}$ i. v.) empfohlen. Es liegen keine kontrollierten Studien über die optimale Therapiedauer einer Infektion mit Yersinien vor. Bei einer Enterokolitis wird zu einer Therapiedauer von 5-7 Tagen, bei einer Bakteriämie von 7 - 14 Tagen geraten. Bei Patienten mit einer Immunsuppression kann eine längere Therapie erwogen werden.

\section{Enterohämorrhagische Escherichia coli (EHEC)}

\section{Empfehlung 2.18: Antimikrobielle Therapie}

Die Indikation zur antibiotischen Behandlung einer EHEC-Infektion sollte zurückhaltend gestellt werden. Als Mittel der ersten Wahl sollte bei gegebener Therapieindikation ein Carbapenem eingesetzt werden.

[Konsensusstärke: Konsens, Empfehlung]

\section{Kommentar}

Enterohämorrhagische Escherichia coli sind gramnegative Stäbchen, welche Zytotoxine, die Shigatoxine (Synonyme: Shiga-likeToxine - SLT, Verotoxine - VT) bilden. Sie werden unter dem Begriff Shigatoxin- bzw. Verotoxin-produzierende E. coli (STEC bzw. VTEC) zusammengefasst. Historisch wurden diejenigen STEC als EHEC bezeichnet, die in der Lage waren, schwere Erkrankungen (hämorrhagische Kolitis und das hämolytisch-urämische Syndrom [HUS]) hervorzurufen [22]. Durch enterohämorrhagische Escherichia coli (EHEC) des Serotyps 0104:H4 kam es von Mai bis Juli 2011 vor allem in Norddeutschland zu einer großen Zahl von Erkrankungen mit blutiger Diarrhö und Entwicklung eines hämolytisch-urämischen Syndroms (HUS) [128]. 
Die Indikation zur antibiotischen Behandlung einer EHEC-Infektion sollte zurückhaltend gestellt werden, da der Krankheitsverlauf nicht günstig beeinflusst wird und unklar ist, ob eine Antibiotikatherapie mit einer verlängerten Symptomdauer, möglicherweise verlängerten EHEC-Ausscheidung und vermehrtem Auftreten eines HUS einhergeht [129]. Besteht eine Indikation für eine systemische Antibiotikagabe im Rahmen von extraintestinalen und generalisierten Infektionen durch EHEC selbst oder im Rahmen von sekundären Komplikationen/Infektionen durch andere Erreger, sollte eine antibiotische Behandlung durchgeführt werden. Die Auswahl des einzusetzenden Antibiotikums kann nicht durch systematische Daten begründet werden. Mit niedriger Evidenz können aufgrund positiver Einzelberichte Carbapeneme empfohlen werden [130, 131]. Hinzuweisen ist an dieser Stelle auch auf eine einzelne Studie, die einen positiven Effekt von Azithromycin mit Verkürzung der Ausscheidungsdauer beschreibt [132].

\section{K-3 Nosokomiale Diarrhö und Clostridium difficile (AG 3) \\ $\nabla$}

\section{Präambel}

Die nosokomiale Diarrhö ist eine häufige Komplikation hospitalisierter Patienten. Sie ist mit signifikanter Morbidität und Mortalität behaftet, verlängert die Krankenhausverweildauer und verursacht erhebliche Kosten [133, 134]. Besonders wichtig in der Behandlung von Patienten mit nosokomialer Diarrhö ist die Identifikation potenzieller Infektionsquellen, weil dies spezifische Maßnahmen in Diagnostik, Therapie und Hygienemanagement nach sich zieht. Die Abgrenzung der nosokomialen von der ambulant erworbenen infektiösen Gastroenteritis ist hinsichtlich eines deutlich unterschiedlichen Erregerspektrums sinnvoll. Eine herausragende Bedeutung kommt dabei $C$. difficile als einem der häufigsten Erreger nosokomialer Infektionen zu [135]. So ist die Inzidenz der nosokomialen $C$. difficile-Infektion in Deutschland mittlerweile doppelt so hoch wie diejenige für MRSA [136]. Die Letalität der CDI ist in den letzten 15 Jahren erheblich gestiegen, möglicherweise auch aufgrund der zunehmenden Verbreitung hypervirulenter/epidemisch bedeutsamer Stämme [42, 137]. Die durch CDI ausgelösten Mehrkosten in der stationären Versorgung in einem deutschen Krankenhaus liegen zwischen 5000 und 10000 Euro pro Fall [138].

Neben $C$. difficile sind Noroviren die wichtigsten Erreger der nosokomialen Diarrhö. Aufgrund ihrer hohen Infektiosität (geringe Infektionsdosis, hohe Umweltstabilität, Übertragung durch direkte und indirekte Kontaktinfektion) kommt es leicht zur Übertragung in Einrichtungen, in denen Menschen auf engem Raum zusammenleben, z. B. in Pflegeheimen und Krankenhäusern. Um Krankenhausausbrüche soweit wie möglich zu vermeiden, ist bei der stationären Versorgung von Patienten mit einer NorovirusInfektion dem Hygienemanagement besondere Aufmerksamkeit zu widmen. Aus diesen Gründen wurden Norovirus-Infektionen für diese Leitlinie im Kapitel „Management der nosokomialen infektiösen Diarrhö“ bearbeitet.

\section{Empfehlung 3.1: Definition nosokomiale Diarrhö}

Eine nosokomiale Diarrhö liegt vor, wenn die Symptome erstmals im Krankenhaus auftreten.

[Konsensusstärke: starker Konsens]

\section{Kommentar}

Es gibt derzeit keine einheitliche Definition der nosokomialen Diarrhö. Gemäß der Definition des Robert Koch-Instituts liegt eine nosokomiale Diarrhö vor, wenn die Symptome mehr als 48 Stunden nach stationärer Aufnahme auftreten [139]. Andere Autoren geben einen Zeitraum von 72 Stunden an [56, 134, 140]. Diese Definitionen basieren auf der Tatsache, dass das Spektrum bakterieller Erreger ab 48-72 Stunden nach stationärer Aufnahme quantitativ von $C$. difficile dominiert wird [23]. Weil in der vorliegenden Leitlinie aber auch die Norovirus-Infektion mit ihrer kurzen Inkubationszeit von 6-50 Stunden als Erreger der nosokomialen Diarrhö berücksichtigt wird und auch $C$. difficile häufig ambulant erworbene Durchfallerkrankungen verursacht, wurde auf die o.g. zeitlichen Einschränkungen verzichtet und jede im Krankenhaus sich erstmalig manifestierende Gastroenteritis/Diarrhö als nosokomial bewertet.

\section{Empfehlung 3.2: Symptome der nosokomialen Gastroenteritis}

Bei folgenden Symptomen soll an eine nosokomiale Gastroenteritis gedacht werden:

$\checkmark \geq 3$ ungeformte Stühle pro Tag

- Erbrechen

[Konsensusstärke: starke Empfehlung, Konsens]

\section{Kommentar}

Bei den genannten Symptomen soll immer an eine nosokomiale Gastroenteritis gedacht werden. Es sei aber darauf hingewiesen, dass eine nosokomiale Gastroenteritis auch viele andere Symptome hervorrufen kann (z.B. Übelkeit, abdominelle Schmerzen, Fieber, Motilitätsstörungen, Megakolon), die gegebenenfalls entsprechend differenzialdiagnostisch gewertet werden sollten.

\section{Empfehlung 3.3: Ursachen der infektiösen nosokomialen Gastroenteritis}

Als infektiöse Ursachen einer nosokomialen Gastroenteritis sollen in erster Linie Clostridium difficile und Noroviren in Betracht gezogen werden.

[Konsensusstärke: starke Empfehlung, starker Konsens]

\section{Kommentar}

Die große Bedeutung von C. difficile als nosokomiales Enteropathogen ist durch zahlreiche Studien gut belegt. Bedingt ist dies durch mehrere sich gegenseitig begünstigende Faktoren (siehe dazu auch Empfehlung 1.5). Bereits durch die stationäre Aufnahme findet eine gewisse Selektion von Patienten mit vorbestehenden Risikofaktoren für eine CDI statt (z. B. Vortherapie mit Antibiotika, Alter höher als 65 Jahre, schwere Komorbidität, Chemotherapie) [141]. Im Krankenhaus besteht für Patienten ein deutlich erhöhtes Risiko für eine Kolonisation mit $C$. difficile. In einer Studie aus Irland betrug die Kolonisationsrate bei hospitalisierten Patienten mehr als $20 \%$, während sie in der gesunden Normalbevölkerung bei weniger als $2 \%$ lag [142]. Die wiederholt beschriebene Assoziation der Kolonisationswahrscheinlichkeit mit der Dauer des Krankenhausaufenthalts spricht dabei für ein konstant vorhandenes kumulatives Expositionsrisiko [143, 144]. Als wichtigster Risikofaktor für eine CDI gilt die Störung der intestinalen Mikrobiotia (Dysbiose) durch Antibiotikaexposition. Auch für diesen Faktor liegen in Krankenhäusern besondere Bedingungen vor, weil hier die Anwendungsdichte von Antibiotika deutlich höher als im ambulanten Be- 
reich ist. Hinzuweisen ist auf die Tatsache, dass dennoch insgesamt mehr als $80 \%$ des jährlichen Antibiotikaverbrauchs in der Humanmedizin in Deutschland im ambulanten Sektor erfolgen [145]. Folgerichtig zeigt sich in den letzten Jahren auch eine Zunahme ambulant erworbener Fälle von CDI [146].

Neben C. difficile und Noroviren spielen andere Erreger bei der nosokomialen Diarrhö eine eher untergeordnete Rolle. Grundsätzlich können aber auch die typischen Erreger der ambulant erworbenen Gastroenteritis aufgrund ihrer mehrtägigen Inkubationszeit erst nach erfolgter stationärer Aufnahme eine Symptomatik verursachen.

\section{Empfehlung 3.4: Nicht infektiöse Ursachen einer nosokomialen Gastroenteritis}

Als nicht infektiöse Ursachen einer nosokomialen Gastroenteritis sollten u. a. in Betracht gezogen werden:

- Medikamente

- Bestrahlung

- Sondenkosternährung

- Darmoperation

[Konsensusstärke: Konsens, Empfehlung]

\section{Kommentar}

Die Diarrhö ist eine unerwünschte Wirkung vieler Medikamente. Besonders häufig tritt sie beim Einsatz von Antibiotika auf. In einer prospektiven Multicenterstudie mit mehr als 2800 Patienten, die eine parenterale Antibiotikatherapie erhielten, lag die Inzidenz der antibiotikaassoziierten Diarrhö bei ca. 10\% [147]. Für die Praxis ist es wichtig, dass die Mehrzahl der Fälle (> $75 \%$ ) einer antibiotikaassoziierten Diarrhö nicht infektiöser Natur, sondern durch Effekte der Antibiotika auf Mukosa und Motilität des Intestinums bedingt sind oder durch Störungen der intestinalen Mikroflora mit sekundären trophischen und sekretionsfördernden Auswirkungen auf die Schleimhaut hervorgerufen werden [134].

\section{Empfehlung 3.5: Stuhldiagnostik}

Bei der nosokomialen Gastroenteritis soll frühzeitig die initiale Erregerdiagnostik auf $\mathrm{C}$. difficile und bei entsprechenden klinischen Hinweisen auf Noroviren durchgeführt werden. [Konsensusstärke: Konsens, starke Empfehlung]

\section{Kommentar}

Aufgrund der kurzen Inkubationszeit der meisten bakteriellen und viralen Durchfallerreger kann die Diagnostik bei nosokomialer Gastroenteritis auf wenige Erreger fokussiert werden, wenn Durchfälle erstmals mindestens 48 Stunden nach stationärer Aufnahme im Krankenhaus auftreten. Bei Durchfall innerhalb von 48 Stunden nach stationärer Aufnahme sollte das gesamte Keimspektrum in die differenzialdiagnostischen Erwägungen eingeschlossen werden. Entsprechend dieser „3-Tage-Regel“ sollte nach Diarrhöen, die später als 48 Stunden nach Aufnahme im Krankenhaus auftreten, die Primärdiagnostik auf das reduzierte Keimspektrum nosokomialer Diarrhö angepasst werden [148]. Die Primärdiagnostik sollte dabei immer $C$. difficile umfassen. Der Nachweis bzw. der Ausschluss von C. difficile hat unmittelbare Konsequenzen für spezifische Therapie- und Hygienemaßnahmen. Bei klinischem Hinweis, z. B. zusätzlichem Erbrechen oder epidemiologisch begründetem Verdacht, sollte immer eine Diagnostik für Noroviren erfolgen [149]. Im Sinne einer Stufendiag- nostik kann bei negativer Initialdiagnostik das Erregerspektrum entsprechend der allgemeinen Empfehlung dieser Leitlinie erweitert werden.

Die $C$. difficile-Diagnostik sollte zeitnah mit sensitiven Testverfahren durchgeführt werden. $\mathrm{Zu}$ den verschiedenen diagnostischen Verfahren bzw. deren Kombination sei auf den Kommentar zur Empfehlung 1.5 verwiesen. Die Norovirus-Diagnostik soll bei symptomatischen Patienten insbesondere aus krankenhaushygienischen Gründen innerhalb weniger Stunden als Schnelltest erfolgen. Dabei sind molekularbiologische Verfahren (z.B. PCR) den Antigentests überlegen und ermöglichen darüber hinaus auch eine Genotypisierung zur Charakterisierung von Ausbrüchen [150]. Der Nachweis dieser meldepflichtigen Durchfallerkrankung hat unmittelbare Implikationen für das Hygienemanagement (Isoliermaßnahmen, viruzide Desinfektionsmittel) und die Identifikation möglicher weiterer Fälle (s. Empfehlung 3.6). Der Therapieerfolg bei nosokomialen Durchfallerkrankungen soll ausschließlich klinisch beurteilt werden. Mikrobiologische Verlaufsuntersuchungen sind nicht indiziert, auch nicht als Kriterium/Voraussetzung für Verlegungen in andere Krankenhäuser oder Pflegeeinrichtungen.

Empfehlung 3.6: Diagnostik bei Norovirus-Ausbrüchen

Im Rahmen von Norovirus-Ausbrüchen sollte die Diagnose weiterer Infektionen ausschließlich klinisch, d.h. anhand der typischen Falldefinitionen gestellt werden.

[Konsensusstärke: starker Konsens, Empfehlung]

\section{Kommentar}

Zur ätiologischen Klärung ist die gezielte Diagnostik parallel zu den anderen üblichen Untersuchungen durchzuführen. Zurzeit gilt als sicherster Nachweis für Noroviren die PCR aus dem Stuhl (Goldstandard). Bei größeren Ausbrüchen ist es nicht notwendig, alle Betroffenen zu untersuchen. In diesen Fällen genügt der Nachweis in der Regel bei maximal 5 der betroffenen Personen, um dann bei den anderen Erkrankten aus der gleichen Umgebung mit ähnlichen Symptomen ebenfalls eine Norovirus-Infektion zu diagnostizieren. Wichtig ist darauf hinzuweisen, dass hygienische Maßnahmen auch nach Sistieren der akuten Symptomatik von ausschlaggebender Bedeutung sind. Der Erregernachweis im Stuhl kann noch Monate nach Abklingen der Symptomatik positiv sein. Auf eine sorgfältige Händehygiene muss daher im Folgezeitraum geachtet werden. Beim Auftreten von Norovirus-Erkrankungen in Krankenhäusern, Gemeinschaftseinrichtungen oder Altenheimen bildet die rasche klinische Abgrenzung auftretender Norovirus-Infektionen von anderen, z. B. durch Lebensmitteltoxine verursachten Gastroenteritiden, die Grundlage einer effektiven Ausbruchsprävention. Wenn die typische Symptomatik und die epidemiologischen Merkmale auf eine Norovirus-Infektion hindeuten, sollten aufgrund der epidemischen Potenz präventive Maßnahmen rasch und konsequent ergriffen werden, auch ohne die Bestätigung durch virologische Untersuchungen abzuwarten [151].

\section{Empfehlung 3.7: Endoskopische Diagnostik}

Der endoskopische Nachweis charakteristischer Pseudomembranen kann dazu beitragen, die Diagnose einer C. difficile-assoziierten Kolitis frühzeitig und evtl. vor Eintreffen der mikrobiologischen Befunde zu stellen.

[Konsensusstärke: Konsens, Empfehlung offen] 


\section{Kommentar}

Der Nachweis von Pseudomembranen in der Sigmoidoskopie/Koloskopie gilt als pathognomonisch für die $C$. difficile-assoziierte pseudomembranöse Kolitis und sollte unmittelbar alle notwendigen therapeutischen Maßnahmen nach sich ziehen [152]. Eine mikrobiologische Diagnose sollte dennoch angestrebt werden. Da nur bei einer Minderheit der Fälle die CDI unter dem Bild einer pseudomembranösen Kolitis verläuft, schließt der fehlende endoskopische Nachweis von Pseudomembranen eine CDI nicht aus (siehe dazu auch die Empfehlung 1.6). Endoskopische Bestätigungsuntersuchungen (Sigmoidoskopie/Koloskopie) einer mikrobiologisch nachgewiesenen CDI sollen nicht durchgeführt werden, da sich daraus keine zusätzlichen Behandlungsoptionen ergeben.

\section{Empfehlung 3.8: Prädiktoren einer schweren CDI}

Folgende mögliche Prädiktoren sollten neben den klinischen Befunden einer schweren Infektion für die Abschätzung des Schweregrades einer CDI berücksichtigt werden:

- Fieber $>38,5^{\circ} \mathrm{C}$

Leukozytose $>15000 \times 10^{9} / 1$

- Linksverschiebung $>20 \%$ stabkernige Granulozyten

- Hypalbuminämie $<30 \mathrm{~g} / \mathrm{l}$

- Kreatininanstieg $>50 \%$ des Ausgangswertes

- Laktaterhöhung $\geq 5 \mathrm{mmol} / \mathrm{l}$

- Alter > 65 Jahre

- Signifikante Komorbidität (z. B. Niereninsuffizienz, Immunsuppression u.a.)

[Konsensusstärke: starker Konsens, Empfehlung]

\section{Kommentar}

Bei mehr als zwei Prädiktoren kann von einem erhöhten Risiko für eine schwer verlaufende CDI ausgegangen werden [153]. Dies hat unmittelbar Einfluss auf die rationale Wahl der medikamentösen Therapie. Insgesamt besteht aber noch ein hoher Forschungsbedarf für zuverlässige Surrogatmarker zur Therapiestratifizierung nach Schweregrad der Infektion. Eine Meldepflicht gemäß IfSG besteht für schwer verlaufende Fälle, definiert als [139]:

- Notwendigkeit einer Wiederaufnahme aufgrund einer rekurrenten Infektion,

- Verlegung auf eine Intensivstation zur Behandlung der CDAD oder ihrer Komplikationen,

- chirurgischer Eingriff (Kolektomie) aufgrund eines Megakolon, einer Perforation oder einer refraktären Kolitis,

- Tod < 30 Tage nach Diagnosestellung und CDI als Ursache oder zum Tode beitragende Erkrankung und/oder Nachweis des Ribotyps 027.

Die Behandlung kritisch kranker Patienten und von Patienten, die sich unter adäquater Therapie nicht bessern, muss frühzeitig interdisziplinär unter Beteiligung eines Abdominalchirurgen geführt werden.

\section{Empfehlung 3.9: Risikofaktoren für eine rezidivierende CDI}

Als gesicherte Risikofaktoren für ein Rezidiv einer CDI sollten berücksichtigt werden:

- Alter des Patienten > 65 Jahre

- fortgesetzte oder erneute Antibiotikatherapie

vorangegangenes Rezidiv

[Konsensusstärke: starker Konsens, Empfehlung]

\section{Kommentar}

Ein großes Problem in der Therapie der CDI ist das Auftreten weiterer Krankheitsepisoden nach initial erfolgreicher Therapie. Klinisch kann hierbei nicht zwischen der Rekurrenz, d. h. erneute Infektion mit demselben Keim der vorangegangenen Episode, und einer Neuinfektion durch einen differenten Stamm unterschieden werden. Im Rahmen dieser Leitlinie wird der Begriff „Rezidiv“ der Einfachheit und Verständlichkeit halber für beide Situationen genutzt, auch wenn dies begrifflich etwas unscharf ist.

Eine geringe Antikörperantwort gegen $C$. difficile-Toxine sowie eine fortbestehende Dysbiose sind stark assoziiert mit dem Risiko für ein Rezidiv der Infektion [154]. Da die Diagnostik dieser serologischen Parameter nicht allgemein verfügbar ist, wurden sie in obiger Empfehlung nicht berücksichtigt. Alter über 65 Jahre, fortgesetzte Antibiotikatherapie und vorangegangene Episoden einer CDI wurden konsistent in mehreren Studien sowie einer Metaanalyse als Risikofaktoren für ein Rezidiv identifiziert [155-157]. Auch Niereninsuffizienz und Immunsuppression waren mit einem erhöhten Rezidivrisiko assoziiert [153]. Da die Evidenzlage für letztere jedoch insgesamt schwächer ist als für die vorgenannten Faktoren, wurden sie nicht in die Empfehlung aufgenommen. Sie können aber in der Risikobewertung des individuellen Patienten mit herangezogen werden (siehe auch Empfehlung 1.5 und $\bullet$ Tab. 7).

\section{Empfehlung 3.10: Supportive Therapie}

Bei Vorliegen einer nosokomialen Gastroenteritis sollten folgende supportive Maßnahmen ergriffen werden:

- Substitution von Volumen und Elektrolyten,

- bei Verdacht auf bzw. bei bestätigter CDI: Absetzen der auslösenden Antibiotika (falls möglich),

- bei Verdacht auf bzw. bei bestätigter CDI: Verzicht auf Motilitätshemmer, inklusive Opiate (soweit möglich).

[Konsensusstärke: Konsens, Empfehlung]

\section{Kommentar}

Wegen des postulierten Zusammenhanges zwischen dem Einsatz von Motilitätshemmern und dem Risiko für die Entwicklung eines toxischen Megakolons gelten Motilitätshemmer bei der CDI als relativ kontraindiziert [152]. Da die CDI durch luminale Toxine vermittelt wird, erscheint dieser Zusammenhang zwischen vermehrter Toxinretention nach Motilitätshemmung und schweren klinischen Verläufen auch pathogenetisch plausibel.

\section{Empfehlung 3.11: Antimikrobielle Therapie der C. difficile-Infektion}

Folgende Empfehlungen gelten für die Therapieindikation be CDI:

- Nur bei leichtem Krankheitsbild kann bei Patienten ohne Risikofaktoren nach Absetzen des auslösenden Antibiotikums und unter engmaschiger klinischer Beobachtung der Spontanverlauf abgewartet und auf eine spezifische Therapie verzichtet werden.

[Konsensusstärke: Konsens, Empfehlung offen]

- In allen anderen Fällen sollte frühzeitig eine spezifische Therapie initiiert werden.

[Konsensusstärke: Konsens, Empfehlung]

- Bei schwerem Krankheitsbild und hochgradigem Verdacht auf eine CDI sollte eine spezifische Therapie bereits parallel zur Diagnostik eingeleitet werden.

[Konsensusstärke: Konsens, Empfehlung] 


\section{Kommentar}

Aufgrund der hohen Morbidität und Mortalität von C.difficile-Infektionen sollte nur bei Patienten mit leichtem Krankheitsbild und unter enger klinischer Beobachtung der Spontanverlauf abgewartet und auf eine spezifische Therapie verzichtet werden. Diese ist bei klinischer Verschlechterung oder fehlender Verbesserung umgehend einzuleiten. Der empfohlene frühzeitige Beginn einer spezifischen Therapie bei schwerem Krankheitsbild oder bei Vorliegen von Prädiktoren für einen schweren Verlauf folgt den allgemeinen Grundsätzen der Therapie einer schweren Infektionskrankheit. Auch die zur Therapie der CDI eingesetzten Antibiotika haben Auswirkungen auf das intestinale Mikrobiom. Dadurch tragen sie selbst zum Rezidivrisiko bei. In einer prospektiven Studie zur Primärtherapie der CDI war ein nicht antibiotisch wirksamer Toxinbinder den antibiotischen Vergleichssubstanzen (Vancomycin, Metronidazol) zwar hinsichtlich der Heilungsrate deutlich unterlegen, im Toxinbinderarm kam es aber zu signifikant weniger Rezidiven als in den beiden Antibiotikaarmen [158].

\section{Empfehlung 3.12: Primärtherapie der C. difficile-Infektion:} Antibiotika

In Abhängigkeit von der Schwere des Krankheitsbilds werden für die spezifische Primärtherapie der CDI folgende Empfehlungen gegeben:

- Bei leichter bis moderater Krankheitsausprägung und in Abwesenheit von Risikofaktoren für einen schweren Verlauf sollte die Therapie mit Metronidazol 3×400 - 500 mg/ Tag p. o. erfolgen.

[Konsensusstärke: starker Konsens, Empfehlung]

- Bei schwerer Krankheitsausprägung oder bei Vorliegen von Prädiktoren für einen schweren Verlauf sollte die Therapie mit Vancomycin, $4 \times 125-250 \mathrm{mg} /$ Tag p. o. erfolgen.

[Konsensusstärke: starker Konsens, Empfehlung]

- Bei erhöhtem Rezidivrisiko und zusätzlichem Vorliegen von Risikofaktoren für Komplikationen (Immunsuppression, Komorbidität) kann der Einsatz von Fidaxomicin $(2 \times 200 \mathrm{mg} /$ Tag p. o.) erwogen werden.

[Konsensusstärke: mehrheitliche Zustimmung² ${ }^{2}$ Empfehlung offen]

- Die Therapiedauer sollte 10 - 14 Tage betragen. [Konsensusstärke: starker Konsens, Empfehlung]

- Nur wenn keine enterale Therapie möglich ist sollte eine parenterale Therapie mit Metronidazol, $3 \times 500 \mathrm{mg}$ i. v./Tag erfolgen.

[Konsensusstärke: starker Konsens, Empfehlung]

- Bei Patienten mit signifikanter Kolondilatation und/oder (Sub-)Ileus kann die spezifische Therapie kombiniert mit Vancomycin (antegrad per Magen-/Duodenalsonde oder retrograd per Kolonsonde) plus i.v. Metronidazol geführt werden.

[Konsensusstärke: starker Konsens, Empfehlung offen]

\section{Kommentar}

Vancomycin und Metronidazol sind seit Jahrzehnten die Standardantibiotika für die Therapie der CDI. Für den Einsatz von Metronidazol sprechen die im Vergleich zu Vancomycin geringeren Kosten.

\footnotetext{
2 Mit einem Zustimmungsgrad von $57 \%$ gilt dieser Teil der Empfehlung aus methodischen Gründen als „nicht angenommen“. Zu dieser Empfehlung gab es eine intensive und kontroverse Diskussion, die sich auf den Einsatz von Fidaxomicin konzentrierte (siehe Kommentar).
}

Bezüglich der Ansprechraten zeigte sich in einer Metaanalyse kein Unterschied zwischen den beiden Substanzen [159]. Bei schwerer CDI war jedoch die Vancomycintherapie der Therapie mit Metronidazol überlegen [158]. Eine prospektiv nach Schweregrad stratifizierte Studie bestätigte die Überlegenheit von Vancomycin gegenüber Metronidazol bei schwerem Verlauf [160]. Aus diesen Gründen wird in allen aktuellen Leitlinien Metronidazol nur für die Therapie milder und moderater Verläufe empfohlen [152, 153, 161], während für schwere Verläufe wie auch bei Patienten mit Prädiktoren für einen schweren Verlauf aufgrund der therapeutischen Überlegenheit primär Vancomycin eingesetzt werden sollte. Auch bei Kontraindikationen gegen Metronidazol sollte primär Vancomycin eingesetzt werden. Die international empfohlene, aus Studien abgeleitete Dosis beträgt $4 \times 125 \mathrm{mg}$ p. o. täglich. Mit dieser Dosierung sind Stuhlkonzentrationen weit über der minimalen Hemmkonzentration für nahezu alle $C$. difficile-Stämme zu erreichen. Durch eine höhere Vancomycindosierung $(4 \times 250-500 \mathrm{mg}$ p. o./Tag) können etwas schneller hohe Fäkalkonzentrationen von Vancomycin erreicht werden [162]. Allerdings zeigte sich in Studien bei schwerer CDI kein besseres Therapieansprechen [163, 164]. Aus diesem Grund wird von der europäischen Leitlinie die Dosierung von $4 \times 125 \mathrm{mg}$ auch für die schwere CDI empfohlen, mit Ausnahme schwerer CDI mit Motilitätsstörung [153]. In Deutschland ist für die orale Therapie nur ein Präparat mit $250 \mathrm{mg}$ Einzeldosis zugelassen. Aus Praktikabilitätsgründen und aufgrund der minimalen Resorption und systemischen Toxizität wird deshalb nach allgemeiner Diskussion die Vancomycintherapie in einer erhöhten Dosierung von $4 \times 250 \mathrm{mg}$ p.o./Tag freigestellt. In begründeten Ausnahmen (z.B. intestinale Motilitätsstörung) kann die perorale Applikation auf $4 \times 500 \mathrm{mg}$ p.os erhöht werden. Bei Vorliegen einer Niereninsuffizienz sollte allerdings die hohe Dosis von $2 \mathrm{~g} /$ Tag nur unter Vancomycinserumspiegelbestimmung erfolgen, um eine systemische Akkumulation nicht zu übersehen. Auch bei Patienten mit Prädiktoren für einen schweren Verlauf sollte Vancomycin aufgrund der therapeutischen Überlegenheit eingesetzt werden.

Die Datenlage zur Selektion von Vancomycin-resistenten Enterokokken (VRE) unter Vancomycin bzw. Metronidazol ist in Abwesenheit aussagekräftiger Vergleichsstudien nicht konklusiv. In einer prospektiven Studie waren 41 von 133 (31\%) initial VREnegativen Patienten positiv für VRE im Stuhl, nachdem sie mit oralem Vancomycin behandelt worden waren [165]. Auf der anderen Seite zeigte sich in Beobachtungs- und Fallkontrollstudien auch bei einer Metronidazoltherapie ein gehäuftes Auftreten von Haut- und Umgebungskontaminationen mit VRE bzw. einer VREBakteriämie [166, 167]. Auch war in einer prospektiven Studie war eine Metronidazoltherapie mit der Persistenz einer vorbestehenden VRE-Kolonisation assoziiert [168]. Daher nehmen vermutlich sowohl die Vancomycin- als auch die Metronidazoltherapie Einfluss auf Kolonisation, Infektion und Umgebungskontamination mit VRE.

Kontrovers wurde der Stellenwert von Fidaxomicin in der Primärtherapie der CDI diskutiert. Als Hauptvorteil dieser neuen Substanz zeigte sich in den Zulassungsstudien eine im Vergleich zu Vancomycin geringere Rezidivrate bei gleichwertigem primärem Ansprechen [169, 170]. Inwieweit dieser Vorteil den hohen Preis der Substanz rechtfertigt, war Gegenstand einer intensiven Diskussion. Eine knappe Mehrheit (57\%) sprach sich für eine „KannEmpfehlung“ zum Einsatz von Fidaxomicin in der Primärtherapie bei Vorliegen von Risikofaktoren für einen rezidivierenden Verlauf und zusätzlichem Risiko für erhöhte Morbidität und Mortalität durch die CDI (z.B. Immunsuppression, schwere Grunderkrankung) aus. Die für einen Konsens notwendige Mehrheit (> 75\%) 
wurde jedoch nicht erreicht (Ausnahme: vorangegangene CDI-Episode, siehe Empfehlung zur Therapie von Rezidiven).

Die parenterale Therapie der CDI wurde bislang nicht systematisch untersucht und ist aus pharmakokinetischer Sicht problematisch. Deshalb sollte einer enteralen Therapie (z. B. auch über Magensonde) immer der Vorzug gegeben werden. Ist dies nicht möglich oder liegt eine schwere Motilitätsstörung vor, kann Metronidazol (nicht aber Vancomycin) auch parenteral verabreicht werden, da es aktiv in das Darmlumen sezerniert wird. [171] Allerdings sollte nach Möglichkeit eine zusätzliche enterale Vancomycintherapie erfolgen, die auch retrograd über eine endoskopisch platzierte (Dekompressions-)Sonde oder über Vancomycinretentionseinläufe direkt in das Kolonlumen appliziert werden kann. Meist wurden für die enterale Vancomycintherapie von Patienten mit Motilitätsstörung erhöhte Vancomycindosen von 1 - 2g/Tag eingesetzt [172 - 174].

Die Prognose einer fulminanten CDI ist ernst. Die rechtzeitige Indikationsstellung zum operativen Vorgehen kann lebensrettend sein. Bei schwerem Krankheitsbild sollte daher im Rahmen einer interdisziplinären Betreuung frühzeitig auch die Möglichkeit der chirurgischen Intervention beachtet werden. Die Operation sollte erfolgen bevor es zu einem signifikanten Laktatanstieg kommt, weil dann die Prognose der Patienten sehr schlecht ist. Die Indikation zur operativen Versorgung ist ebenfalls gegeben bei einer Perforation, Verschlechterung unter konservativer Therapie, toxischem Megakolon, akutem Abdomen oder einem therapierefraktären Ileus. Einzelne Gruppen berichten als Alternative zur Kolektomie über die kolonerhaltende Anlage eines doppelläufigen Ileostoma mit Kolonlavage und anschließender intraluminaler Vancomycintherapie über das Stoma, was bei frühzeitiger operativer Intervention im Vergleich zur Kolektomie mit einer geringeren Mortalität assoziiert war [175].

\section{Empfehlung 3.13: Therapie von Rezidiven}

Für die Therapie von Rezidiven einer CDI gelten folgende Empfehlungen:

- Die Therapie des ersten Rezidivs sollte analog zu den Therapieempfehlungen der Ersterkrankung erfolgen.

[Konsensusstärke: Konsens, Empfehlung]

- Alternativ kann die Therapie des ersten Rezidivs mit Fidaxomicin ( $2 \times 200 \mathrm{mg}$ p. o./Tag für 10 Tage) erfolgen.

[Konsensusstärke: Konsens, Empfehlung offen]

- Ab dem zweiten Rezidiv kann die Therapie mit einem Vancomycinausschleich- bzw. Pulsschema oder mit Fidaxomicin erfolgen.

[Konsensusstärke: Konsens, Empfehlung offen]

- Bei multiplen Rezidiven kann die Therapie mittels fäkalem Mikrobiomtransfer erfolgen.

[Konsensusstärke: Konsens, Empfehlung offen]

\section{Kommentar}

Rezidive einer CDI treten in ca. 20\% der Fälle auf [154]. Eine Resistenzentwicklung der Clostridien auf Vancomycin oder Metronidazol ist bislang in Europa nicht zu verzeichnen. Da weder Metronidazol noch Vancomycin Vorteile bezüglich des Auftretens weiterer Rezidive bieten, gelten für die Auswahl der Substanz die gleichen Kriterien wie bei der Primärtherapie [176]. Nach aktueller Datenlage weist die Therapie mit Fidaxomicin ein geringeres Rezidivrisiko auf. So fanden sich in zwei großen randomisiert kontrollierten Studien weniger Rezidive nach Therapie mit Fidaxomicin als nach Vancomycin [169, 170]. In einer gepoolten Subgruppenanalyse der Patienten, die nach einer bereits vorange-
Tab. 8 Vancomycinausschleichschema zur Therapie der rezidivierenden CDI.

\begin{tabular}{ll}
\hline Therapie/Dosierung & Dauer \\
\hline Vancomycin; $4 \times 125 \mathrm{mg} / \mathrm{Tag}$ & $10-14$ Tage (Standardtherapie) \\
\hline Vancomycin; $2 \times 125 \mathrm{mg} / \mathrm{Tag}$ & 7 Tage \\
\hline Vancomycin; $1 \times 125 \mathrm{mg} / \mathrm{Tag}$ & 7 Tage \\
\hline $\begin{array}{l}\text { Vancomycin; } 1 \times 125 \mathrm{mg} \text { jeden } \\
\text { 2.-3 Tag }\end{array}$ & $2-8$ Wochen \\
\hline
\end{tabular}

gangenen CDI-Episode in die Studien eingeschlossen wurden ( $n=128$ ) war das relative Risiko für ein weiteres Rezidiv nach Fidaxomicin um nahezu $50 \%$ geringer als nach Vancomycintherapie (19,7 versus 35,5\%) [169]. Daher stellt Fidaxomicin eine gute Therapieoption für die rezidivierende CDI dar.

Bislang ungeklärt ist das Vorgehen bei Auftreten von mehr als zwei Rezidiven. Bei diesen Patienten ist das Rezidivrisiko besonders hoch. Nach dem zweiten Rezidiv kommt es in $40-60 \%$ der Fälle zu weiteren CDI-Episoden. Metronidazol kommt für die Behandlung diese Patienten aufgrund seiner potenziellen Neurotoxizität bei prolongiertem Einsatz nicht infrage [177]. Kasuistisch und in Fallserien wurden Patienten mit multiplen CDI-Rezidiven erfolgreich mit Vancomycin in verschiedenen Ausschleich- und/ oder Pulsschemata behandelt [178]. Meist wurde - mit gewissen Modifikationen - das folgende Regime verwendet, das auch von der IDSA empfohlen wird [152] ( $\bullet$ Tab. 8).

Theoretische Überlegungen begründen, dass durch die abschließende alternierende Gabe von Vancomycin die im Darm verbliebenen Clostridiensporen an den Vancomycin-freien Tagen aussporen können, um dann als vegetative Formen abgetötet zu werden. Für die deutschen Verhältnisse kann dieses Schema mit jeweils 125(-250) mg als Einzeldosis angepasst werden (siehe Erläuterungen zur Empfehlung der antibiotischen Primärtherapie der CDI). Systematische klinische Studien für die Vancomycinausschleichbzw. Pulstherapie existieren allerdings nicht. Fidaxomicin wird aufgrund seines insgesamt geringen Rezidivrisikos als alternative Therapieoption empfohlen, auch wenn bislang keine prospektive Studie zur Behandlung multipler Rezidive vorliegt.

Die Erstbeschreibung einer erfolgreichen therapeutischen Übertragung von Stuhl eines gesunden Donors auf einen Patienten mit einer CDI erfolgte bereits 1958 [179]. Zahlreiche Fallbeschreibungen und kleine Kohortenuntersuchungen konnten die Effektivität dieser „Stuhltransplantation“ belegen, die inzwischen korrekter als fäkaler Mikrobiomtransfer bezeichnet wird [180]. Inzwischen liegt eine randomisierte kontrollierte Studie vor, die bei Patienten mit multiplen Rezidiven eine signifikante Überlegenheit des Mikrobiomtransfers gegenüber einer konventionellen Rezidivtherapie mit Vancomycin zeigt [181]. Der fäkale Mikrobiomtransfer ist damit eine experimentelle kausale Therapieform, mit der sehr schnell eine protektive Darmflora aufgebaut werden kann, die sich durch eine hohe Diversität auszeichnet. In begründeten Einzelfällen, d. h. in Fällen, in denen mit verschiedenen medikamentösen Rezidivtherapien keine dauerhafte Remission zu erreichen war, kann die Stuhltransplantation sehr effektiv eingesetzt werden. Bei dieser Indikation wird sie auch in aktuellen europäischen Leitlinien ausdrücklich als alternative Therapie empfohlen. Nach wie vor bestehen jedoch Sicherheitsbedenken, die auch durch ein (kosten-)intensives Screening des Donors (z. B. auf HIV, Hepatitis, Enteropathogene, Stuhlparasiten, multiresistente Erreger) nicht vollständig ausgeräumt werden können. Dies betrifft insbesondere langfristige bislang unbe- 
kannte Wechselwirkungen der transferierten Mikrobiota mit dem Wirt. Mögliche Haftungsfragen sind bislang genauso wenig geklärt wie die Kostenübernahme durch die Krankenkassen. Derzeit gibt es Initiativen zur Standardisierung des Verfahrens in Bezug auf Spenderauswahl, -testung, Stuhlpräparation, Dosierung, Kryokonservierung und Applikationsform (duodenal, intrakolonisch, oral als Kapseln). Es ist davon auszugehen, dass mittel- bis langfristig geprüfte und validierte Bakterienpräparationen entwickelt werden, mit denen eine kurative Therapie der CDI durch spezifische Mikrobiota erreicht werden kann. Um weitere Daten zur klinischen Wirksamkeit und der langfristigen Sicherheit eines Mikrobiomtransfers zu erhalten, wurde ein nationales, internetbasiertes Register eingerichtet, in der u. a. Patientencharakteristika, Details zur Durchführung des Mikrobiomtransfers sowie ein längerfristiges Follow-up der Patienten erfasst werden (Einzelheiten unter: www.kim4.uniklinikum-jena.de).

Empfehlung 3.14: Voraussetzungen zum Management von Patienten mit infektiöser Gastroenteritis

Ein Hygieneteam, ein Antibiotic Stewardship Team und eine ausreichende Anzahl von Zimmern in denen Patienten kontaktisoliert werden können, sollten vorhanden sein bzw. etabliert werden.

[Konsensusstärke: starker Konsens, Empfehlung]

\section{Kommentar}

Wichtig für eine erfolgreiche Infektionsprävention sind strukturelle Maßnahmen in jedem Klinikum entsprechend der KRINKO-Empfehlungen für „Personelle und organisatorische Voraussetzungen zur Prävention nosokomialer Infektionen“ [182]. Hauptrisikofaktor für die CDI ist eine vorausgegangene Antibiotikatherapie. Interventionen, die den Antibiotikaverbrauch in Therapie und Prophylaxe reduzieren, können die Inzidenz von CDI senken. Die Wirksamkeit von Antibiotic-Stewardship-Maßnahmen für die Reduktion nosokomialer $C$. difficile-Infektionen ist vielfach durch Studien belegt $[183,184]$. Die Voraussetzungen für Antibiotic Stewardship finden sich in der aktuellen S3-Leitlinien (http://www.awmf.org/uploads/ tx_szleitlinien/092 0011_S3_Antibiotika_Anwendung_im_Krankenhaus_2013-12.pdf).

Empfehlung 3.15: Infektionsprävention bei unklarer infektiöser Gastroenteritis

Bei Verdacht auf infektiöse Gastroenteritis sollen folgende über Standardhygiene hinausgehenden Maßnahmen ergriffen werden (Kontaktisolierung):

- Patienten sollen im Einzelzimmer untergebracht werden.

- Wenn eine Einzelunterbringung nicht möglich ist, kann strikte Kittel- und Handschuhpflege vorausgesetzt - auch eine Unterbringung im Mehrbettzimmer erfolgen.

- Patienten sollen eine eigene Toilette benutzen.

- Bei direktem Kontakt mit dem Patienten oder der patientennahen Umgebung sollen Schutzkittel und Handschuhe getragen werden.

- Bei zusätzlichem Erbrechen soll ein Mundschutz getragen werden.

- Geräte wie Stethoskop, RR-Manschette etc. sollen patientenbezogen eingesetzt werden.

- Patienten sollten bis 48 Stunden nach Sistieren der klinischen Symptomatik kontaktisoliert werden.

[Konsensusstärke: starker Konsens, starke Empfehlung]

\section{Kommentar}

Kontaktisolierungsmaßnahmen wurden von den Centers for Disease Control and Prevention (CDC, USA) definiert und sind international allgemein akzeptiert [185]. Wie schon ausgeführt sind Noroviren und $C$. difficile die häufigsten nosokomialen Durchfallerreger, deshalb orientiert sich die Empfehlung zur Aufhebung der Kontaktisolierungsmaßnahmen an diesen beiden Erregern. Der Begriff „Klinische Symptomatik“ umfasst neben Durchfall und/oder Erbrechen auch abdominelle Beschwerden.

\section{Empfehlung 3.16: Hygienemaßnahmen bei CDI}

Bei CDI sollen neben anderen Maßnahmen (s. Empfehlung 4.2) zusätzlich folgende Maßnahmen ergriffen werden:

- Bei Kontakt mit potenziell kontaminierten Flächen oder Materialien sollen Einmalhandschuhe getragen werden. Unmittelbar nach Beendigung des Kontakts sollen die Handschuhe ausgezogen werden.

[Konsensusstärke: starker Konsens, starke Empfehlung]

- Nach Kontakt mit Patienten und potentiell kontaminierten Flächen oder Materialien sollen die Hände (auch nach dem Tragen von Handschuhen) sowohl mit einem Händedesinfektionsmittel desinfiziert als auch mit Seife gewaschen werden.

[Konsensusstärke: starker Konsens, starke Empfehlung]

- Es sollte eine tägliche Flächendesinfektion mit einem sporozidwirksamen Desinfektionsmittel durchgeführt werden. [Konsensusstärke: starker Konsens, Empfehlung]

\section{Kommentar}

Das Vermeiden einer Kontamination der Hände durch Tragen von Handschuhen gilt als die mit Abstand effektivste Maßnahme zur Prävention von Kontaktinfektionen. In Anbetracht der zentralen Bedeutung der alkoholischen Händedesinfektion für die Prävention anderer nosokomialer Infektionen (z. B. durch multiresistente Erreger) und dem vielfachen Nachweis von multiresistenten Erregern bei antibiotisch vorbehandelten Patienten mit CDI sollte die Priorität auch bei CDI Patienten auf die alkoholische Händedesinfektion gelegt und keinesfalls durch alleiniges Händewaschen ersetzt werden.

Theoretische Grundlage für das zusätzliche Händewaschen ist der Umstand, dass Sporen von C. difficile mit alkoholhaltigen Desinfektionsmitteln nicht inaktiviert werden. Mithilfe der etablierten alkoholischen Händedesinfektion ist es also nicht möglich, die Sporen abzutöten. Geschultes Händewaschen ist zwar effektiver in der Entfernung von Sporen als die alkoholische Händedesinfektion, aber auch hiermit gelingt nur eine Keimreduktion [186]. Zudem hat außerhalb von Ausbrüchen die Umstellung der alkoholischen Händedesinfektion auf Händewaschen in keiner Studie die Inzidenz von C. difficile senken können [187 - 189]. Wichtig bei Reinigung und Desinfektion von Flächen ist der mechanische Effekt in Kombination mit sporoziden Desinfektionsmitteln [190]. Hierfür ist eine Schulung und Überwachung des Reinigungspersonals sinnvoll. Patientennahe Flächen (z.B. Nachttische) sollten mehrmals täglich gereinigt und desinfiziert werden. Die aktuellen Leitlinien der Society for Healthcare Epidemiology of America (SHEA) [191] empfehlen ähnlich wie die Empfehlungen des RKI eine Aufhebung der Kontaktisolierung zwei Tage nach Sistieren des Durchfalls [139]. Auch bei erfolgreich behandelten Patienten kann $C$. difficile häufig noch lange im Stuhl nachgewiesen werden. Die Keimdichte ist jedoch geringer, sodass in der Regel kein erhöhtes Übertragungsrisiko besteht. 
Empfehlung 3.17: Hygienemaßnahmen bei Gastroenteritis verursacht durch Noroviren oder andere unbehüllte Viren

Bei nosokomialer Gastroenteritis durch Noroviren und andere unbehüllte Viren (Adeno-, Rotaviren) sollen folgende über die Standardhygieneempfehlungen und die allgemeinen Empfehlungen bei V.a infektiöse Gastroenteritis hinausgehende Maßnahmen ergriffen werden:

- Bei Umgang mit Erbrochenem oder Diarrhöstuhl soll Mundschutz getragen werden.

[Konsensusstärke: starker Konsens, starke Empfehlung]

- Bei Patienten mit Norovirus-Infektion sollte bereits bei Betreten des Zimmers Mundschutz getragen werden.

[Konsensusstärke: starker Konsens, Empfehlung]

- Zur Händedesinfektion sollte ein viruzidwirksames Mittel eingesetzt werden.

[Konsensusstärke: starker Konsens, Empfehlung]

- Zur täglichen Flächendesinfektion sollten viruzide Mittel verwendet werden.

[Konsensusstärke: starker Konsens, Empfehlung]

- Die Kontaktisolierung kann 48 Stunden nach Sistieren der klinischen Symptomatik aufgehoben werden. [Konsensusstärke: starker Konsens, Empfehlung offen]

\section{Kommentar}

In der CDC-Leitlinie von 2011 wird keine Empfehlung für ein viruswirksames Händedesinfektionsmittel ausgesprochen, [192] während die aktuellen Empfehlungen des RKI dies vorsehen [151]. Hintergrund sind Studien mit Testviren, in denen hochprozentiger Ethanol weniger wirksam gegen Noroviren war als $62 \%$ Ethanol [193]. Noroviren werden vor allem über Kontakt (Haut, Hände, kontaminierte Oberflächen) übertragen. Sie sind resistent gegen Umwelteinflüsse und können auf verunreinigten Flächen mehr als zwölf Tage lang ansteckend bleiben. Eine Übertragung kann auch über feine Tröpfchen („Aerosole“) stattfinden, z. B. im Rahmen des Brechdurchfalls. Aus diesem Grund sollen bei Betreten eines Zimmers mit Patienten mit Norovirus-Infektion ein Mundschutz angelegt werden. Bei bekannten Patienten in der Rekonvaleszenz ohne Erbrechen wäre es aus präventiven Gründen auch vertretbar, einen Mundschutz nur situationsbezogen zu tragen (direkter Umgang mit Erbrochenem oder Stuhl).

\section{Empfehlung 3.18: Stellenwert von Probiotika zur}

Prophylaxe der CDI

Eine allgemeine Empfehlung für den prophylaktischen Einsatz von Probiotika kann aufgrund der unzureichenden Datenlage und der Heterogenität der eingesetzten Bakterienspezies nicht gegeben werden.

[Konsensusstärke: starker Konsens]

\section{Kommentar}

Über die unter 2.5 diskutierten Daten hinaus, wurden 2013 in einem Cochrane-Review zur Prävention der CDI 23 RCTs mit insgesamt 4213 Teilnehmern analysiert. Insgesamt kamen die Autoren zu dem Ergebnis, dass das relative Risiko an einer CDI zu erkranken durch Einsatz von Probiotika um 64\% gesenkt werden konnte [194]. Aufgrund der Heterogenität der untersuchten Probiotika wurde dennoch die Evidenz der Studien für einen präventiven Effekt als insgesamt nur moderat eingestuft. Nach dem Erscheinen dieser Übersicht wurde die bis dato größte randomisierte kontrollierte Studie zum Thema „Probiotika zur Primärprävention einer CDI“ mit 2941 Teilnehmer publiziert. Die Interventionsgruppe erhielt ein Kombinationspräparat mit Lactobazillen und Bifidobakterien. Hier zeigte sich kein signifikanter Unterschied in den Gruppen bezüglich des Auftretens von antibiotikaassoziierter Diarrhö oder einer CDI [147].

\section{K-4 Diarrhö bei Immundefizienz (AG 4)}

$\nabla$

\section{Präambel}

Infektionen bei Patienten mit Immundefekten bzw. Immundefizienz spielen in unserem Gesundheitssystem eine immer größere werdende Rolle. Eine allgemein verbindliche Definition, was eine Immundefizienz ist, ist schwierig und kann sicher auch nicht alle Patienten erfassen. Um Patienten mit einem erhöhten Risiko zu definieren, erscheint es sinnvoll, den Begriff „angeborene oder erworbene Immundefizienz" auf Erkrankungen und Therapien zu begrenzen, bei denen regelmäßig mit Infektionen durch opportunistische Pathogene zu rechnen ist. Wichtig erscheint aber auch der Hinweis, dass bei Patienten mit Immundefizienz auch das Risiko für die klassischen gastrointestinalen Infektionen erhöht ist.

\section{Empfehlung 4.1: Mikrobiologische Diagnostik}

Bei Patienten mit einer angeborenen oder erworbenen Immundefizienz sollten Besonderheiten hinsichtlich Erregerspektrum, Verlauf und Therapie/Prävention infektiöser Enteritiden beachtet werden.

[Konsensusstärke: starker Konsens, Empfehlung]

\section{Kommentar}

Eine veränderte und auch vermehrte Anfälligkeit für gastrointestinale Infektionen besteht vor allem bei folgenden Patienten mit angeborenen und erworbenen Immundefekten $[195,196]$ :

- Primäre Immundefizienzsyndrome (z.B. Common Variable Immunodefiency, X-chromosomal vererbte Agammaglobulinämie, kombinierte T- and B-Zell-Defekte, T-Zell-Defekte wie das DiGeorge-Syndrom, Ataxia teleangiectasia, WiskottAldrich-Syndrom),

- Selektiver IgA-Mangel,

- Humanes Immundefizienz-Virus(HIV)-Infektion,

- Transplantation (Stammzellen und solide Organe)

- Neutropenie

- Autoimmunerkrankungen unter immunsuppressiver Therapie (u. a. mit einer Kortikosteroidtherapie über einen Zeitraum von mindestens vier Wochen mit einer Dosis $\geq 10 \mathrm{mg} / \mathrm{Tag}$, „disease modifying antirheumatic drugs“ (DMARDs), Azathioprin, Methotrexat, Leflunomid, Anti-TNF $\alpha$-Antikörper und anderen Biologika)

In der Abschätzung der Gefährdung ist das Ausmaß der Immunsuppression von besonderer Bedeutung. Eine besondere Risikogruppe stellen folgende Patientengruppen dar:

- Zustand nach Stammzell- bzw. Knochenmarktransplantation (dauerhaft)

- fortgeschrittene HIV-Infektion (CD4+-T-Zellzahl <200/ul)

- schwere anhaltende Neutropenie

- kombinierte T- und B-Zell-Defekte

Insbesondere bei diesen Patienten können atypische klinische Verläufe, gehäufte Rezidive und Chronifizierung auftreten [196 - 198]. 


\section{Empfehlung 4.2: Mikrobiologische Diagnostik}

Auch bei Patienten mit ausgeprägtem Immundefekt sollte bei unkomplizierter Diarrhö (kurze Dauer, keine Begleitsymptome) keine routinemäßige mikrobiologische Diagnostik durchgeführt werden.

[Konsensusstärke: Konsens, Empfehlung]

\section{Kommentar}

Diese Empfehlung ist intensiv diskutiert worden; vor dem Hintergrund der Häufigkeit gastrointestinaler Infektionen auch bei Patienten mit Immundefizienz, dem selbstlimitierenden Charakter und der Seltenheit des Erregernachweises wird zunächst ein Zuwarten in der Diagnostik empfohlen. Es ist aber sinnvoll, engmaschige klinische Verlaufskontrollen durchzuführen, um möglichst frühzeitig einen protahierten oder komplizierten Verlauf zu erkennen. Ausnahmen können sich aus dem klinischen Bild und der Anamnese ergeben:

- Patienten mit entsprechender Reiseanamnese, beruflicher Exposition, Erkrankungen im persönlichen Umfeld (z. B. Familie etc.)

- Patienten unter einer Immunsuppression, die mit einem erhöhten Risiko für eine spezielle Infektion (z. B. CMV-Infektion nach Knochenmarktransplantation oder myelosuppressiver Therapie) einhergeht

- Immunsupprimierte Patienten mit Hinweis auf einen früheren Erregernachweis und Anhalt für ein Rezidiv oder einen protrahierten Verlauf (z. B. bei Lamblien)

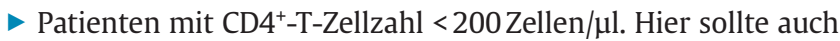
eine Stuhluntersuchung auf Mikrosporidien und Kryptosporidien durchgeführt werden [199, 200].

Außerdem gelten selbstverständlich die entsprechenden Indikationen zur mikrobiologischen Diagnostik (siehe AG 1, Empfehlung 1.2).

\section{Empfehlung 4.3: Mikrobiologische Diagnostik}

In Abhängigkeit von Symptomen/Anamnese (Medikamentenanamnese, Reiseanamnese, Beruf, Kontakt mit Tieren, Erkrankungen im sozialen Umfeld ggf. sexuelle Praktiken) und Art des Immundefektes sollte ggf. auf die in $\bullet$ Tab. 9 aufgeführten Pathogene untersucht werden.

[Konsensusstärke: Konsens, Empfehlung]

\section{Kommentar}

Eine weiterführende Erregerdiagnostik sollte dabei gezielt durchgeführt werden je nach individuellem Risikoprofil. Zu bedenken sind dabei folgende Erreger ( $\bullet$ Tab.9).

Der Nachweis dieser Erreger kann teilweise schwierig sein, sodass die Möglichkeit falsch negativer Befunde bedacht werden sollte; ggf. sind die Untersuchungen zu wiederholen und sinnvollerweise ist ein entsprechendes Referenzlabor einzubeziehen. Wenn Enteritissalmonellen nachgewiesen werden, sollte eine Serotypisierung durchgeführt werden (siehe dazu auch den Kommentar von Empfehlung 1.3).

Enteropathogene Escherichia coli als Auslöser einer Enteritis sind zwar relativ häufig, brauchen aber aufgrund der geringen klinischen Relevanz nicht in der Basisdiagnostik erfasst zu werden. Wegen der klinischen und epidemiologischen Bedeutung von EHEC-Infektionen ist aber bei entsprechendem klinischem Verdacht (insbesondere blutige Diarrhö, Hämolyse, Thrombopenie, Ausbruchssituation) auch hieran zu denken und eine spezielle

\begin{tabular}{|c|c|}
\hline $\begin{array}{l}\text { Protozoen } \\
\text { [201] }\end{array}$ & $\begin{array}{l}\text { Isospora belli } \\
\text { (Reiseanamnese V. a. Afrika/Tropen, V. a. T-zelluläre } \\
\text { Immundefekte) } \\
\text { Cyclospora sp } \\
\text { (T-zelluläre Immundefekte, Reiseanamnese) } \\
\text { Mikrosporidien } \\
\text { (T-zelluläre Immundefekte, Reiseanamnese) } \\
\text { Kryptosporidien } \\
\text { (T-zelluläre Immundefekte, insbesondere HIV) } \\
\text { Dientamoeba fragilis } \\
\text { Strongyloides stercoralis } \\
\text { (selten, HTLV-1-Infektion) } \\
\text { unsicher ist die Bedeutung von Blastocystis hominis, da } \\
\text { die pathogenetische Relevanz als Krankheitserreger } \\
\text { unklar ist }\end{array}$ \\
\hline Viren & $\begin{array}{l}\text { Adenovirus } \\
\text { (fast nur bei Kindern nach Stammzell- bzw. Knochen- } \\
\text { marktransplantation, seltene Ausbrüche) [202] }\end{array}$ \\
\hline Bakterien & $\begin{array}{l}\text { Mycobacterium avium-Komplex und andere nicht tuber- } \\
\text { kulöse Mykobakterien } \\
\text { (V.a. schwere T-zelluläre Immundefekte) [203, 204] } \\
\text { Mycobacterium tuberculosis-Komplex } \\
\text { (Endemiegebiete, Risikopopulationen) [205] }\end{array}$ \\
\hline Pilze & $\begin{array}{l}\text { Histoplasmose } \\
\text { (Reiseanamnese V. a. USA, Zentral- und Südamerika) [206] } \\
\text { Kokzidioidomykose (Reiseanamnese V.a. Amerika) }\end{array}$ \\
\hline
\end{tabular}

Diagnostik erforderlich (siehe AG 1, Empfehlung 1.4 und entsprechender Kommentar).

\section{Empfehlung 4.4: Endoskopische Untersuchung}

Bei Patienten mit ausgeprägter Immundefizienz sollte eine endoskopische Untersuchung mit Biopsien in folgenden Situationen frühzeitig durchgeführt werden:

- anhaltende Diarrhö ohne Erregernachweis oder Erreger, die das Krankheitsbild nicht hinreichend erklären

- fehlendes Therapieansprechen

[Konsensusstärke: starker Konsens, Empfehlung]

\section{Kommentar}

In der Regel ist die Beschränkung auf eine Rektosigmoidoskopie ausreichend [207]. Bei chronischer Diarrhö und dem Verdacht auf eine Mycobacterium avium-intracellulare-Infektion sollte allerdings eine Ösophagogastroskopie durchgeführt werden. Die Endoskopie kann zudem zur Differenzialdiagnostik indiziert sein, so zum Beispiel zur Detektion einer ischämischen Kolitis führen. Neben der Beurteilung der Architektur und Mukosa sollte die Endoskopie dazu dienen Biopsien sowohl für eine histologische als auch für eine mikrobiologische Aufarbeitung zu gewinnen. Insbesondere atypische Mykobakterien (MAC), CMV- und Candidainfektionen sind in der Regel nur bioptisch zu sichern.

Intestinale Candidainfektionen wurden bisher nur bei einzelnen immundefizienten Patienten mit enteraler Barrierestörung beobachtet. Die Diagnose erfordert eine endoskopische Untersuchung mit Gewebebiopsie zum histopathologischen Nachweis eines invasiven Wachstums von Candida in Gewebe und Gefäßen, da Stuhluntersuchungen eine Differenzierung zwischen einer kommensalen Besiedelung oder einer intestinalen Infektion nicht zulassen. Daten zur Inzidenz intestinaler Candidainfektionen oder einer Assoziation mit Diarrhö bei immundefizienten Patienten liegen nicht vor [208]. 
Die optimale Methode zur Detektion einer klinisch relevanten CMV-Infektion bei Patienten mit Immundefekten ist bisher nicht etabliert. Der gelegentliche Nachweis intranukleärer Einschlusskörper im Rahmen einer histopathologischen Untersuchung zeigt nicht notwendigerweise eine klinisch signifikante CMV-Infektion an. Hingegen sind multiple intranukleäre Einschlusskörperchen als beweisend anzusehen [209, 210]. Die histologische Untersuchung ist durch eine CMV-PCR aus dem peripheren Blut zu ergänzen (siehe auch „Aktualisierte Leitlinie zur Diagnostik und Therapie der Colitis ulcerosa 2011 - Ergebnisse einer Evidenzbasierten Konsensuskonferenz“, Kapitel 6: Infektiologische Probleme, AWMF-Registriernummer: 021/009).

Im Rahmen einer Ösophagogastroskopie können Gewebsproben und Duodenalsaft auf Giardia lamblia untersucht werden, diese Untersuchungen sind jedoch nicht sensitiver als adäquat untersuchte Stuhlproben [45].

\section{Empfehlung 4.5: Bildgebende Untersuchungen}

Bildgebende Untersuchungen sollten nicht routinemäßig zur Abklärung der Genese einer infektiösen Gastroenteritis durchgeführt werden. Auch bei immundefizienten Patienten sollte keine routinemäßige radiologische Schnittbildgebung durchgeführt werden.

[Konsensusstärke: starker Konsens, Empfehlung]

\section{Kommentar}

Insgesamt gelten in dieser Situation die gleichen Empfehlungen wie bei immunkompetenten Patienten. Zur Abklärung der Genese einer infektiösen Gastroenteritis sind diese Verfahren (Röntgen-Abdomen-Übersicht, CT-Abdomen, MRT-Abdomen) in der Regel nicht hilfreich. Ausnahmen bilden hierbei die Abklärung extraintestinaler Manifestationen sowie der Verdacht auf Komplikationen (Megakolon, Fisteln, Abszesse etc.). Am ehesten sollte in bestimmten Fällen zunächst eine weitere Abklärung durch eine Sonografie (z.B. zum Nachweis pathologischer Kokarden, Darmwandverdickung, abdominelle Lymphknoten etc.) in Betracht gezogen werden.

\section{Empfehlung 4.6: Supportive Maßnahme}

Möglichkeiten zur Verbesserung der reduzierten Immunfunktion sollten geprüft werden.

[Konsensusstärke: Konsens, Empfehlung]

\section{Kommentar}

Bei dem Verdacht oder Nachweis einer infektiösen Gastroenteritis bei immundefizienten Patienten sollte die Möglichkeit zur Verbesserung der reduzierten Immunfunktion geprüft werden. Hierzu zählt vor allem die Reduktion ggf. Pausierung einer medikamentösen Immunsuppression soweit dieses von der Aktivität der Grunderkrankung her vertretbar ist. Des Weiteren kann bei Patienten mit Neutropenie während oder nach Chemotherapie aufgrund einer malignen Grunderkrankung die Immunfunktion durch die frühzeitige Gabe von Granulozytenkolonie stimulierendem Faktor (G-CSF) verbessert werden [211]. Die Einleitung oder Umstellung einer hochaktiven antiretroviralen Therapie (HAART) bei HIV-positiven Patienten stellt eine weitere Möglichkeit dar, die zu einer Verbesserung der Immunfunktion führt.

\section{Empfehlung 4.7: Empirische antiinfektive Therapie}

Eine empirische antiinfektive Therapie sollte auch bei einem immundefizienten Patienten nicht routinemäßig erfolgen.

[Konsensusstärke: Konsens, Empfehlung]

Bei Patienten mit ausgeprägter Immundefizienz und ausgeprägter Klinik sollte eine empirische antiinfektive Therapie wie bei immungesunden Patienten erfolgen. Hierbei sollte das erhöhte Risiko einer Clostridium difficile-Infektion beachtet und ggf. die Therapie erweitert werden.

[Konsensusstärke: Konsens, Empfehlung]

\section{Kommentar}

Als empirische Therapie sollten Azithromycin ( $500 \mathrm{mg} / \mathrm{d}$ p. o.) für 3 Tage oder Ciprofloxacin ( $1 \mathrm{~g} /$ Tag p. o. oder $800 \mathrm{mg} /$ Tag i.v.) für 3-5 Tage oder Ceftriaxon ( $2 \mathrm{~g} /$ Tag i.v.) für 3-5 Tage oder bei entsprechenden Risikofaktoren für eine CDI Metronidazol eingesetzt werden (siehe auch Empfehlungen 2.7 und 3.12). Auf Arzneimittelinteraktionen (z.B. mit immunsuppressiven Medikamenten) ist zu achten.

\section{Empfehlung 4.8: CMV-Enterokolitis}

Bei immundefizienten Patienten mit nachgewiesener CMV-Enterokolitis sollte eine antivirale Therapie durchgeführt werden. [Konsensusstärke: starker Konsens, starke Empfehlung]

\section{Kommentar}

Die Induktionstherapie bei immundefizienten Patienten mit nachgewiesener CMV-Enterokolitis sollte in der Regel mit Ganciclovir intravenös erfolgen. Alternativ können Valganciclovir oder Foscarnet in Betracht gezogen werden [212]. Nach Abklingen der initialen klinischen Symptome sollte eine initiale parenterale Therapie auf Valganciclovir per os umgestellt werden.

Während einer CMV-Therapie sollte ein regelmäßiges CMV-Monitoring erfolgen, erstmalig 7 Tage nach Therapiebeginn, um ein Therapieansprechen bzw. -versagen bei möglicher Resistenz zu erkennen. Bei Patienten mit Neutropenie sollte eine CMV-PCR (CMV-Kopienzahl) aus dem Blut erfolgen, während bei nicht neutropenen Patienten auch CMV-pp65 (Antigenämie) aus dem Blut bestimmt werden kann. Die Induktionstherapie sollte für mindestens 14 Tage erfolgen - unter Beachtung des Verlaufs der Antigenämie oder Virusreplikation im peripheren Blut und des klinischen Ansprechens. Eine Erhaltungstherapie mit oralem Valganciclovir sollte bei Patienten mit Relapse einer CMV-Infektion erfolgen und kann bei Patienten mit anhaltendem schwerem Immundefekt auch langfristig erwogen werden.

\section{Empfehlung 4.9: Isolationsmaßnahmen}

Auch bei immundefizienten Patienten sollten sich die Isolationsmaßnahmen bei Norovirus-Infektionen nur nach der Klinik (bis einschließlich $48 \mathrm{~h}$ nach Sistieren der Diarrhö) richten. [Konsensusstärke: starker Konsens, Empfehlung]

\section{Kommentar}

Zwar lässt sich bei immundefizienten Patienten eine verlängerte Ausscheidung von Noroviren nachweisen, und einige Patienten bleiben Dauerausscheider, es gibt aber keine Evidenz für Maßnahmen, die über eine Standardhygiene hinausgehen [213]. Bisher ist ein nur einziger Fall einer fraglichen Übertragung durch einen Dauerausscheider berichtet worden, obwohl es viele Pa- 
tienten mit Langzeitausscheidung gibt, sodass, wie bei anderen Patienten auch 48 Stunden nach Sistieren der Diarrhön keine besonderen Isolationsmaßnahmen erforderlich sind. Eine Verlaufsdiagnostik bei diesen Patienten erübrigt sich mangels klinischer Relevanz.

\section{Empfehlung 4.10: Therapie der Adenovirus-Infektion}

Eine etablierte Therapie der Adenovirus-Infektion existiert nicht. Bei immundefizienten Patienten mit schwerem Krankheitsbild kann eine frühzeitige antivirale Therapie erwogen werden.

[Konsensusstärke: starker Konsens, Empfehlung offen]

\section{Kommentar}

Das höchste Risiko einer schweren Adenovirusinfektion zeigt sich bei immundefizenten Patienten nach Knochenmarktransplantation oder Transplantation solider Organe. Nach Möglichkeit sollte hier eine Reduktion der immunsuppresiven Therapie erfolgen [214]. Unter Berücksichtigung der Nebenwirkungen, insbesondere der Nephrotoxizität, kann zusätzlich auch eine antivirale Therapie mit Cidofovir (off-label) erwogen werden [202]. Cidofovir ist ein azyklisches Nukleotidanalogon von Deoxycytidinmonophosphat und hemmt die virale DNA-Polymerase. Während In-vitro-Daten eine gute Wirksamkeit gegen verschiedene humane Adenovirussubgruppen zeigten, gibt es nur wenige klinische Studien zur Wirksamkeit von Cidofovir [202].

\section{Empfehlung 4.11: Mycobacterium avium complex}

Die Therapie einer Mycobacterium avium complex(MAC)-Infektion sollte mit Clarithromycin, Ethambutol und Rifabutin erfolgen.

[Konsensusstärke: starker Konsens, Empfehlung]

\section{Kommentar}

Primär sollte die Therapie einer MAC-Infektion mit Clarithromycin $2 \times 500 \mathrm{mg}$ p. o., Ethambutol $1 \times 15 \mathrm{mg}$ pro kg Körpergewicht p.o. und Rifabutin $1 \times 300 \mathrm{mg}$ p.o. über $1-2$ Monate erfolgen. Als Alternative kann eine Therapie mit Azithromycin $1 \times 500 \mathrm{mg}$ p. o., Ethambutol $1 \times 15 \mathrm{mg}$ pro kg Körpergewicht p.o. und Rifabutin $1 \times 300 \mathrm{mg}$ p. o. erfolgen.

Bei erfolgreicher hochaktiver antiretroviraler Therapie (HAART) bei HIV-positiven Patienten (HIV-RNA unter Nachweisgrenze) kann die Therapie für eine MAC-Infektion 6 Monate nach Anstieg der CD4-Zellzahl >100/Mikroliter unter entsprechenden Kontrollen abgesetzt werden. Eine primäre Chemoprophylaxe wird nicht empfohlen, allerdings muss bei Patienten ohne Immunrekonstitution (CD4-Zellzahl persistent <50/Mikroliter) eine lebenslange Therapie erfolgen. Hier sollte die Sekundärprophylaxe primär mit Azithromycin $1 \times 1200 \mathrm{mg}$ pro Woche p.o. erfolgen, alternativ auch mit Clarithromycin $2 \times 500 \mathrm{mg}$ p.o.. Siehe auch Leitlinien der Deutschen AIDS-Gesellschaft e.V. (DAIG) (www. daignet.de/site-content/hiv-therapie/leitlinien-1).

\section{Empfehlung 4.12: Clostridium difficile-Infektion}

Die Therapie der Clostridium difficile-Infektion soll bei immundefizienten Patienten wie bei immungesunden Patienten erfolgen.

[Konsensusstärke: starker Konsens, starke Empfehlung]

\section{Kommentar}

Immundefizente Patienten haben ein höheres Risiko an einer Clostridium difficile-Infektion zu erkranken, zudem zeigen diese häufiger einen schweren Verlauf der Erkrankung. Dabei spielt die Grunderkrankung, die Art der Immunsuppression und die Umgebung eine entscheidende Rolle. Dementsprechend unterschiedlich sind die Inzidenzraten. Bei Patienten mit Z.n. Lungentransplantation zeigten sich Inzidenzraten bis $31 \%$, bei Z. n. Nieren- oder Lebertransplantation um 3-4\%, und ca. $9 \%$ bei Patienten nach Hochdosischemotherapie oder autologer Stammzelltransplantation [215, 216]. Während sich Häufigkeit und Ausprägung der Erkrankung bei immundefizienten Patienten von denen bei immunkompetenten Patienten unterscheidet, entspricht die Therapie der von immunkompetenten Patienten [217].

\section{Empfehlung 4.13: Kryptosporidien}

Eine spezifische Therapieempfehlung bei Kryptosporidien kann nicht ausgesprochen werden. Im Vordergrund soll die Möglichkeit zur Verbesserung des Immunstatus stehen. [Konsensusstärke: starker Konsens, Empfehlung offen]

\section{Kommentar}

Im Vordergrund der Behandlung steht eine supportive Therapie mit Infusionslösungen und ggf. Motilitätshemmer. Eine effektive Therapie existiert nicht. Für HIV-infizierte Patienten ist die antiretrovirale Therapie (HAART) zur Verbesserung der Immunfunktion von entscheidender Bedeutung. Bei immundefizienten Patienten ist ein erweitertes Erregerspektrum bei intestinalen Infektionen und ggf. eine spezifische Therapie zu beachten. $\triangle$ Tab. 10 soll einen Überblick über die empfohlene Therapie bei gesicherten Erregernachweis und die entsprechende Therapiedauer geben.

\section{K-5 Akute Gastroenteritis bei Reiserückkehrern (AG 5)} $\nabla$

\section{Präambel}

Die Reisediarrhö gilt als die häufigste Infektionskrankheit bei Fernreisen. Mehr als 100 Mio. Personen reisen jedes Jahr aus den Industrieländern in tropische und subtropische Regionen weltweit und exponieren sich damit dem Risiko einer Reisediarrhö. In Hochrisikogebieten wie Mittelamerika, dem tropischen Afrika oder Südasien sind 15-50\% der Reisenden betroffen, in anderen Regionen wie China oder der Karibik rechnet man mit einer Inzidenz von 8-15\%. Insgesamt geht man somit von einer Gesamtzahl von etwa 40 Mio. Erkrankungen pro Jahr weltweit aus [219, 220]. Als Risikofaktoren für die Reisediarrhö sollten folgende Faktoren Beachtung finden:

- Unterschiede im Hygienestandard zwischen Heimat- und Reiseland,

- die Nahrungsmittelhygiene vor Ort (Diätfehler) und

- eingeschränkte oder reduzierte Magensäuresekretion

(z. B. Protonenpumpeninhibitoreinnahme, Z. n. Gastrektomie). Ebenso ist belegt, dass Jugendliche und junge Erwachsene eine überdurchschnittlich hohe Inzidenz aufweisen, was wahrscheinlich durch eine höhere Aufnahmerate potenziell risikoreicher Nahrungsmittel bei Jüngeren zu erklären ist [221]. Eine genetische Prädisposition für die Reisediarrhö scheint ebenso belegt. So sind Einzelnukleotidpolymorphismen (SNP) in Genen für Inflammationsmarker mit erhöhter Empfänglichkeit assoziiert, z. B. im Gen für Interleukin-8, Interleukin-10, CD14 und Lactoferrin $[222,223]$. 
Tab. 10 Therapie intestinaler Infektionen bei immundefizienten Patienten.

\begin{tabular}{|c|c|c|c|}
\hline Erreger & 1. Wahldosis/Tag & alternative Dosis/Tag & Therapiedauer \\
\hline Kryptosporidien & $\begin{array}{l}\text { keine gesicherte Therapie; Versuch mit Pa- } \\
\text { romomycin } 4 \times 500 \mathrm{mg} / \text { d oder } 3 \times 1000 \mathrm{mg} / \\
\text { d p. o., evt. in Kombination mit Azithromy- } \\
\text { cin } 1 \times 600 \mathrm{mg} \text { p. o. }\end{array}$ & Nitazoxanide $2 \times 500 \mathrm{mg} / \mathrm{d}$ & 14 Tage \\
\hline Mikrosporidien & Albendazol $2 \times 400 \mathrm{mg} / \mathrm{d}$ p. o. & Fumagillin $3 \times 20 \mathrm{mg} \mathrm{p.} \mathrm{o}$ & 14 Tage \\
\hline $\begin{array}{l}\text { Isospora spp. (Syno- } \\
\text { nym Cytoisosporiasis) }\end{array}$ & Trimethoprim/Sulfa. $960 \mathrm{mg} 2-4 \times / \mathrm{d}$ & & $10-14$ Tage \\
\hline $\begin{array}{l}\text { Strongyloides sterco- } \\
\text { ralis }\end{array}$ & Ivermectin $200 \mu \mathrm{g} / \mathrm{kg}$ p. o. $1 \times 1$ & Albendazol $10 \mathrm{mg} / \mathrm{kg} / \mathrm{d}$ & $\begin{array}{l}2 \text { Tage (Ivermectin) } \\
7 \text { Tage (Albendazol) }\end{array}$ \\
\hline M. tuberculosis & $\begin{array}{l}\text { Isoniazid } 5 \mathrm{mg} / \mathrm{kg}^{+} \\
\text {Rifampicin } 10 \mathrm{mg} / \mathrm{kg}+ \\
\text { Ethambutol } 15 \mathrm{mg} / \mathrm{kg} / \mathrm{d}+ \\
\text { Wechsel mit Pyrazinamid } 35 \mathrm{mg} / \mathrm{kg} / \mathrm{d}\end{array}$ & & 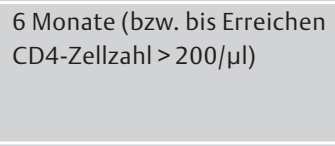 \\
\hline M. avium-Komplex & $\begin{array}{l}\text { Clarithromyin } 2 \times 500 \mathrm{mg} / \mathrm{d}+ \\
\text { Ethambutol } 15 \mathrm{mg} / \mathrm{kg} / \mathrm{d}+ \\
\text { Rifabutin } 300 \mathrm{mg} / \mathrm{die}\end{array}$ & & $\begin{array}{l}\text { mind. } 6 \text { Monate nach Immun- } \\
\text { rekonstitution (bzw. } 3 \text { Mona- } \\
\text { te nach Erreichen CD4-Zell- } \\
\text { zahl > } 100 / \mu \mathrm{l} \text { ) }\end{array}$ \\
\hline CMV & $\begin{array}{l}\text { Ganciclovir } 5 \mathrm{mg} / \mathrm{kg} 2 \times / \mathrm{d} \text { i. v. oder } \\
\text { Valganciclovir } 2 \times / \mathrm{d} 900 \mathrm{mg} \mathrm{p} \text {. o. oder } \\
\text { Foscarnet } 2 \times 90 \mathrm{mg} / \mathrm{kg} 2 \times / \mathrm{d} \text { i. v. }\end{array}$ & evtl. Cidofovir & 3 Wochen \\
\hline Giardia lamblia & Metronidazol $3 \times 500 \mathrm{mg}$ für $5-7$ Tage & $\begin{array}{l}\text { Tinidazol } 2 \mathrm{~g} / \mathrm{d} \text { Einmaldosis oder } \\
\text { Ornidazol } 2 \mathrm{~g} / \mathrm{d} \text {, oder Secnidazol } 2 \mathrm{~g} / \mathrm{d} \text { oder } \\
\text { Nitazoxanide } 2 \times 500 \mathrm{mg} \text { für } 3 \text { Tage oder } \\
\text { Albendazol } 1 \times 400 \mathrm{mg} \text { tgl. für } 5 \text { Tage } \\
\text { bei therapieresistenten Fällen [218]: Triple- } \\
\text { therapie } z \text {. B. mit einem } 5 \text {-Nitroimidazol + } \\
\text { Mebendazol } 3 \times 200 \mathrm{mg} / \mathrm{d}+\text { Chloroquin } \\
2 \times 250 \mathrm{mg} / \mathrm{d} \text { für } 5-10 \text { Tage }\end{array}$ & \\
\hline
\end{tabular}

\section{Empfehlung 5.1: Definition}

Zur Abgrenzung leichterer von klinisch schwereren und möglicherweise komplikationsträchtigen Verläufen einer Reisediarrhö sollten folgende Parameter herangezogen werden: fieberhafte Durchfallepisoden, blutige Diarrhö, vorbestehende Komorbidität (Immunsuppression etc.) und das Alter des Patienten (Risikogruppen: Säuglinge, Senioren).

[Konsensusstärke: starker Konsens, Empfehlung]

\section{Kommentar}

Die Reisediarrhö ist normalerweise eine milde bis moderate Durchfallerkrankung, die innerhalb der ersten Woche im Reiseland auftritt und nach 3-5 Tagen spontan sistiert. Trotz der überwiegend milden Verläufe sind etwa ein Viertel der Reisenden gezwungen, ihre Reiseaktivitäten zu ändern. Dies impliziert auch, dass die Reisediarrhö in den meisten Fällen im Reiseland auftritt. Schwere dysenterische Verläufe mit blutiger Diarrhö, oft assoziiert mit Fieber, kommen bei weniger als $10 \%$ der Fälle von Reisediarrhö vor (Lateinamerika, Afrika 1-3\%, Indien bis 9\%) (๑ Tab. 11) [224]. Komplikationsträchtige schwere Verläufe können zu Elektrolyt- und Flüssigkeitsverlusten mit konsekutivem Nierenversagen und Kreislaufproblemen führen. Ferner kann die Resorption erforderlicher Medikamente beeinträchtigt sein. Ein postentzündliches Reizdarmsyndrom kommt bei 5 - $10 \%$ der Fälle vor [225].

Verläufe mit Komplikationen treten häufiger bei Komorbiditäten auf, wobei besonders immunsupprimierte Patienten gefährdet sind (z.B. HIV-Patienten mit fortgeschrittener Immundefizienz, Patienten unter immunsuppressiver Therapie, Tumorpatienten mit vorheriger Chemotherapie, Patienten mit Niereninsuffizienz etc.). Auch Reisende in den Altersextremen (Säuglinge, Senioren)
Tab.11 Klinische Syndrome der Reisediarrhö.

\begin{tabular}{|c|c|c|}
\hline klinisches Syndrom & $\begin{array}{l}\text { Häufigkeit } \\
\text { in \% }\end{array}$ & zu bedenkende Erreger \\
\hline $\begin{array}{l}\text { akute Gastroenteritis } \\
\text { (dominierend Erbrechen) }\end{array}$ & $10 \%$ & $\begin{array}{l}\text { Noroviren, Toxine von } \\
\text { Staphylococcus aureus } \\
\text { oder Bacillus cereus }\end{array}$ \\
\hline $\begin{array}{l}\text { akute wässrige(-breiige) } \\
\text { Diarrhö }\end{array}$ & $80 \%$ & $\begin{array}{l}\text { alle Erreger, z. B. ETEC, } \\
\text { EAEC, Shigellen, Campy- } \\
\text { lobacter, Salmonellen, } \\
\text { Noroviren }\end{array}$ \\
\hline $\begin{array}{l}\text { blutige Diarrhö (oft mit } \\
\text { Fieber) }\end{array}$ & $1-9 \%$ & $\begin{array}{l}\text { Shigellen, E. histolytica, } \\
\text { Campylobacter, Salmo- } \\
\text { nellen } \\
\text { EHEC }\end{array}$ \\
\hline $\begin{array}{l}\text { persistierende Diarrhö } \\
\text { (>14 Tage) }\end{array}$ & $2-5 \%$ & $\begin{array}{l}\text { Lamblien, E. histolytica, } \\
\text { Kryptosporidien, Cyclo- } \\
\text { spora, Shigellen, Mikro- } \\
\text { sporidien }\end{array}$ \\
\hline postinfektiöser Reizdarm & $5-10 \%$ & $\begin{array}{l}\text { nach akuter Reisediarrhö } \\
\text { bei suszeptiblen Personen }\end{array}$ \\
\hline
\end{tabular}

sind durch schwere Verläufe erheblich gefährdet. Dies bedeutet, dass Reisende über die Gefahr schwerer Verläufe vor der Reise aufgeklärt und informiert werden sollen, um in der Akutsituation vor Ort rasch zu reagieren. Bei den Zeichen für schwere Verläufe bzw. einer Risikokonstellation soll im Reiseland ein Arzt kontaktiert werden. 


\section{Empfehlung 5.2: Ätiologie}

Das Erregerspektrum der Reisediarrhö unterscheidet sich vom Spektrum der ambulant erworbenen Diarrhö in Mitteleuropa. Bei der Reisediarrhö sollen je nach Reiseregion folgende Erreger stärker bedacht werden: Enterotoxinbildende E. coliStämme (ETEC), andere pathogene E. coli-Stämme (EAEC, EIEC), Shigellen und Protozoen (E. histolytica, Lamblien).

[Konsensusstärke: Konsens, starke Empfehlung]

\section{Kommentar}

Die in Mitteleuropa vorkommenden häufigsten Erreger der ambulant erworbenen Diarrhö sind Noroviren, Rotaviren, Campylobacter und Salmonellen ( $\bullet$ Abb. 1). Diese Erreger können zwar auch bei Fernreisen erworben werden, doch dominieren bei der Reisediarrhö andere Erreger. Dazu gehören insbesondere Enterotoxinbildende E. coli-Stämme (ETEC), andere pathogene $E$. coliStämme (EAEC, EIEC) und Shigellen. Bei einer persistierenden Diarrhö länger als 2-4 Wochen sollen auch Protozoen (besonders E. histolytica und Lamblien) bedacht werden. Mit zunehmender Dauer der Diarrhö wird eine parasitäre Genese der Durchfallepisode wahrscheinlicher [226]. Eine länder- oder kontinentspezifische Erregerzuordnung ist nicht möglich, doch gibt es gewisse epidemiologische Trends, die beachtet werden können. Diese werden exemplarisch anhand einer Studie in 0 Tab. 12 aufgelistet [227]. Für die Erstellung der Erregerhäufigkeiten wurden die Stuhlproben von Patienten mit Reisediarrhö im Reiseland entnommen und untersucht:

In Erweiterung dieser Studie werden in letzter Zeit zunehmend Noroviren bei der Reisediarrhö beschrieben und es ist auf die Bedeutung von Clostridium difficile auch bei Reisenden hingewiesen worden [228, 229]. Auch andere seltenere Erreger wie Bacteroides fragilis und Arcobacter species wurden beobachtet [230].

\section{Empfehlung 5.3: Indikation zur mikrobiologischen \\ Diagnostik}

Eine mikrobiologische Diagnostik sollte beim Reiserückkehrer in folgenden Konstellationen erfolgen: Fieberhafte Diarrhö, blutige Diarrhö, Diarrhödauer länger als 5 Tage, schwere klinische Verläufe (Exsikkose, Hypotonie, Tenesmen) oder bei Gruppenerkrankungen/Ausbruchssituationen (dann aus epidemiologischen Gründen).

[Konsensusstärke: Konsens, Empfehlung]

Tab. 12 Ätiologie der Reisediarrhö.

\begin{tabular}{|lccc|}
\hline Erreger & $\begin{array}{c}\text { Indien } \\
(\mathbf{n = 2 9 3 )}\end{array}$ & $\begin{array}{l}\text { Kenya } \\
(\mathbf{n = 3 7 9 )}\end{array}$ & $\begin{array}{c}\text { Jamaica } \\
(\mathbf{n = 3 2 2})\end{array}$ \\
\hline ETEC & 24,2 & 33,0 & 11,8 \\
\hline Shigellen & 9,6 & 9,2 & 0,3 \\
\hline Salmonellen & 10,2 & 2,6 & 7,8 \\
\hline Campylobacter spp. & 2,7 & 4,5 & 5,0 \\
\hline Aeromonas spp. & 3,4 & 2,4 & 0,0 \\
\hline Plesiomonas spp. & 6,8 & 1,8 & 0,0 \\
\hline Vibrio species & 5,5 & 4,0 & 0,0 \\
\hline G. lamblia & 4,4 & 0,0 & 0,6 \\
\hline E. histolytica & 2,0 & 0,0 & 0,6 \\
\hline Kryptosporidien & 1,7 & 0,0 & 0,3 \\
\hline Rotaviren & 5,1 & 5,6 & 9,1 \\
\hline kein Erreger & 44,0 & 49,1 & 68,3 \\
\hline
\end{tabular}

\section{Kommentar}

Eine Reisediarrhö tritt aufgrund der Epidemiologie - wie oben dargestellt - in der Regel im Reiseland auf. Der Kontakt zu den neuen möglichen Erregern im Reiseland führt in den meisten Fällen in der ersten Reisewoche zur Reisediarrhö. Da die überwiegende Mehrzahl der Episoden von Reisediarrhö spontan innerhalb von 3-5 Tagen sistiert, bedeutet dies, dass die meisten an einer Reisediarrhö Erkrankten zum Ende der Reise bereits wieder beschwerdefrei sind und nicht mehr unter Durchfallsymptomen leiden [225].

Bei jedem Fernreisenden, der mehr als 5 Tage unter Diarrhö leidet, sollte eine mikrobiologische Diagnostik erfolgen. Für den in der Empfehlung angegebenen Zeitraum „länger als 5 Tage“ gibt es jedoch keine kontrollierten Studien, sodass es sich hier um eine Expertenmeinung handelt.

Ferner sollte dies auch bei allen Patienten mit einem schweren oder komplikationsträchtigen Verlauf erfolgen (z. B. fieberhafte Diarrhö, Diarrhö mit Blutabgängen, Exsikkose, Hypotonie, Niereninsuffizienz). Gerade bei diesen Patientengruppen können Therapieversager aufgrund von resistenten bakteriellen Erregern besonders problematisch sein [231].

\section{Empfehlung 5.4: Indikation zur mikrobiologischen Diagnostik II}

Bei einem Tropenrückkehrer mit fieberhafter Diarrhö nach Reise in Malariagebiete soll eine sofortige Malariadiagnostik (medizinischer Notfall, Sofortdiagnostik) erfolgen. Bei jeder fieberhaften Diarrhö $\left(>38,5{ }^{\circ} \mathrm{C}\right)$ sollten Blutkulturen gewonnen werden.

[Konsensusstärke: starker Konsens, starke Empfehlung]

\section{Kommentar}

Das klinische Bild einer Malaria (insbesondere einer Malaria tropica) und einer fieberhaften Diarrhö kann sich so weit überschneiden, dass nach klinischen Kriterien keine Differenzierung beider Erkrankungen möglich ist. Aufgrund der intestinalen Schizogonie bei der Malaria kommt es zu einer parasitären Vermehrung auch in den intestinalen Organen mit der Konsequenz einer Diarrhö. Eine Durchfallsymptomatik kommt bei der Malaria tropica in bis zu 25\% der Fälle vor. Eine Malaria gilt immer als medizinischer Notfall, da sich das klinische Bild innerhalb kurzer Zeit mit möglicherweise tödlichen Konsequenzen verschlechtern kann. Daher soll eine Malariadiagnostik bei fieberhafter Diarrhö bei Tropenrückkehrern mit Dringlichkeit als notfallmäßige Sofortdiagnostik erfolgen [232]. Wie bei anderen fieberhaften Erkrankungen unklarer Ätiologie soll auch bei fieberhafter Diarrhö eine Diagnostik mit Entnahme von Blutkulturen erfolgen. Auf diese Art sollen bakteriämische Verläufe einer Shigellose, Salmonellose oder Campylobacter-Infektion erfasst werden, aber auch andere wichtige Differenzialdiagnosen ausgeschlossen werden. Dazu gehört auch der Typhus abdominalis, wenngleich diese Erkrankung zunächst nicht mit Diarrhö assoziiert ist und erst spät in der Phase der Organmanifestation Durchfälle vorkommen können.

\section{Empfehlung 5.5: Umfang der mikrobiologischen Diagnostik}

Beim Reiserückkehrer mit fieberhafter und/oder blutiger Diarrhö sollte eine Stuhldiagnostik auf bakterielle Erreger (Shigellen, Campylobacter, Salmonellen) und Amöben erfolgen. [Konsensusstärke: starker Konsens, Empfehlung] 


\section{Kommentar}

Invasive Erreger führen über die Einwanderung in die Mukosa nicht nur zu einer Schädigung mit reduzierter Oberfläche mit geringerer Rückresorption, sondern können auch zu fieberhaften Verläufen und blutiger Diarrhö führen. Die typische ShigellenRuhr (bakterielle Ruhr) ist charakterisiert durch häufige blutigschleimige Durchfälle, Fieber, heftige Tenesmen und Abgeschlagenheit (Erreger oft Shigella dysenteriae). Leichtere Verläufe mit wässriger Diarrhö und ohne Fieber können vorkommen und werden eher durch Shigella flexneri, Shigella sonnei und Shigella boydii verursacht $[14,106,107]$.

Campylobacter species sind in Südostasien als Erreger der Reisediarrhö bedeutsamer als ETEC. Die meisten Fälle werden durch Campylobacter jejuni und Campylobacter coli hervorgerufen. Campylobacter fetus ist deutlich seltener, kann aber bei Personen mit geschwächtem Immunsystem zu Bakteriämien führen. Klinisch dominieren meist wässrige, aber auch blutige Durchfälle und Bauchschmerzen [219, 228]. Entamoeba histolytica kann zu blutig-schleimiger Diarrhö mit subfebrilen Temperaturen oder auch Fieber führen (Amöbenruhr). Extraintestinale Komplikationen, insbesondere der Amöben-Leberabszess sind zu bedenken. Für die Diagnostik ist zu beachten, dass es apathogene Amöbenarten gibt, die mikroskopisch nicht von Entamoeba histolytica zu differenzieren sind. Eine sichere Diagnosestellung ist über die PCR oder den mikroskopischen Nachweis phagozytierter Erythrozyten in den Amöben möglich [219].

\section{Empfehlung 5.6: Mikrobiologische Diagnostik bei persistierender Reisediarrhö}

Bei persistierender Diarrhö (> 14 Tage) nach vorangegangener Fernreise sollte eine Diagnostik zum Ausschluss folgender Erreger oder Erkrankungen erfolgen:

- Bakterielle Erreger (Shigellen, Salmonellen, Campylobacter), Amöben, Lamblien.

Eine zusätzliche Diagnostik sollte in speziellen klinischen Situationen zum Ausschluss folgender Erreger oder Erkrankungen erfolgen:

a) Bei initial erfolgloser Diagnostik und insbesondere bei Immunsuppression:

> Yersinien, Mykobakterien, Kryptosporidien, Cyclospora, Mikrosporidien, Isospora belli und Helminthen.

b) Bei vorangegangener Antibiotikatherapie oder Chemotherapie:

Clostridium difficile

c) Bei Eosinophilie:

Strongyloides stercoralis, Isospora belli

d) Bei Langzeitaufenthalt im Reiseland:

Tropische Sprue

[Konsensusstärke: starker Konsens, Empfehlung]

\section{Kommentar}

Das diagnostische Procedere bei einer persistierenden Diarrhö (>14 Tage) oder chronischer Diarrhö (>4 Wochen) unterscheidet sich beim Tropenrückkehrer nicht grundsätzlich von der persistierenden Diarrhö, die hierzulande erworben wurde. Nach einer Fernreise gilt es, parasitäre Ursachen stärker zu bedenken. Die häufigsten parasitären Ursachen einer persistierenden Diarrhö sind Protozoeninfektionen, insbesondere Entamoeba histolytica und Giardia lamblia; deutlich seltener und überwiegend bei Immunsupprimierten beschrieben sind Kokzidien (Kryptosporidien, Cyclospora, Isospora belli) und Mikrosporidien [233]. Hel- mintheninfektionen gehen typischerweise nicht mit einer Durchfallsymptomatik einher, sondern zeigen eher ein unspezifisches abdominelles Beschwerdebild mit Schmerzen, Blähungen, Unwohlsein und begleitender Eosinophilie. Eine Eosinophilie kommt bei Helminthen und bei Isospora belli vor, nicht jedoch bei Amöben und Lamblien.

\section{Empfehlung 5.7: therapeutische Basismaßnahme}

Als therapeutische Basismaßnahme soll die orale Rehydratation eingesetzt werden (Ersatz von Flüssigkeit und Elektrolyten). [Konsensusstärke: starker Konsens, starke Empfehlung]

\section{Kommentar}

Orale Rehydratationslösungen verhindern Komplikationen wie Exsikkose, Hypotonie, prärenales Nierenversagen und somit auch Todesfälle. Entsprechende Anweisungen, wie diese Lösungen auch unter einfachen Bedingungen in ressourcenarmen Ländern hergestellt werden können, werden von der WHO veröffentlicht (siehe auch Kapitel 2). Der Einsatz dieser Trinklösungen ist jedoch keine kausale Therapie gegen die Durchfallerreger. Essenziell ist die Verhinderung der oben genannten Komplikationen.

\section{Empfehlung 5.8: empirische Antibiotikatherapie}

Eine empirische Antibiotikatherapie sollte bei Diarrhö mit Fieber und/oder Blutabgängen oder bei Risikopatienten für Komplikationen (Immunsupprimierte, onkologische Patienten, Senioren) eingesetzt werden.

[Konsensusstärke: starker Konsens, Empfehlung]

Bei Verdacht auf bakterielle Erreger ohne Fieber und Blutabgänge kann eine empirische Antibiotikatherapie eingesetzt werden.

[Konsensusstärke: starker Konsens, Empfehlung offen] In beiden Fällen sollte, unter Beachtung der Resistenzsituation im Reiseland, Azithromycin (500 mg/Tag p. o. für 3 Tage oder $1000 \mathrm{mg}$ einmalig p. o.) oder Ciprofloxacin ( $1 \mathrm{~g} /$ Tag p. o. oder $800 \mathrm{mg} /$ Tag i. v.) eingesetzt werden.

[Konsensusstärke: starker Konsens, Empfehlung]

\section{Empfehlung 5.9: empirische Antibiotikatherapie}

Bei Verdacht auf eine Infektion mit Amöben sollte bei schwerem Krankheitsbild nach Einleitung einer Diagnostik Metronidazol $(3 \times 10 \mathrm{mg} / \mathrm{kg} /$ Tag $(\max .3 \times 800 \mathrm{mg})$ i. v. oder p. o. über 10 Tage eingesetzt werden. Anschließende Behandlung einer evtl. noch bestehenden Darmlumeninfektion: Paromomycin $3 \times 500 \mathrm{mg} /$ Tag p. o. über $9-10$ Tage

[Konsensusstärke: starker Konsens, Empfehlung]

\section{Kommentar}

In vielen Studien der letzten 30 Jahre konnte für die verschiedensten Präparate gezeigt werden, dass Antibiotika in der Lage ist, die Diarrhöfrequenz zu senken und die Diarrhödauer zu verkürzen. In Anbetracht einer sich entwickelnden Antibiotikaresistenz hat sich das Spektrum der untersuchten Antibiotika jedoch im Laufe der Zeit gewandelt. Für eine empirische Antibiotikatherapie ist eine Kenntnis der Resistenzsituation in den jeweiligen Ländern unabdingbar.

Shigellen: Studien von Isolaten von Reiserückkehrern zeigen hohe Resistenzraten gegen Penicilline, Cotrimoxazol und Tetrazyklin. In einigen Ländern Ostasiens besteht eine hohe Resistenzrate gegen 
Cephalosporine der 3. Generation. Ciprofloxacin-Resistenz ist in den meisten Teilen der Welt selten, erreicht jedoch auf dem indischen Subkontinent hohe Raten. Die Azithromycin-Resistenz wird seltener beobachtet, es wurden jedoch auch zu diesen Erregern Einzelfälle von Resistenzen beschrieben [219, 234].

Campylobacter: Eine Antibiotikatherapie von Campylobacter-Infektionen führt zu einer Verkürzung der Diarrhödauer von gut einem Tag. Weltweit werden sehr hohe und weiter ansteigende Resistenzraten gegen Chinolone berichtet, sodass Chinolone für eine empirische Therapie an Bedeutung verloren haben. Makrolide weisen hingegen weiterhin eine gute Wirksamkeit auf [235]. Entamoeba histolytica: Die Amöbenruhr wird mit Metronidazol behandelt. Metronidazol ist jedoch nicht ausreichend wirksam gegen Amöben im Darmlumen. Diese können auch dann noch vorhanden sein, wenn sie bei einer parasitologischen Stuhluntersuchung nicht mehr nachweisbar sind. Daher muss immer eine Nachbehandlung mit einem darmlumenwirksamen Medikament erfolgen. In einer vergleichenden Untersuchung hat sich hierbei das Paromomycin (z. B. Humatin ${ }^{\circledR}$ ) dem Diloxanid-Furoat (z.B. Furamide ${ }^{\circledR}$ ) überlegen gezeigt. Resistenzen von E. histolytica spielen bisher keine Rolle [219, 233]. Für die Diagnostik und Therapie der Amöbenruhr wird auf die AWMF-Leitlinie „Diagnostik und Therapie der Amöbenruhr“" (042/002) verwiesen.

Gerade bei invasiven Erregern, die eher schwere Verläufe mit Fieber und Blutabgängen bedingen, haben die Verkürzung der Krankheitsdauer und die Verhinderung von Komplikationen einen hohen Stellenwert. Bei invasiven bakteriellen Erregern, die zu Fieber und blutiger Diarrhö führen können, sollten bevorzugt Azithromycin oder Ciprofloxacin eingesetzt werden (abhängig von der Resistenzsituation im Reiseland). Bei nicht invasiven Erregern (toxinvermittelte Genese), die in der Regel mit einem blanderen klinischen Bild einhergehen, können empirisch Ciprofloxacin, Azithromycin oder Rifaximin eingesetzt werden [236]. Der Nutzen einer Antibiotikatherapie sollte individuell unter dem Aspekt einer möglichen Resistenzentwicklung abgewogen werden. Je blander das klinische Bild ist, umso mehr muss der Antibiotikaeinsatz kritisch hinterfragt werden.

\section{Empfehlung 5.10: Motilitätshemmer}

Bei ausgeprägter Durchfallsymptomatik (ohne Fieber und Blutabgang) können Motilitätshemmer eingesetzt werden. Der Einsatz soll nur kurzfristig (maximal 3 Tage) erfolgen.

[Konsensusstärke: Konsens, Empfehlung offen]

\section{Kommentar}

Für Motilitätshemmer konnte bei nicht invasiven Erregern ohne Fieber und Blutabgängen eine Verkürzung der Diarrhödauer und -frequenz gezeigt werden [224]. Motilitätshemmer sind jedoch kontraindiziert bei fieberhafter oder blutiger Reisediarrhö sowie bei kleinen Kindern. Um Komplikationen zu vermeiden, ist nur ein Kurzzeiteinsatz (maximal 3 Tage) gerechtfertigt (siehe auch Kapitel 2). In Bezug auf die Reduktion der Stuhlfrequenz und Diarrhödauer ist eine Kombination von Antibiotika und Motilitätshemmern einer alleinigen Gabe von Antibiotika oder von Loperamid überlegen [68, 69, 237]. Der Nutzen einer solchen ggf. kombinierten Therapie sollte nach einer individuellen RisikoNutzen-Analyse erfolgen.

\section{Empfehlung 5.11: Supportive Therapie}

Es gibt keine ausreichende Evidenz für den supportiven Einsatz von Tannin, Kaolin, Pektin und medizinischer Kohle. Daher sollten diese Substanzen nicht eingesetzt werden.

[Konsensusstärke: starker Konsens, Empfehlung]

\section{Kommentar}

Ergänzende supportive Therapieansätze werden von Laien eingesetzt und in der Laienpresse diskutiert. Es gibt jedoch keine überzeugenden vergleichenden wissenschaftlichen Studien für den Einsatz von Tannin, Kaolin, Pektin oder medizinischer Kohle. Bei fehlender wissenschaftlicher Evidenz sollten diese Substanzen nicht eingesetzt werden. Für den Einsatz von Bismuthsubsalicylat existieren Studien aus dem amerikanischen Bereich, in denen die Effektivität dieser Substanz belegt ist. Da Bismuthsubsalicylat jedoch in Europa nicht im Handel ist, wird hier keine Empfehlung ausgesprochen.

\section{Empfehlung 5.12: Probiotika}

Für den präventiven und therapeutischen Einsatz von Probiotika ist die Datenlage uneinheitlich. Es gibt Hinweise für eine Wirksamkeit definierter Probiotika bei bestimmten Erregern, daher kann der Einsatz erwogen werden. [Konsensusstärke: starker Konsens, Empfehlung offen]

\section{Kommentar}

Die Datenlage für den prophylaktischen Einsatz von Probiotika ist nicht eindeutig. So konnte zum Beispiel in einer Metaanalyse von 12 randomisiert kontrollierten Studien mit 4709 Patienten für S. boulardii eine mäßige, jedoch signifikante Reduktion von Reisediarrhöepisoden gezeigt werden ( $R R=0,85$, 95\% KI 0,790,91) [238]. In anderen Arbeiten konnte dies jedoch nicht bestätigt werden [239]. Erschwerend kommt hinzu, dass die auf dem deutschen Markt befindlichen Probiotika eine extrem heterogene Gruppe mit unterschiedlichen Mikroorganismen (Bakterien, Hefen etc.) in den verschiedensten Dosierungen darstellen, die miteinander kaum vergleichbar sind. Ein Einsatz kann daher individuell erwogen werden. Ebenfalls ist die Datenlage für den therapeutischen Einsatz der Probiotika bei Reisediarrhö nicht eindeutig.

\section{Empfehlung 5.13: Reiseberatung}

Die Reiseberatung zur Prophylaxe der Reisediarrhö sollte folgende Informationen enthalten: Bedeutung und Häufigkeit der Reisediarrhö, Betonung der Nahrungsmittelhygiene, individuelle Risikofaktoren und das Herausstellen der Primärtherapie mit oraler Rehydratation. Zur Nachhaltigkeit der vermittelten Empfehlung sollten schriftliche Informationen mitgegeben werden. [Konsensusstärke: starker Konsens, Empfehlung]

\section{Kommentar}

Vor einer Fernreise sollte eine individuelle Reiseberatung durch einen tropen- oder reisemedizinisch erfahrenen Arzt erfolgen. Neben der Vielzahl von Empfehlungen zur Impfprophyalxe und Malariaexpositions- und Chemoprophylaxe müssen Empfehlungen zur Prophylaxe und Selbsttherapie der Reisediarrhö essenzieller Bestandteil jeder Reiseberatung vor Tropen- und Fernreisen sein. Bei der Anzahl dieser Empfehlungen wird das Besprechen der Reisediarrhö oftmals vernachlässigt. Es ist daher umso wichtiger dem Rei- 
senden einen schriftlichen Empfehlungsplan mitzugeben, um mit erforderlicher Nachhaltigkeit die Bedeutung zu unterstreichen. Darüber hinaus sollte die Nahrungsmittelhygiene propagiert werden, da auf diese Art die Exposition mit Keimen eindeutig reduziert werden kann. In verschiedenen Studien wurde in Reiseländern gezeigt, dass eine Vielzahl von Gerichten in Restaurants bakteriell kontaminiert waren [240, 241].

\section{Empfehlung 5.14: Ärztliche Hilfe im Reiseland}

Erkrankte mit Reisediarrhö sollten auch im Reiseland ärztliche Hilfe suchen, wenn folgende klinische Konstellationen vorliegen: fieberhafte oder blutige Diarrhö, persistierendes Erbrechen, fehlende ausreichende Flüssigkeitsaufnahme, reduzierter Allgemeinzustand (Exsikkose, Hypotonie, Kollapsneigung) oder Komorbidität mit Gefährdung des Patienten.

[Konsensusstärke: starker Konsens, Empfehlung]

\section{Kommentar}

Es ist selbstverständlich, dass eine schwere oder komplikationsträchtige Episode einer Reisediarrhö eine rasche ärztliche Konsultation im Reiseland erforderlich macht. Dies soll eine klinische Verschlechterung verhindern und eine rasche ärztliche Hilfe ermöglichen. Diese Information sollte in jeder Reiseberatung herausgestellt werden.

\section{Empfehlung 5.15: Selbsttherapie}

Zur Selbsttherapie der Reisediarrhö im Reiseland sollte eine ausführliche Aufklärung vor der Reise erfolgen. Der Reisende sollte darauf hingewiesen werden, dass die Reisediarrhö in den meisten Fällen mild und selbstlimitierend ist. Als Primärtherapie soll die orale Rehydratation empfohlen werden. [Konsensusstärke: starker Konsens, starke Empfehlung]

\section{Kommentar}

Die Notwendigkeit zur Rehydratation kann nicht genügend betont werden. Wenn eine orale Flüssigkeitsaufnahme nicht ausreichend möglich ist, sollte ärztliche Hilfe in Anspruch genommen werden. Auf diese Therapieoptionen muss in der Reiseberatung bereits hingewiesen werden.

\section{Empfehlung 5.16: Selbsttherapie}

Falls die Indikation für eine Selbsttherapie vorliegt, sollte sie unter Berücksichtigung der regionalen Resistenzsituation mit Azithromycin, Ciprofloxacin oder Rifaximin durchgeführt werden. In der Selbsttherapie sollte eine möglichst kurze Therapiedauer gewählt werden (Azithromycin $1 \times 1000 \mathrm{mg}$ p. o. als Einzeldosis, Ciprofloxacin $2 \times 500 \mathrm{mg} /$ Tag p.o. für 3 Tage, oder Rifaximin $3 \times 200 \mathrm{mg} /$ Tag p. o. für 3 Tage).

[Konsensusstärke: starker Konsens, Empfehlung]

\section{Kommentar}

Die Effektivität von Azithromycin, Ciprofloxacin und Rifaximin ist aus vielen Studien hinreichend belegt $[219,224]$. Es sollte im Vorfeld darauf hingewiesen werden, dass diese antimikrobiellen Substanzen nicht gegen Viren und Parasiten wirken. Diese Medikamente sollten nach vorheriger sorgfältiger Aufklärung durch den Arzt verschrieben werden und dieser sollte auf die Begrenzungen bezüglich Einnahmedauer und Dosierung (siehe 5.10) hinweisen. In vielen Ländern des Südens existieren Medikamentenfälschun- gen in erheblichem Ausmaß. Es ist daher zu empfehlen, potenziell erforderliche Medikamente mitzunehmen und nicht auf eine adäquate Medikamentenversorgung im Reiseland zu hoffen.

\section{Empfehlung 5.17: Chemoprophylaxe}

Eine antimikrobielle Chemoprophylaxe der Reisediarrhö soll nur in besonders begründeten Einzelfällen durchgeführt werden.

[Konsensusstärke: starker Konsens, starke Empfehlung]

\section{Kommentar}

In vielen Studien ist für unterschiedliche Antibiotika gezeigt worden, dass der prophylaktische Einsatz von Antibiotika im Vergleich zu Plazebo zu einer geringeren Häufigkeit von Reisediarrhöepisoden führt. Dies ist mit guter Evidenz unter anderem für die Prophylaxe mit Chinolonen und Rifaximin gezeigt worden [242, 243]. Die Effektivität soll gegen die möglichen Nebenwirkungen einer kontinuierlichen täglichen Antibiotikaprophylaxe abgewogen werden. Für Azithromycin gibt es keine gute Datenlage zur Chemoprophylaxe. Geäußerte Einwände gegen eine Antibiotikaprophylaxe sind wie folgt:

- Erschwerte nachfolgende Therapie bei Versagen der Antibiotikaprophylaxe.

- Fehlende Wirksamkeit gegen Viren und Parasiten.

- Gefühl der falschen Sicherheit und Vernachlässigen der Nahrungsmittelhygiene.

- Nebenwirkungen der Antibiotika (Risiko für Clostridium difficile-Infektion etc.).

- Induktion von Resistenzen

- Die begründete Antibiotikatherapie ist kosteneffektiver als eine generelle Antibiotikaprophylaxe

- Keine immunologische Wirtsreaktion gegen pathogene bakterielle Erreger.

Eine regelmäßige, tägliche Antibiotikaprophylaxe kann daher nur in wenigen Ausnahmesituationen erwogen werden und muss dann detailliert mit dem Reisenden besprochen werden. Studien zu solchen Ausnahmekonstellationen liegen nicht vor. Die Reise- bzw. Einnahmedauer sollte dabei 2 - 3 Wochen nicht überschreiten. Mögliche Risikokonstellationen können sein: Immunsupprimierte Patienten (z. B. AIDS), chronisch entzündliche Darmkrankheiten (CED), wichtige z. B. politische oder sportliche Aktivitäten.

\section{Empfehlung 5.18: Impfungen}

Eine Impfung gegen die Vielzahl der Erreger von Reisediarrhö ist nicht verfügbar und auch nicht in Kürze zu erwarten. Der Cholera-Impfstoff $\left(\right.$ Dukoral ${ }^{\circledR}$ ) weist eine Kreuzreaktivität gegen ETEC auf. Der Einsatz kann für gezielte Risikogruppen (CED-Patienten, Patienten mit eingeschränkter oder reduzierter Magensäuresekretion) erwogen werden.

[Konsensusstärke: starker Konsens, Empfehlung offen]

\section{Kommentar}

Der Pathomechanismus von Enterotoxischen Escherichia coli (ETEC) ist dem von Vibrio cholerae eng verwandt und führt zu einer enterotoxininduzierten, sekretorischen Diarrhö. ETEC sind in der Lage, zwei Enterotoxine zu produzieren, ein hitze- und säurelabiles Enterotoxin (LT) sowie ein hitzestabiles Enterotoxin (ST). LT ist eng strukturverwandt und wirkungsgleich mit dem Choleraenterotoxin und entfaltet seine Wirkung über eine Aktivierung der 
Adenylatcyclase mit nachfolgendem Anstieg des intestinalen cAMP. Der Choleraimpfstoff (Dukoral ${ }^{\circledR}$ ) ist ein hitzeinaktivierter Impfstoff, der über sekretorische Antikörper die Kolonisation und die Toxinwirkung im Intestinaltrakt verhindert. Dieser Impfstoff ist für die Prophylaxe der ETEC-Reisediarrhö in Deutschland nicht zugelassen (aber in der Schweiz). Eine limitierte Risikoreduktion ist bei Reisenden in der Prophylaxe der Reisediarrhö mit einer Impfeffektivität von $28 \%$ gezeigt worden [244]. Bei folgenden Risikogruppen kann der Impfstoff in Betracht gezogen werden: z. B. Reisende mit CED, Immunsupprimierte, eingeschränkte oder reduzierte Magensäuresekretion (Protonenpumpeninhibitorlangzeittherapie), Neigung zu rezidivierenden Episoden einer Reisediarrhö, chronische Erkrankungen mit erhöhtem Komplikationsrisiko [245].

\section{K-6 Morbus Whipple (AG 6)}

\section{Präambel}

Der Erreger Tropheryma whipplei ist in der Umwelt, z. B. in Abwässern, weit verbreitet. Neuere molekulargenetische Untersuchungen und die kulturelle Aufzucht des Erregers haben wesentlich zum Verständnis der Infektion mit $T$. whipplei beigetragen. So konnte festgestellt werden, dass bei etwa $2-4 \%$ der Bevölkerung eine asymptomatische Kolonisierung des Darmlumens vorliegt. Bei Kindern wurde eine akute, selbstlimitierende Infektion mit akuter Gastroenteritis, respiratorischen Symptomen und Fieber beschrieben. Daneben ist in den letzten Jahren auch über lokalisierte Formen der T. whipplei Infektion, z. B. an Herzklappen oder im ZNS berichtet worden. Bis dahin war die Infektion mit T. whipplei nur im Kontext des 1907 von George Hoyt Whipple beschriebenen Morbus Whipple bekannt. Die häufigsten Erscheinungen des M. Whipple sind gastrointestinale Symptome, Gelenkbeschwerden und eine Reihe systemischer Manifestationen. Genaue Zahlen zur Epidemiologie liegen nicht vor, der M. Whipple gilt jedoch als sehr selten. Bisherige Empfehlungen zur Diagnostik und Therapie stützen sich auf Beobachtungen, die rückblickend durch Beschreibung kleinerer oder größerer Fallserien gewonnen wurden, am umfassendsten in der Arbeit von W.O. Dobbins anhand von 696 Patienten [246]. Seit 2010 liegen auch prospektiv gewonnene Daten zur klinischen Präsentation und zur Therapie des M. Whipple vor [247, 248]. Die im Rahmen von zwei Studien gewonnenen Befunde vermögen natürlich nicht, das gesamte Spektrum der Krankheit abzudecken, weshalb Übersichtsartikel und Expertenmeinungen weiterhin eine Rolle spielen. Die Leitlinien versuchen, diesem unvollständigen Kenntnisstand gerecht zu werden. Es ist in jedem Fall empfehlenswert, sich bei Verdacht auf M. Whipple mit einem Zentrum in Verbindung zu treten, das über Erfahrung bei diesem Krankheitsbild verfügt, um die Vielzahl der diagnostischen Maßnahmen optimal einzusetzen.

\section{Empfehlung 6.1: Symptome}

Bei folgenden Symptomen ungeklärter Ursache soll nach Ausschluss anderer, insbesondere häufigerer Ursachen an einen M. Whipple/Infektion mit T. whipplei gedacht werden:

- Kombination von Arthritis, Gewichtsabnahme und chronischer Diarrhö

- chronische seronegative Arthritis

- kulturnegative Endokarditis

- Blicklähmung und Myoklonus

[Konsensusstärke: starker Konsens, starke Empfehlung]

\section{Kommentar}

Meist gehen die Arthralgien den enteritischen Beschwerden jahrelang voraus. Jedoch können, teils isoliert, teils in Kombination, auch andere Symptome auftreten ( $\bullet$ Tab. 13), bei denen nach Ausschluss häufigerer Ursachen auch an einen M. Whipple gedacht werden sollte [249 - 251]. Patienten mit einem M. Whipple sind bei Diagnosestellung im Durchschnitt 55 Jahre alt [247, 248]. Eine Erkrankung von Patienten unter 30 Jahren ist unwahrscheinlich. Früher wurde der M. Whipple bevorzugt bei Männern beobachtet (Ratio $\mathrm{M}: \mathrm{F}=8: 1$ ), in neueren Studien ist dieses Verhältnis geringer (Ratio $\mathrm{M}: \mathrm{F}=$ eher 3:1) [248, 251]. Erhöhte Inflammationsparameter finden sich häufig; ein normaler BSGoder CRP-Wert schließt einen M. Whipple jedoch nicht aus. Reduzierte IgG2 und erhöhte IgM-Konzentrationen im Serum wurden bei M. Whipple Patienten beschrieben, können aber nicht als diagnostische Parameter gewertet werden [252]. Eine weitere Manifestation kann eine kulturnegative Endokarditis sein, die ebenfalls in Kombination mit anderen Symptomen oder isoliert auftreten kann $[253,254]$. Die Diagnose der durch T. whipplei

Tab. 13 Weitere mögliche Manifestationen des M. Whipple.

\begin{tabular}{|c|c|c|c|}
\hline & gastrointestinale Symptome & systemische Symptome & ZNS-Manifestationen \\
\hline häufig & $\begin{array}{l}\text { chronischer Durchfall } \\
\text { Gewichtsverlust } \\
\text { Malabsorption }\end{array}$ & $\begin{array}{l}\text { abdominelle, periphere oder thorakale Lymphknoten- } \\
\text { vergrößerung } \\
\text { Kachexie } \\
\text { chronisch entzündliches Syndrom (Erhöhung von BSG, } \\
\text { CRP, Hb-Abfall, Thrombozytose) }\end{array}$ & $\begin{array}{l}\text { Blicklähmung } \\
\text { Myoklonus }\end{array}$ \\
\hline $\begin{array}{l}\text { weniger } \\
\text { häufig }\end{array}$ & rezidivierende Bauchschmerzen & $\begin{array}{l}\text { chronisches, rekurrentes Fieber } \\
\text { Serositis } \\
\text { Aszites } \\
\text { periphere Ödeme } \\
\text { Hypalbuminämie } \\
\text { Tendosynovitis } \\
\text { Myalgien } \\
\text { chronischer Husten }\end{array}$ & $\begin{array}{l}\text { Gedächtnisstörung } \\
\text { Ataxie } \\
\text { psychiatrische Veränderungen }\end{array}$ \\
\hline selten & $\begin{array}{l}\text { okkultes Blut, rezidivierende gas- } \\
\text { trointestinale Blutungen }\end{array}$ & $\begin{array}{l}\text { Hepatomegalie } \\
\text { Splenomegalie } \\
\text { Hautveränderungen Hyperpigmentation } \\
\text { entzündliche Veränderungen am Auge }\end{array}$ & $\begin{array}{l}\text { gestörter Schlaf-Wachrhythmus } \\
\text { Hyperphagie }\end{array}$ \\
\hline
\end{tabular}


verursachten kulturnegativen Endokarditis erfolgt in der Regel nach dem Herzklappenersatz, da der Erregernachweis erst aus dem entfernten Gewebe mittels Histologie oder PCR erfolgen kann [255].

\section{Empfehlung 6.2: Diagnose}

Bei Verdacht auf M. Whipple soll als erste diagnostische Maßnahme eine Ösophagogastroduodenoskopie (ÖGD) mit Entnahme von Duodenalbiopsien erfolgen. Folgende histopathologische Untersuchungen sollten durchgeführt werden:

- Biopsie aus der Duodenalschleimhaut und PAS-Färbung (zur zusätzlichen Durchführung einer PCR, siehe Empfehlung 6.4)

[Konsensusstärke: Konsens, starke Empfehlung]

\section{Empfehlung 6.3: Diagnose}

Bei folgenden Endoskopiebefunden sollen Duodenalbiopsien erfolgen:

- Weißlich-gelbliche Mukosaveränderungen, histologisch

Lymphzysten in der Duodenalschleimhaut

- Erkennbare Zottenabflachung

[Konsensusstärke: Konsens, starke Empfehlung]

\section{Kommentar}

Der Nachweis von Makrophagen, die große Mengen an diastaseresistenten Periodic acid-Schiff (PAS)-positiven Partikeln enthalten, gilt nach wie vor als Diagnosestandard eines M. Whipple, der immer primär eingesetzt werden soll [256, 257]. Eine Ziehl-Neelsen-Färbung sollte in jedem Fall zum Ausschluss einer atypischen mykobakteriellen Infektion durchgeführt werden.

In vielen Fällen von M. Whipple sind im Rahmen einer Endoskopie keine makroskopischen Auffälligkeiten der duodenalen Mukosa zu erkennen, jedoch können weißlich-gelbliche Mukosaveränderungen in der Duodenalschleimhaut und eine erkennbare Zottenabflachung in der Zoomendoskopie oder Mosaikmuster bei der Chromoendoskopie ein Hinweis auf einen M. Whipple sein. Erythematöse und/oder erosive Veränderungen im Duodenum sind nicht typisch. Bei jedem klinischen Verdacht sollen mehrere, (am besten $\geq 5$ ) Biopsien an verschiedenen Stellen entnommen werden, da die Infiltration durch Makrophagen fleckförmig sein kann. Bei fehlenden gastrointestinalen Symptomen, auffälligen endoskopischen Befunden oder einem klinischen Verdacht, der sich durch extraintestinale Symptome begründet, sollten ebenfalls Biopsien entnommen werden, da eine histologische Untersuchung positiv ausfallen kann [249, 251].

\section{Empfehlung 6.4: Diagnose}

Bei histopathologischer Verdachtsdiagnose sollte eine Bestätigung durch einen in der Diagnostik des M. Whipple erfahrenen Pathologen mit einer Subtypenklassifizierung der Makrophagen sowie eine PCR durchgeführt werden.

[Konsensusstärke: Konsens, Empfehlung]

Die PCR sollte durch eine Sequenzierung oder eine zweite spezifische PCR bestätigt werden.

[Konsensusstärke: Konsens, Empfehlung]

Ein M. Whipple sollte nicht allein aufgrund einer positiven PCR aus Lunge oder Verdauungstrakt (einschließlich Mundhöhle) diagnostiziert werden.

[Konsensusstärke: Konsens, Empfehlung]

\section{Kommentar}

Bei der Histopathologie sollten PAS-positive Zellen nach der Einteilung von Herbay klassifiziert werden. Erst das Verschwinden von Makrophagen vom Typ 1 und das Erscheinen von Makrophagen vom Typ 2 - 4 dokumentieren den Erfolg der Therapie. PASpositive Zellen in der Darmschleimhaut sind oft jahrelang nach erfolgreicher Therapie nachzuweisen [257]. Da diese Klassifizierung der PAS-positiven Makrophagen Erfahrung erfordert, ist es sinnvoll, die Proben von einem in der Diagnose des M. Whipple versierten Pathologen begutachten zu lassen. Die T. whipplei-spezifische PCR hat diagnostisch große Bedeutung erlangt [258261]. Aussagekräftig wird sie in akkreditierten Laboratorien durchgeführt, die das Ergebnis durch Sequenzierung und/oder die Analyse verschiedener T. whipplei Gene bestätigen, um falsch positive Ergebnisse durch unspezifische Amplifikationen zu vermeiden.

Beim Vorliegen einer charakteristischen Klinik und einem eindeutigen mikroskopischen Befund wurde die Notwendigkeit einer T. whipplei-spezifischen PCR kontrovers diskutiert, die Mehrheit der Konsensuskonferenz (86\% der Teilnehmer) war dennoch für die Empfehlung einer PCR. Auf das Minderheitsvotum im Anschluss wird verwiesen. Bei klinischem Verdacht auf M. Whipple aber mikroskopischen Befunden, die weniger charakteristisch oder schwierig zu beurteilen sind, kann eine positive T. whipplei-spezifische PCR die Diagnose absichern.

Eine PCR ist in dieser Situation sinnvoll, da PAS-positive Zellen auch andere Ursachen haben können. Bei negativer PCR gilt es zu bedenken, dass ein M. Whipple vorliegen könnte, der im Vorfeld antibiotisch (an-)behandelt worden ist [247, 248, 251]. In jedem Fall sollte abgeklärt werden, ob eine für einen M. Whipple suffiziente antibiotische Behandlung vorangegangen ist, da auch eine nicht ausreichende Therapie zur negativen PCR von Duodenalbiopsien führen kann. Es ist unbedingt empfehlenswert, bei nicht eindeutiger, konventioneller Histologie ein in der M. Whipple Diagnostik erfahrenes Zentrum zu konsultieren. Dort kann zur Klärung zusätzlich die T. whipplei-spezifische Immunhistochemie eingesetzt werden. Alternativ können zur Absicherung der Diagnose Proben von anderen Geweben evaluiert werden. Ein positives Ergebnis einer T. whipplei-spezifischen PCR in der Dünndarmbiopsie (oder anderen Oberflächen, die mit der Umwelt in Kontakt treten) ohne korrespondierenden klinischen Verdacht kann irreführend sein. Eine alleinige positive PCR beweist per se keineswegs einen aktiven, behandlungsbedürftigen M. Whipple, da auch eine Kolonisierung des Darmlumens mit T. whipplei ohne invasive Infektion, die bei $2-4 \%$ der gesunden Bevölkerung Europas beobachtet wurde, oder eine akute $T$. whipplei-induzierte Gastroenteritis, zu einem positiven Ergebnis der PCR führen kann. Höhere Raten asymptomatischer fäkaler Ausscheider von T. whipplei sind bei Personen mit erhöhter Exposition oder unter schlechten hygienischen Bedingungen beschrieben worden, da der Erreger offensichtlich von Mensch zu Mensch übertragen wird [262-264]. Diese Infektionen sind in der Regel selbstlimitierend, und ein M. Whipple entwickelt sich nur in den seltensten Fällen. Eine luminale Besiedelung kann aber auch bei Patienten mit M. Whipple nach wirksamer antibiotischer Therapie vorkommen. Selbst beim Zusammentreffen einer positiven PCR und PAS-positiven Makrophagen in der Biopsie ist eine erneute Antibiotikatherapie dann nicht angezeigt, wenn bei fehlender Klinik lediglich Makrophagen der Subtypen 2-4 persistieren. Im Gegensatz zur Diagnostik aus dem Gastrointestinaltrakt und der Lunge ist die T. whipplei-spezifische PCR bei der Diagnostik in Körperflüssigkeiten (Liquor, Syno- 
vialflüssigkeit, Pleuraerguss, Ascites, etc.) bei antibiotisch nicht vorbehandelten Patienten eindeutig und unersetzlich.

\section{Minderheitsvotum zu Empfehlung 6.4}

\section{Hintergrund}

Der Empfehlung von 86\% der Mitglieder der Konsensuskonferenz, dass bei der Diagnostik eines M. Whipple mittels Dünndarmbiopsie in jedem Fall eine PCR zum Nachweis von T. whipplei durchgeführt werden sollte, können sich der Leiter der Whipple-Studie (G.E.F.) und die für diese Studie verantwortlichen Pathologen (Hendrik Bläker und Christoph Loddenkemper) nicht anschließen. Da bei der Kosten-Nutzen-Abwägung einer routinemäßig durchgeführten T. whipplei-spezifischen PCR in der Dünndarmbiopsie der finanzielle Aufwand beträchtlich, der Zusatznutzen aber gering ist, und da zudem ein Risiko von Fehlinterpretation und Verzögerung des Therapiebeginns besteht, sollte eine T. whipplei-spezifische PCR in der Dünndarmbiopsie nicht regelhaft, sondern lediglich bei diagnostischen Unklarheiten angefordert werden.

Primärdiagnose:

Typische Klink, keine antibiotische Vorbehandlung, charakteristischer mikroskopischer Befund durch einen infektiologisch geschulten Pathologen: Zottenverplumpung, massenhaft, intensiv angefärbte PAS-positive Makrophagen in der Lamina propria mit grob-granulärem Zytoplasma entsprechend einem Subtyp 1 nach von Herbay $[256,257]$ und eine negative Ziehl-Neelsen-Färbung zum Ausschluss einer Mykobakteriose sichern die Diagnose eines M. Whipple auf der Basis der Histologie. Die Indikation zur Therapie ist ohne direkten Erregernachweis gegeben. Der Zusatznutzen der PCR ist gering, zudem sind Kosten (GOÄ Ziffern 4780, 4783 und 4787 für Isolierung, PCR und Sequenzierung; Faktor 1,15, insgesamt: 227,90 Euro) zu berücksichtigen. Der Aufwand vergrößert sich, wenn Endoskopie und Biopsie für die PCR wiederholt werden müssen. Das Warten auf das PCR-Ergebnis verzögert zudem den Beginn der Therapie. Naturgemäß erreichen die Empfehlungen in Leitlinien hier Grenzen; eine PCR der Dünndarmbiopsie bei der Diagnosestellung kann auch hilfreich und wegweisend sein. Die Konsultation eines der Zentren, welches an der Whipplestudie beteiligt war, kann sinnvoll sein $[247,248]$. Wenn notwendig kann die PCR im pathologischen Speziallabor aus in paraffineingebettetem Material nachgeholt oder eine Immunhistochemie durchgeführt werden. Verlaufskontrolle:

Wenn nach evidenzbasierter Antibiotikatherapie Krankheitssymptome und Entzündungswerte rückläufig sind, und in der Dünndarmschleimhaut die Anzahl der PAS-positiven Makrophagen abnimmt, deren Zytoplasma zudem nicht mehr granulär ist (Übergang zu den Subtypen 2-4 nach von Herbay), lässt sich ein Erfolg der Behandlung absehen, der durch weitere Beobachtung gesichert werden kann. Eine PCR verursacht Kosten (s. o.!) und unterscheidet nicht Rezidiv von luminaler Kolonisierung. Dabei besteht die Gefahr, dass ein positives Ergebnis der PCR als Indikation zu einer erneuten antibiotischen Therapie fehlinterpretiert wird. Das Risiko falscher Interpretation steigt in dem Maße, indem die PCR zur Voraussetzung der Diagnose gemacht wird.

\section{Empfehlung 6.5: Diagnose}

Wenn bei negativem histologischen Duodenalbefund weiterhin der Verdacht auf einen M. Whipple besteht, sollten in Abhängigkeit von den klinischen Befunden weitere Proben untersucht werden.

[Konsensusstärke: Konsens, Empfehlung]

\section{Kommentar}

Besonders bei isolierten Infektionen mit $T$. whipplei, die sich mit zentralnervösen Symptomen, als chronische seronegative Arthritis, mit Lymphadenopathie, Tendosynovitis oder Myalgien und seltener als Infektionen von Auge oder Lunge manifestieren können, kann die Analyse duodenaler Biopsien negativ ausfallen. In diesen Fällen sollten andere diagnostische Proben herangezogen werden [249, 265, 266]. Der Nachweis von PAS-positiven Zellen kann neben Proben aus dem Gastrointestinaltrakt (Antrum, Jejunum, Ileum) auch aus soliden Organen oder Geweben wie z. B. Lymphknoten, Synovialgewebe, resezierten Herzklappen, Haut oder Knochenmark erfolgen. In Proben aus dem Kolon oder ZNS sind die PAS-Färbungen allerdings meist unspezifisch oder schwer zu beurteilen und deshalb nicht als alleinige diagnostische Untersuchung zu empfehlen. Die PCR sollte im Rahmen einer weiterführenden Diagnostik aus PAS-positiven Proben zur Bestätigung erfolgen. Sie ist von besonderer diagnostischer Bedeutung bei der Untersuchung aller sterilen Flüssigkeiten wie z. B. Liquor, Synovialflüssigkeit, Augenkammerflüssigkeit und anderen serösen Körperflüssigkeiten, aber auch von ZNS-Biopsien.

\section{Empfehlung 6.6: Diagnose}

Eine PCR-Untersuchung aus dem Liquor soll vor Beginn der antibiotischen Behandlung bei jedem Patienten mit M. Whipple durchgeführt werden.

[Konsensusstärke: starker Konsens, starke Empfehlung]

\section{Kommentar}

Aufgrund der häufigen asymptomatischen ZNS-Beteiligung (bis $50 \%$ im Rahmen des M. Whipple ist eine T. whipplei-spezifische PCR aus dem Liquor in jedem Fall - auch bei der Abwesenheit einer zerebralen Symptomatik - vor Initiierung der Behandlung indiziert. Ein positiver Liquor soll im Verlauf der Therapie kontrolliert werden und sollte in jedem Fall negativ werden $[247,251]$.

\section{Empfehlung 6.7: Diagnose}

Folgende diagnostische Maßnahmen sind für die Diagnose des M. Whipple nicht zielführend und sollten nicht durchgeführt werden:

- Faeces: PCR

- Mundhöhle/Speichel: PCR

- Kolon: Mukosabiopsie

- Hirnbiopsie: PAS-Färbung

[Konsensusstärke: starker Konsens, Empfehlung]

\section{Kommentar}

Da es gesunde Ausscheider von T. whipplei gibt, ist eine isolierte PCR aus Proben von Grenzflächen, an der der Mensch mit der Umwelt in einem engen Kontakt steht (Gastrointestinaltrakt, Atemtrakt), nicht zielführend für die Diagnose eines M. Whipple [260, 262, 264]. Zwar wird in spezialisierten Forschungslaboren der Faeces- und Speichel-PCR ein gewisser Stellenwert zugesprochen, der aber noch international definiert werden muss. PASFärbungen von Kolon- und ZNS-Biopsien sind oft unspezifisch positiv und daher nicht aussagekräftig für die M. Whipple Diagnostik. 


\section{Empfehlung 6.8: Therapie}

Die Behandlung eines Patienten mit M. Whipple sollte in Absprache mit einem darin erfahrenen Therapeuten erfolgen.

[Konsensusstärke: starker Konsens, Empfehlung]

Bei M. Whipple soll eine Antibiotikatherapie mit Ceftriaxon/ Cotrimoxazol durchgeführt werden.

[Konsensusstärke: starker Konsens, starke Empfehlung]

\section{Kommentar}

Aufgrund der Seltenheit der Erkrankung, den häufigen untypischen klinischen Bildern, sowie der Erfahrung einzelner Zentren sollte die Behandlung des M. Whipple mit erfahrenen Therapeuten abgestimmt werden.

Die derzeit empfohlene antibiotische Therapie bei M. Whipple besteht in der Gabe von Ceftriaxon $2 \mathrm{~g}$ täglich i. v. über 14 Tage, gefolgt von Cotrimoxazol $960 \mathrm{mg} 2 \times 1$ täglich per os über $1 \mathrm{Jahr}$. Die Kombination von Ceftriaxon und Cotrimoxazol hat sich in zwei prospektiven Behandlungsstudien als wirksam erwiesen [247, 248]. Eine 12-monatige Verabreichung von Cotrimoxazol wird empfohlen, da diese in einer prospektiv randomisierten Studie überprüft wurde. Eine 3-monatige Gabe führt zu gleichen Therapieergebnissen, dieses stützt sich jedoch auf eine retrospektive Auswertung und besitzt somit eine niedrigere Evidenz. Details der Studien zu den empfohlenen Therapieregimen und zu weiteren Therapieprotokollen sind in $\bullet$ Tab. 14 dargestellt.

In Einzelfällen sind Therapieversuche mit verschiedenen anderen Präparaten als Mono- oder Kombinationstherapie durchgeführt worden. Eine generelle Nutzenbewertung ist aufgrund der unzureichenden Datenlage nicht möglich [268, 269]. Bei zerebrospinaler Infektion, selbst falls sie asymptomatisch ist, sollten wegen der ungünstigen Prognose alle Therapiemöglichkeiten ausgeschöpft werden. Im Falle eines Patienten einer therapierefraktären, zerebrospinalen Manifestation hat sich die Therapiekombination von Minocyclin und Chloroquin als wirksam erwiesen [270].

\section{Arzneimittelunverträglichkeit}

Bei Unverträglichkeit von Ceftriaxon sollte Meropenem und bei Unverträglichkeit von Cotrimoxazol sollte Doxycyclin verabreicht werden. Eine Unverträglichkeit von Ceftriaxon, die dazu führt, dass das Präparat abgesetzt werden muss, ist unwahrscheinlich. Allerdings kann es zu einer möglicherweise kristallinduzierten Cholezystitis, kommen. Eine Unverträglichkeit von Cotrimoxazol kommt häufiger vor. Unter Doxycyclin beobachtet man nicht selten eine phototoxische Dermatitis.

\section{Jarisch-Herxheimer-Reaktion}

Eine seltene, hoch fieberhafte Komplikation ist die JarischHerxheimer-Reaktion (JHR). Dabei tritt Fieber unmittelbar nach der erstmaligen Gabe von Antibiotika auf und hält meist bis zu 48 Stunden an. Außer eventuell antipyretischen Maßnahmen besteht keine Indikation zur Therapie. Eine JHR sollte nicht mit einem inflammatorischen Immunrekonstitutionssyndrom (IRIS) verwechselt werden (s. Empfehlung 6.9).

\section{Therapieresistenz}

Therapieresistente zentralnervöse Infektionen werden nicht selten beschrieben [249]. Angaben zur Häufigkeit in einem nicht selektionierten, ausreichend antibiotisch behandelten Patienten-

Tab. 14 Therapieprotokolle bei M. Whipple.

\section{Intervention und ggf. Kontrollgruppe}

\section{Studiendesign}

\section{- prospektiv randomisiert}

- 40 Patienten

- Nachbeobachtung 89

(71 - 126) Monate

\section{Ergebnis/Signifikanz \\ Rezidivrate, Komplikationen}

\begin{tabular}{|c|c|c|c|}
\hline $\begin{array}{l}\text { intravenöse initiale The- } \\
\text { rapie gefolgt von oraler } \\
\text { Therapie über } 1 \text { Jahr } \\
\text { [247] }\end{array}$ & $\begin{array}{l}\text { Ceftriaxon } 2 \mathrm{~g} \text { tgl. i. v. über } 14 \text { Tage } \\
\text { gefolgt von Cotrimoxazol } 960 \text { mg } 2 \times \text { tgl. } \\
\text { per os über } 1 \text { Jahr } \\
\text { gegen } \\
\text { Meropenem } 3 \times 1 \mathrm{~g} \mathrm{tgl.} \mathrm{i.} \mathrm{v.} \mathrm{über} 14 \text { Tage } \\
\text { gefolgt von Cotrimoxazol } 960 \text { mg } 2 \times \text { tgl. } \\
\text { per os über } 1 \text { Jahr }\end{array}$ & $\begin{array}{l}\text { - prospektiv randomisiert } \\
\text { - } 40 \text { Patienten } \\
\text { - Nachbeobachtung } 89 \\
\text { (71-126) Monate }\end{array}$ & $\begin{array}{l}\text { - } 37 \text { Patienten rezidivfrei } \\
\text { - } \text { kein signifikanter Unterschied ob Ceftria- } \\
\text { xon oder Meropenem in der Initialtherapie } \\
\text { - } 1 \text { therapieresistente ZNS-Infektion } \\
\text { - } 2 \text { Todesfälle (Herzinfarkt, Aspirations- } \\
\text { pneumonie) }\end{array}$ \\
\hline \multicolumn{4}{|c|}{ alternative Therapieprotokolle } \\
\hline $\begin{array}{l}\text { intravenöse initiale The- } \\
\text { rapie gefolgt von oraler } \\
\text { Therapie über } 3 \text { Monate } \\
\text { [248] }\end{array}$ & $\begin{array}{l}\text { Ceftriaxon } 2 \mathrm{~g} 1 \times \text { tgl. i. v. über } 14 \text { Tage } \\
\text { gefolgt von } \\
\text { Cotrimoxazol } 960 \mathrm{mg} 2 \times \text { tgl. per os über } \\
3 \text { Monate }\end{array}$ & $\begin{aligned} \text { - } & \text { prospektiv } \\
\text { - } & 40 \text { Patienten, } \\
\text { - } & \text { Nachbeobachtung } 80 \\
& \text { (54 - 103) Monate }\end{aligned}$ & $\begin{array}{l}\text { - } 36 \text { Patienten rezidivfrei } \\
\text { - } \text { kein signifikanter Unterschied zu } 12 \text { Mo- } \\
\text { naten Cotrimoxazol } \\
\text { - } 1 \text { Rezidiv im Kniegelenk nach } 63 \text { Monaten, } \\
\text { - } 3 \text { Todesfälle (IRIS, Candidasepsis, Pneu- } \\
\text { monie). }\end{array}$ \\
\hline orale Therapie [267] ${ }^{1}$ & $\begin{array}{l}\text { unterschiedliche Dauer und Kombinatio- } \\
\text { nen; alle mit Doxycyclin } 100 \text { mg } 2 \times \text { tgl. } \\
\text { per os + Hydroxychloroquin } 200 \text { mg } 3 \times \\
\text { tgl. per os Im Anschluss meist Doxycyclin } \\
\text { lebenslang }{ }^{1}\end{array}$ & $\begin{aligned} \text { - } & \text { Fallserie } \\
\text { - } & 29 \text { Patienten } \\
\text { - } & \text { Nachbeobachtung } 59 \\
& (1 \text { - 125) Monate }\end{aligned}$ & $\begin{array}{l}\text { - } 24 \text { Patienten rezidivfrei } \\
\text { - } 3 \text { Patienten beim Follow-up verloren } \\
\text { - } 1 \text { Patient mit Uveitis (non-compliance) } \\
\text { - } 1 \text { Todesfall }\end{array}$ \\
\hline $\begin{array}{l}\text { orale Therapie über } \\
12 \text { Monate }\end{array}$ & $\begin{array}{l}\text { Doxycyclin } 100 \text { mg } 2 \times \text { tgl. per os + Hy- } \\
\text { droxy-chloroquin } 200 \text { mg } 2 \times \text { tgl. per os } \\
\text { über } 1 \text { Jahr } \\
\text { (bei ZNS Befall zusätzlich Cotrimoxazol²) } \\
\text { gegen } \\
\text { empfohlene Standard-therapie (siehe } \\
\text { oben) }\end{array}$ & $\begin{aligned} & \text { - } \text { prospektiv randomisiert } \\
& \text { - bisher } 23 \text { Patienten } \\
& \text { - Nachbeobachtung } 27 \\
& \text { ( } 2 \text { - } 45 \text { ) Monate ( } 24 \text { Mo- } \\
& \text { nate sind vorgesehen) }\end{aligned}$ & $\begin{array}{l}\text { - ein Ergebnis liegt noch nicht vor } \\
\text { - Patienten können noch aufgenommen } \\
\text { werden } \\
\text { - Ansprechpartner ist Studienleiter Prof. Dr. } \\
\text { Dr. Thomas Schneider, Med. Klinik I der } \\
\text { Charité -Universitätsmedizin Berlin, } \\
\text { Campus Benjamin Franklin }\end{array}$ \\
\hline
\end{tabular}

14 Patienten initial Cotrimoxazol (1 - 24 Monate; je 7 mit und ohne initiale intravenöse Therapie) nach Rezidiven oder Resistenzentwicklung gefolgt von Doxycyclin + Hydroxychloroquin bei 12 und Doxycyclin + Hydroxychloroquin + Sulfadiazin bei 2 Patienten (7 - 48 Monate); 8 Patienten Doxycyclin + Hydroxychloroquin ( 5 - 84 Monate); 5 Patienten mit ZNS Befall Doxycyclin + Hydroxychloroquin + Cotrimoxazol/Sulfadiazin (12 - 36 Monate); je 1 Patient Doxycyclin + Hydroxychloroquin + Rifampicin (1 Monat) und nur Doxycyclin (96 Monate); bei 22 Patienten im Anschluss Doxycyclin lebenslang (1 - 48 Monate).

2 Bei ZNS Befall zusätzlich: 960 mg Cotrimoxazol 5 ×tgl. bis Liquor PCR negativ, dann $2 \times$ tgl. per os. 
kollektiv sind nicht erhältlich. Im Rahmen der oben genannten Therapiestudien wurde unter Ceftriaxon/Meropenem/Cotrimoxazol bei einem Patienten eine therapieresistente zentralnervöse Infektion festgestellt [270]. Eine persistierende zentralnervöse Infektion sollte von irreversiblen zerebralen Defekten nach erfolgreicher antibiotischer Therapie unterschieden werden. Eine Therapieresistenz auf die Kombination Ceftriaxon und Cotrimoxazol in extrazerebralen Organsystemen ist in Studien bislang nicht publiziert worden, jedoch sind bei einer Monotherapie mit Cotrimoxazol Resistenzentwicklungen gegen den einzig wirksamen Bestandteil Sulfamethoxazol beschrieben worden [271].

\section{Rezidive, Neuinfektion}

Nach Literaturdaten können Rezidive noch nach Jahren auftreten und betreffen häufiger das ZNS. Allerdings lässt sich in früheren Berichten über Rezidive nicht immer klären, ob die ursprüngliche Antibiotikatherapie ausreichend gewesen war. In der prospektiven Therapiestudie wurde während einer durchschnittlich siebenjährigen Nachbeobachtungszeit bei 80 Patienten lediglich eine rezidivierende T. whipplei-Arthritis beobachtet [248].

Rezidive sind durch unterschiedliche Stämme von T. whipplei möglich. Eine Neuinfektion mit einem anderen Genotyp kann ohne spezielle Untersuchungen nicht von einem Rezidiv unterschieden werden [272].

\section{Assoziierte Krankheitsbilder}

Vereinzelt wurden in der Literatur Assoziationen mit Lymphomen, Amyloidose, Candidasepsis sowie häufiger mit Gardia lamblia Infektion berichtet [273].

\section{Sterblichkeit}

In der präantibiotischen Ära vor 1952 scheint der M. Whipple in allen Fällen tödlich verlaufen zu sein. Sichere Daten zur Sterblichkeit bei ausreichend antibiotisch behandelten Patienten sind nicht erhältlich. In den beiden prospektiven Therapiestudien starben fünf der 80 Patienten [247, 248]. Bei zweien war die T. whipplei-Infektion indirekt als Todesursache zu werten.

\section{Empfehlung 6.9: Entziundliches \\ Immunrekonstitutionssyndrom (IRIS)}

Bei Wiederauftreten entzündlicher Symptome unter und nach Therapie soll an ein entzündliches Immunrekonstitutionssyndrom (Immune Reconstitution Inflammatory Syndrome = IRIS) gedacht werden. Dies betrifft insbesondere Patienten mit vorhergegangener immunsuppressiver Therapie oder ZNS-Befall. Zur Diagnostik und Therapie (z. B. Steroide) soll ein erfahrenes Zentrum zu Rate gezogen werden.

[Konsensusstärke: starker Konsens, starke Empfehlung]

\section{Hintergrund}

Die Diagnose eines entzündlichen Immunrekonstitutionssyndrom (Immune Reconstitution Inflammatory Syndrome=IRIS) bei Morbus Whipple kann bei Vorliegen von drei Kriterien gestellt werden [274]:

1. Ansprechen auf die antibiotische Therapie innerhalb von 3 Wochen.

2. Wiederauftreten systemischer oder lokaler Entzündung länger als eine Woche anhaltend, ohne Anhalt für andere Ursachen (z.B. Infektion, manifest werdender Tumor, allergische Reaktion, etc.).

3. Wirksamkeit der antibiotischen Therapie, nachgewiesen durch Histologie (Subtypen) und PCR.

In einer Kohorte von 142 Patienten mit M. Whipple war bei $10 \%$ der Patienten ein IRIS festzustellen. Mögliche Manifestationen ei- nes IRIS bei M. Whipple sind Fieber, Polyarthritis, Orbitopathie mit Erblindung, Dünndarmperforation, hypothalamisches Syndrom, Erythema nodosum, Pleuritis, Meningitis, Hirnabszess oder Endokarditis. Ein IRIS kann noch Jahre nach der initialen Antibiotikatherapie auftreten und letal verlaufen. Für ein Wiederauftreten entzündlicher Symptome während und nach antibiotischer Therapie war ein IRIS häufiger verantwortlich als ein Therapieversagen. Ein erhöhtes Risiko besteht vornehmlich, aber nicht ausschließlich, bei Patienten mit vorhergegangener immunsuppressiver Therapie oder mit schwerem ZNS-Befall [274]. Erfahrungen zur Therapie eines IRIS zeigen, dass eine rechtzeitige Identifizierung von Risikopatienten, Antizipation beim Wiederauftreten von Entzündungszeichen während oder nach der antibiotischen Therapie und frühzeitiger Einsatz von Glukokortikoiden von Bedeutung sind. Eine vorbestehende Steroidmedikation darf während der antibiotischen Therapie nicht beendet werden. Bei Verdacht auf IRIS sollte frühzeitig ein Zentrum konsultiert werden.

\section{Empfehlung 6.10: Therapie}

Zur Verlaufskontrolle soll die Befund gebende Primärdiagnostik wiederholt werden.

[Konsensusstärke: starker Konsens, starke Empfehlung] Verlaufskontrollen sollten 6 und 12 Monate nach Behandlungsbeginn durchgeführt werden.

[Konsensusstärke: starker Konsens, Empfehlung]

Bei initial positivem Liquorbefund soll nach 12 Monaten eine Kontrolle erfolgen.

[Konsensusstärke: starker Konsens, starke Empfehlung] Klinische Verlaufskontrollen sollten lebenslang erfolgen. [Konsensusstärke: starker Konsens, Empfehlung]

\section{Hintergrund}

Während des ersten Jahres nach Beginn der Antibiotikatherapie sind Kontrolluntersuchungen notwendig, um zu prüfen, ob eine Remission erzielt wurde. Dabei steht die Beobachtung des klinischen Verlaufs im Vordergrund, unterstützt wird diese durch den Verlauf der ggf. erhöhten laborchemischen Entzündungsparameter. Bei intestinalem Befall sollte der endoskopisch-bioptische Befund nach 6 und 12 Monaten überprüft werden, vornehmlich mittels PAS-Färbung und Beurteilung von Zahl und zytologischem Aspekt der PAS-positiven Makrophagen. Im Vergleich zum Ausgangsbefund nimmt nach erfolgreicher Therapie während des ersten Jahres die Dichte der PAS positiven Makrophagen in der Lamina propria des Dünndarms ab, ihr Zytoplasma verliert die Granularität und wird blasser. Subtyp 1 verändert sich in Richtung Subtyp 3 oder 4 [257]. Eine persistierend positive T. whipplei-PCR in Biopsien der intestinalen Mukosa ist für sich allein kein Hinweis auf ein Therapieversagen (siehe die Abschnitte Diagnostik und Minderheitsvotum).

Bei Lymphknotenvergrößerung oder bei Endokarditis sollten neben klinischer und laborchemischer Verlaufsbeobachtung auch sonografische bzw. echokardiografische Kontrollen durchgeführt werden. Die Verlaufsbeurteilung einer T. whipplei-Arthritis erfolgt ebenfalls klinisch und laborchemisch durch Messung der Entzündungsparameter. Eine Kontrolle mittels T. whipplei-spezifischer PCR entfällt, wenn Lymphknoten nicht mehr vergrößert sind, bzw. keine Gelenkergüsse mehr bestehen.

Bei zerebrospinaler Manifestation mit positivem Liquorbefund soll neben der klinischen Beobachtung eine Verlaufskontrolle mittels Liquoruntersuchung und T. whipplei-spezifischer PCR nach 12 Monaten erfolgen. Abhängig vom klinischen Verlauf oder bei unklaren 
histologischen Befunden kann es notwendig werden, den Zeitraum von Kontrolluntersuchungen über ein Jahr hinaus zu verlängern. Die klinische Beobachtung eines jeden Patienten, der wegen M. Whipple behandelt worden ist, sollte wegen möglicher Spätrezidive oder Spätkomplikationen lebenslang erfolgen [272].

\section{Abkürzungsverzeichnis}

AIDS Acquired Immune Deficiency Syndrome (englisch für

AWMF "Arbeitsgemeinschaft der Wissenschaftlichen Medizinischen Fachgesellschaften e.V.

BfR Bundesinstitut für Risikobewertung

BSG Blutkörperchensenkungsgeschwindigkeit

CCFA Cycloserine Cefoxitin Fructose Agar

CDC Centers for Disease Control and Prevention

CED chronisch entzündliche Darmerkrankung

CDI Clostridium difficile-Infektion

CRP C-reaktives Protein

DGHM Deutsche Gesellschaft für Hygiene und Mikrobiologie

DGI Deutsche Gesellschaft für Infektiologie

DGIM Deutsche Gesellschaft für Innere Medizin

DGKH Deutsche Gesellschaft für Krankenhaushygiene e. V

DGP Deutsche Gesellschaft für Pathologie

DMARDs Disease modifying antirheumatic drugs

cAMP zyklisches Adenosinmonophosphat

CMV Cytomegalievirus

DAIG Deutsche AIDS-Gesellschaft e.V.

DTG Deutsche Gesellschaft für Tropenmedizin und Internationale Gesundheit

DGVS Deutsche Gesellschaft für Gastroenterologie, Verdauungs- und Stoffwechselerkrankungen

EAEC Enteroaggregative Escherichia coli

EHEC Enterohämorrhagische Escherichia coli

EIA/ELISA Enzymgekoppelter Immunadsorptionstest (engl. Enzyme Linked Immunosorbent Assay)

EIEC Enteroinvasive Escherichia coli

EPEC Enteropathogene Escherichia coli

ESCMID Europäische Gesellschaft für Klinische Mikrobiologie und Infektionskrankheiten

ETEC Enterotoxinbildende Escherichia coli

G-CSF Granulozytenkolonie stimulierender Faktor

GDH Glutamatdehydrogenase

GPGE Gesellschaft für Pädiatrische Gastroenterologie und Ernährung

HAART hochaktive antiretrovirale Therapie (englisch highly active antiretroviral therapy)

HIV Humanes Immundefizienzvirus (englisch human immunodeficiency virus)

HTLV Humanes T-lymphotropes Virus

HUS Hämolytisch-urämisches Syndrom

IDSA Infectious Diseases Society of America

IfSG Infektionsschutzgesetz

IRIS Inflammatorisches Immunrekonstitutionssyndrom (englisch Immune Reconstitution Inflammatory Syndrome)

JHR Jarisch-Herxheimer-Reaktion

KRINKO Kommission für Krankenhaushygiene und Infektionsprävention

MAC Mycobacterium avium-Komplex

MIQ mikrobiologisch-infektiologische Qualitätsstandards

NSAIDs nicht steroidale Antiphlogistika
ÖGD Ösophagogastroduodenoskopie

PAS Periodic Acid Schiff Reaktion

PCR Polymerase-Kettenreaktion (englisch Polymerase Chain Reaction)

PEG Paul-Ehrlich Gesellschaft für Chemotherapie e.V.

PPI Protonenpumpeninhibitor

RCT randomisierte kontrollierte Studie (englisch randomized controlled trial)

RKI Robert Koch-Institut

SHEA Society for Healthcare Epidemiology of America

SIRS systemisches inflammatorisches Responsesyndrom

SNP Einzelnukleotid-Polymorphismus (englisch Single

Nucleotide Polymorphism)

STEC Shigatoxin produzierende E. coli

STX Shigatoxin

VRE Vancomycin-resistente Enterokokken

VTEC Verotoxin produzierende E. coli

ZNS Zentralnervensystem

Weitere Mitglieder der Leitlinienkommission in alphabetischer Reihenfolge einschließlich Affiliation:

T. Andus ${ }^{21}$, C. Berg ${ }^{22}$, H. Bläker ${ }^{23}$, R. Duchmann ${ }^{24}$, S. Ebensberger ${ }^{18}$,

T. Feldt ${ }^{25}$, A. Flieger ${ }^{9}$, T. Frieling ${ }^{26}$, W. Heise ${ }^{27}$, M. Höhne ${ }^{9}$, D. Jaspersen ${ }^{28}$,

A. Jefremow ${ }^{29}$, B. Jensen ${ }^{25}$, I. Koop ${ }^{30}$, B. Lembcke ${ }^{31}$, C. Loddenkemper ${ }^{32}$,

C. Lübbert ${ }^{33}$, H. Matthes ${ }^{34}$, M. Menges ${ }^{35}$, J. Richter ${ }^{25}$, C. Spinner ${ }^{36}$,

H. Sudeck ${ }^{37}$, R. Vogelmann ${ }^{38}$, P. Walger ${ }^{39}$

\section{Institute}

Klinik für Innere Medizin IV, Zentrum für Infektionsmedizin und Krankenhaushygiene und IFB Sepsis und Sepsisfolgen, Universitätsklinikum Jena der Friedrich-Schiller-Universität Jena, Jena

2 Medizinische Klinik für Gastroenterologie, Infektiologie und Rheumatologie, Charité - Universitätsmedizin Berlin, Campus Benjamin Franklin, Berlin

3 DRK Krankenhaus Neuwied, Neuwied

${ }^{4}$ Abteilung Infektiologie, Klinik für Innere Medizin II, Universitätsklinikum Freiburg, Freiburg

5 Deutsche Gesellschaft für Gastroenterologie, Verdauungs- und Stoffwechselkrankheiten e.V. (DGVS), Berlin

6 Klinik für Gastroenterologie, Hepatologie und Infektiologie, Otto von Guericke Universität Magdeburg, Magdeburg

Abteilung für Innere Medizin, Krankenhaus Maria Hilf GmbH, Daun

Krankenhaushygiene, Klinikum München, München

Robert Koch-Institut, Berlin

10 Medizinische Klinik I mit Schwerpunkt Gastroenterologie, Infektiologie und Rheumatologie, Campus Benjamin Franklin, Charité Universitätsmedizin Berlin, Berlin

11 Institut für Medizinische Mikrobiologie und Hygiene, Universitätsklinikum des Saarlandes und Medizinische Fakultät der Universität des Saarlandes, Homburg

12 Medizinische Klinik und Poliklinik I, Universitätsklinikum Bonn, Bonn

13 Arbeitsgemeinschaft der Wissenschaftlichen Medizinischen Fachgesellschaften e.V. (AWMF), Philipps-Universität, Marburg

14 Medizinische Klinik, Universitätsklinikum Knappschaftskrankenhaus Bochum, Bochum

15 Klinik und Poliklinik für Innere Medizin, Abteilung für Tropenmedizin und Infektionskrankheiten, Universitätsmedizin Rostock, Rostock

16 Klinik und Poliklinik für Innere Medizin I, Universitätsklinikum Regensburg, Regensburg

17 I. Medizinische Klinik und Poliklinik, Universitätsklinikum Hamburg-Eppendorf, Hamburg

18 Klinik für Innere Medizin IV (Gastroenterologie, Hepatologie und Infektiologie), Universitätsklinikum Jena der Friedrich-Schiller-Universität Jena, Jena

19 Klinik für Gastroenterologie und Infektiologie, Klinikum Ernst von Bergmann $\mathrm{gGmbH}$, Potsdam

20 Institut für Medizinische Mikrobiologie und Krankenhaushygiene, Medizinische Hochschule Hannover, Hannover

21 Klinikum Stuttgart, Klinik für allgemeine Innere Medizin, Gastroenterologie, Hepatologie und internistische Onkologie, Stuttgart

22 Universitätsklinikum Tübingen, Abteilung Innere Medizin I, Hepatologie, Gastroenterologie, Infektiologie, Tübingen

23 Institut für Pathologie an der Charité, Berlin

24 Hospital zum heiligen Geist, Medizinische Klinik, Frankfurt am Main

25 Klinik für Gastroenterologie, Hepatologie und Infektiologie, Universitätsklinikum Düsseldorf, Düsseldorf 
26 Medizinische Klinik II (Gastroenterologie, Hepatologie, Neurogastroenterologie, Infektiologie, Hämatologie, Onkologie und Palliativmedizin), HELIOS Klinikum Krefeld, Krefeld

27 Evangelisches Krankenhaus Königin Elisabeth Herzberge gGmbH, Innere Medizin, Berlin

28 Medizinische Klinik II, Gastroenterologie, Infektiologie, Stoffwechselerkrankungen, Klinikum Fulda gAG, Fulda

29 Medizinische Klinik 1, Zentrum für Molekulare Entzündungs- und Tumorforschung, Universitätsklinikum Erlangen, Erlangen

30 Klinik für Allgemeine Innere Medizin, Gastroenterologie; Ev. Amalie Sieveking-Krankenhaus, Hamburg

31 Medizinische Klinik, St. Barbara-Hospital, Katholische Kliniken EmscherLippe GmbH, Gladbeck

32 Gemeinschaftspraxis für Pathologie „PathoTres“, Berlin

33 Klinik und Poliklinik für Gastroenterologie und Rheumatologie, Universitätsklinikum Leipzig, Leipzig

34 Klinik für Innere Medizin mit Schwerpunkt Gastroenterologie, Gemeinschaftskrankenhaus Havelhöhe gGmbH, Berlin

35 Klinik für Innere Medizin II: Gastroenterologie, Hepatologie, Diabetologie und Infektionskrankheiten, Diakonie-Klinikum Schwäbisch Hall gGmbH, Schwäbisch Hall

36 II. Medizinische Klinik, Klinikum rechts der Isar, Technische Universität München, München

37 Innere Medizin und Tropenmedizin, Bundeswehrkrankenhauses Hamburg am Bernhard-Nocht Institut, Hamburg

38 II. Medizinische Klinik, Universitätsmedizin Mannheim, Universität Heidelberg, Mannheim

39 Johanniter-Kliniken Bonn gGmbH, Johanniter-Krankenhaus, Internistische Intensivmedizin und Infektiologie, Bonn

Die Interessenkonflikte sind unter dem Link

www.dgvs.de/leitlinien/gastrointestinale-infektionen-und-mor bus-whipple/ einsehbar.

\section{Literatur}

1 Lankisch PG, Mahlke R, Lübbers $H$ et al. Leitsymptom Diarrhoe. Dtsch Arztebl 2006; 103 (5): A261 - A268

2 Wilking $H$, Spitznagel $H$, Werber $D$ et al. Acute gastrointestinal illness in adults in Germany: a population-based telephone survey. Epidemiol Infect 2013; 141 (11): 2365-2375

3 Lynen Jansen P, Stallmach A, Lohse AW et al. Entwicklung infektiöser Durchfallserkrankungen zwischen den Jahren 2000 und 2012. Z Gastroenterol 2014; 52 (6): 549-557

4 Lynen Jansen P, Preiß JC, Muche-Borowski C et al. The guidelines program of the DGVS. Z Gastroenterol 2013; 51 (7): $643-650$

5 Fischbach W, Malfertheiner P, Hoffmann J et al. S3-Leitlinie „Helicobacter pylori und gastroduodenale Ulkuskrankheit” der Deutschen Gesellschaft für Verdauungs- und Stoffwechselkrankheiten (DGVS). Z Gastroenterol 2009; 47 (1): 68 - 102

6 Kist M, Mauch H, Podbielski A et al. Mikrobiologisch-infektiologische Qualitätsstandards (MiQ), MIQ 09: Gastrointestinale Infektionen. 2. Ed. München: Elsevier, Urban \& Fischer; 2013

7 Farthing M, Lindberg G, Dite P et al. World Gastroenterology Organisation practice guideline: Acute diarrhea. Available at: http://www. worldgastroenterology.org/assets/downloads/en/pdf/guidelines/ 01_acute_diarrhea.pdf

8 Siegel DL, Edelstein PH, Nachamkin I. Inappropriate testing for diarrheal diseases in the hospital. JAMA 1990; 263 (7): 979-982

9 Guerrant RL, Van Gilder T, Steiner TS et al. Practice guidelines for the management of infectious diarrhea. Clin Infect Dis 2001; 32 (3): 331 351

10 Jansen A, Stark K, Kunkel J et al. Aetiology of community-acquired, acute gastroenteritis in hospitalised adults: a prospective cohort study. BMC Infect Dis 2008; 8: 143

11 Caspary WF, Lüpke NP, Oldiges FJ et al. Diarrhoe in der ärztlichen Praxis. Eine Bestandsaufnahme. Med Wochenschr 1995; 137: 411 -415

12 Riaz MM, Patel MJ, Khan MS et al. Clinical characteristics and predictors of positive stool culture in adult patients with acute gastroenteritis. J Pak Med Assoc 2012; 62 (1): 20 - 24

13 Kotloff KL, Winickoff JP, Ivanoff B et al. Global burden of Shigella infections: implications for vaccine development and implementation of control strategies. Bull World Health Organ 1999; 77 (8): 651 - 666

14 Niyogi SK. Shigellosis. J Microbiol 2005; 43 (2): 133-143

15 McAuliffe GN, Anderson TP, Stevens $M$ et al. Systematic application of multiplex PCR enhances the detection of bacteria, parasites, and viruses in stool samples. J Infect 2013; 67 (2): $122-129$
16 Lennon G, Reidy N, Collins PJ et al. A comparison of the efficiency of ELISA and selected primer sets to detect Norovirus isolates in southern Ireland over a four-year period (2002-2006): variation in detection rates and evidence for continuing predominance of NoV GII.4 genotype. Arch Virol 2014; 159 (7): 1697-1705

17 Robert Koch-Institut. Rotaviren-Erkrankungen: RKI-Ratgeber für Ärzte. Available at: http://www.rki.de/DE/Content/Infekt/EpidBull/ Merkblaetter/Ratgeber_Rotaviren.html

18 Bielaszewska M, Mellmann A, Zhang W et al. Characterisation of the Escherichia coli strain associated with an outbreak of haemolytic uraemic syndrome in Germany, 2011: a microbiological study. Lancet Infect Dis 2011; 11 (9): $671-676$

19 Frank C, Werber D, Cramer JP et al. Epidemic profile of Shiga-toxin-producing Escherichia coli 0104:H4 outbreak in Germany. N Engl J Med 2011; 365 (19): 1771 - 1780

20 Robert Koch-Institut. Abschliessende Darstellung und Bewertung der epidemiologischen Erkenntnisse im EHEC 0104:H4 Ausbruch; 2011, Available at: http://www.rki.de/DE/Content/InfAZ/E/EHEC/EHEC_ 0104/EHEC-Abschlussbericht.pdf?_blob=publicationFile

21 Vallieres E, Saint-Jean M, Rallu F. Comparison of three different methods for detection of Shiga toxin-producing Escherichia coli in a tertiary pediatric care center. J Clin Microbiol 2013; 51 (2): 481 - 486

22 Robert Koch-Institut. Erkrankungen durch Enterohämorrhagische Escherichia coli (EHEC): Ratgeber für Ärzte. Available at: http://www. rki.de/DE/Content/Infekt/EpidBull/Merkblaetter/Ratgeber_EHEC.html

23 Bauer MP, Notermans DW, van Benthem BH et al. Clostridium difficile infection in Europe: a hospital-based survey. Lancet 2011; 377 (9759): $63-73$

24 D'Agostino RB Sr, Collins SH, Pencina KM et al. Risk Estimation for Recurrent Clostridium difficile Infection Based on Clinical Factors. Clin Infect Dis 2014; 58 (10): 1386-1393

25 Friedman HS, Navaratnam $P$, Reardon $G$ et al. A retrospective analysis of clinical characteristics, hospitalization, and functional outcomes in residents with and without Clostridium difficile infection in US longterm care facilities. Curr Med Res Opin 2014; 30 (6): 1121 - 1130

26 Raveh D, Rabinowitz B, Breuer GS et al. Risk factors for Clostridium difficile toxin-positive nosocomial diarrhoea. Int J Antimicrob Agents 2006; 28 (3): $231-237$

27 Vojtilova L, Freibergerova M, Jurankova J et al. Epidemiological factors influencing the development of relapsing and severe Clostridium difficile infection. Epidemiol Mikrobiol Imunol 2014; 63 (1): 27-35

28 Slimings C, Riley TV. Antibiotics and hospital-acquired Clostridium difficile infection: update of systematic review and meta-analysis. J Antimicrob Chemother 2014; 69 (4): 881 - 891

29 Pakyz AL, Jawahar $R$, Wang $Q$ et al. Medication risk factors associated with healthcare-associated Clostridium difficile infection: a multilevel model case-control study among 64 US academic medical centres. J Antimicrob Chemother 2014; 69 (4): 1127-1131

30 Kwok CS, Arthur AK, Anibueze CI et al. Risk of Clostridium difficile infection with acid suppressing drugs and antibiotics: meta-analysis. Am J Gastroenterol 2012; 107 (7): 1011 -1019

31 Tleyjeh IM, Bin Abdulhak AA, Riaz M et al. Association between proton pump inhibitor therapy and clostridium difficile infection: a contemporary systematic review and meta-analysis. PLoS One 2012; 7 (12): e50836

32 Dulny G, Zalewska M, Mlynarczyk G. An analysis of risk factors of Clostridiumdifficile infection in patients hospitalized in the teaching hospital in 2008. Przegl Epidemiol 2013; 67 (3): 445 -450, 547-551

33 Garg S, Mirza YR, Girotra M et al. Epidemiology of Clostridium difficileassociated disease (CDAD): a shift from hospital-acquired infection to long-term care facility-based infection. Dig Dis Sci 2013; 58 (12): $3407-3412$

34 Das R, Feuerstadt P, Brandt LJ. Glucocorticoids are associated with increased risk of short-term mortality in hospitalized patients with clostridium difficile-associated disease. Am J Gastroenterol 2010; 105 (9): 2040 - 2049

35 Collini PJ, Bauer M, Kuijper E et al. Clostridium difficile infection in HIV-seropositive individuals and transplant recipients. J Infect 2012; 64 (2): $131-147$

36 West M, Pirenne J, Chavers B et al. Clostridium difficile colitis after kidney and kidney-pancreas transplantation. Clin Transplant 1999; 13 (4): $318-323$

37 Lübbert C, Johann C, Kekule AS et al. Immunosuppressive treatment as a risk factor for the occurrence of clostridium difficile infection (CDI). Z Gastroenterol 2013; 51 (11): 1251 - 1258 
38 Planche TD, Davies KA, Coen PG et al. Differences in outcome according to Clostridium difficile testing method: a prospective multicentre diagnostic validation study of C difficile infection. Lancet Infect Dis 2013; 13 (11): $936-945$

39 Debast SB, Bauer MP, Kuijper EJ et al. European Society of Clinical Microbiology and Infectious Diseases: update of the treatment guidance document for Clostridium difficile infection. Clin Microbiol Infect 2014; 20 (Suppl 2): 1 - 26

40 Surawicz CM, Brandt LJ, Binion DG et al. Guidelines for diagnosis, treatment, and prevention of Clostridium difficile infections. Am J Gastroenterol 2013; 108 (4): 478 -498; quiz 499

41 Finch LS, Duncan CM. Molecular test to determine toxigenic capabilities in GDH-positive, toxin-negative samples: evaluation of the Portrait toxigenic C. difficile assay. Br J Biomed Sci 2013; 70 (2): 62 - 66

42 Jones AM, Kuijper EJ, Wilcox $M H$. Clostridium difficile: a European perspective. J Infect 2013; 66 (2): 115-128

43 von Muller L, Halfmann A, Herrmann M. Current data and trends on the development of antibiotic resistance of Clostridium difficile. Bundesgesundheitsblatt Gesundheitsforschung Gesundheitsschutz 2012; 55 (11): $1410-1417$

44 Wei SC, Hung CC, Chen MY et al. Endoscopy in acquired immunodeficiency syndrome patients with diarrhea and negative stool studies. Gastrointest Endosc 2000; 51 (4): 427 - 432

45 Wahnschaffe $U$, Ignatius $R$, Loddenkemper $C$ et al. Diagnostic value of endoscopy for the diagnosis of giardiasis and other intestinal diseases in patients with persistent diarrhea from tropical or subtropical areas. Scand J Gastroenterol 2007; 42 (3): 391 - 396

46 Shah RJ, Fenoglio-Preiser C, Bleau BL et al. Usefulness of colonoscopy with biopsy in the evaluation of patients with chronic diarrhea. Am J Gastroenterol 2001; 96 (4): 1091 - 1095

47 Berdichevski T, Keller N, Rahav G et al. The impact of pseudomembrane formation on the outcome of Clostridium difficile-associated disease. Infection 2013; 41 (5): 969 -977

48 Ben-Horin S, Margalit M, Bossuyt P et al. Prevalence and clinical impact of endoscopic pseudomembranes in patients with inflammatory bowel disease and Clostridium difficile infection. J Crohns Colitis 2010; 4 (2): $194-198$

49 Nomura K, Fujimoto Y, Yamashita $M$ et al. Absence of pseudomembranes in Clostridium difficile-associated diarrhea in patients using immunosuppression agents. Scand J Gastroenterol 2009; 44 (1): $74-78$

50 Pavlidis $P$, Chedgy FJ, Tibble JA. Diagnostic accuracy and clinical application of faecal calprotectin in adult patients presenting with gastrointestinal symptoms in primary care. Scand J Gastroenterol 2013; 48 (9): 1048-1054

51 Taylor WI, Schelhart D. Effect of temperature of incubation on performance of media in the detection of enteric pathogens. Appl Microbiol 1973; 25 (6): 940 - 944

52 Valenstein P, Pfaller M, Yungbluth $M$. The use and abuse of routine stool microbiology: a College of American Pathologists Q-probes study of 601 institutions. Arch Pathol Lab Med 1996; 120 (2): 206-211

53 Khanna S, Pardi DS, Rosenblatt JE et al. An evaluation of repeat stool testing for Clostridium difficile infection by polymerase chain reaction. J Clin Gastroenterol 2012; 46 (10): 846-849

54 Deshpande A, Pasupuleti V, Patel P et al. Repeat stool testing for Clostridium difficile using enzyme immunoassay in patients with inflammatory bowel disease increases diagnostic yield. Curr Med Res Opin 2012; 28 (9): 1553 - 1560

55 Hiatt RA, Markell EK, $\mathrm{Ng}$ E. How many stool examinations are necessary to detect pathogenic intestinal protozoa? Am J Trop Med Hyg 1995; 53 (1): $36-39$

56 McFarland LV, Mulligan ME, Kwok RY et al. Nosocomial acquisition of Clostridium difficile infection. N Engl J Med 1989; 320 (4): 204-210

57 Atia AN, Buchman AL. Oral Rehydration Solutions in Non-Cholera Diarrhea: A Review. Am J Gastroenterol 2009; 104 (10): 2596-2604

58 Rao SSC, Summers RW, Rao GRS et al. Oral rehydration for viral gastroenteritis in adults: a randomized, controlled trial of 3 solutions. J Parenter Enteral Nutr 2006; 30 (5): 433 - 439

59 Binder HJ, Brown I, Ramakrishna BS et al. Oral Rehydration Therapy in the Second Decade of the Twenty-first Century. Curr Gastroenterol Rep 2014; 16 (3): 376

60 Hartling L, Bellemare S, Wiebe $N$ et al. Oral versus intravenous rehydration for treating dehydration due to gastroenteritis in children. Cochrane Database Syst Rev 2006, (3): CD004390

$61 \mathrm{Hou}$ FQ Wang Y, Li J et al. Management of acute diarrhea in adults in China: a cross-sectional survey. BMC Public Health 2013; 13: 41
62 Thielman NM, Guerrant RL. Clinical practice. Acute infectious diarrhea. N Engl J Med 2004; 350 (1): 38 -47

63 Huang DB, Awasthi M, Le BM et al. The role of diet in the treatment of travelers' diarrhea: a pilot study. Clin Infect Dis 2004; 39 (4): $468-471$

64 Sanders JW, Frenck RW, Putnam SD et al. Azithromycin and loperamide are comparable to levofloxacin and loperamide for the treatment of traveler's diarrhea in United States military personnel in Turkey. Clin Infect Dis 2007; 45 (3): 294-301

65 Murphy GS, Bodhidatta L, Echeverria P et al. Ciprofloxacin and loperamide in the treatment of bacillary dysentery. Ann Intern Med 1993; 118 (8): $582-586$

66 Ericsson CD, DuPont HL, Okhuysen PC et al. Loperamide plus azithromycin more effectively treats travelers' diarrhea in Mexico than azithromycin alone. J Travel Med 2007; 14 (5): 312-319

67 Ericsson CD, DuPont HL, Mathewson JJ et al. Treatment of traveler's diarrhea with sulfamethoxazole and trimethoprim and loperamide. JAMA 1990; 263 (2): 257 - 261

68 Taylor DN, Sanchez JL, Candler W et al. Treatment of travelers' diarrhea: ciprofloxacin plus loperamide compared with ciprofloxacin alone. A placebo-controlled, randomized trial. Ann Intern Med 1991; 114 (9): $731-734$

69 Dupont HL, Jiang ZD, Belkind-Gerson J et al. Treatment of travelers' diarrhea: randomized trial comparing rifaximin, rifaximin plus loperamide, and loperamide alone. Clin Gastroenterol Hepatol 2007; 5 (4): $451-456$

70 Bergström T, Alestig K, Thorén K et al. Symptomatic treatment of acute infectious diarrhoea: loperamide versus placebo in a double-blind trial. J Infect 1986; 12 (1): 35 - 38

71 Kato H, Kato H, Nakamura $M$ et al. A case of toxic megacolon secondary to Clostridium difficile-associated diarrhea worsened after administration of an antimotility agent and molecular analysis of recovered isolates. J Gastroenterol 2007; 42 (6): 507 - 508

72 Schneider A, Rünzi M, Peitgen K et al. Campylobacter jejuni-induced severe colitis - a rare cause of toxic megacolon. Z Gastroenterol 2000; 38 (4): $307-309$

73 McGregor A, Brown M, Thway K et al. Fulminant amoebic colitis following loperamide use. J Travel Med 2007; 14 (1): 61 -62

74 Eronen M, Putkonen H, Hallikainen $T$ et al. Lethal gastroenteritis associated with clozapine and loperamide. Am J Psychiatry 2003; 160 (12): $2242-2243$

75 Walley T, Milson D. Loperamide related toxic megacolon in Clostridium difficile colitis. Postgrad Med J 1990; 66 (777): 582

76 Cuadrado-Gómez LM, Arranz-Caso A, Albarrán-Hernández F et al. Toxic megacolon caused by loperamide as initial form of Crohn disease. Rev Clin Esp 1994; 194 (3): $201-202$

77 Petit R, Bouziane A, Calès $P$ et al. Toxic megacolon caused by loperamide-myorelaxants combination. Gastroenterol Clin Biol 1993; 17 (1): $62-63$

78 Bell BP, Griffin PM, Lozano P et al. Predictors of hemolytic uremic syndrome in children during a large outbreak of Escherichia coli 0157:H7 infections. Pediatrics 1997; 100 (1): E12

79 Eberlin M, Mück T, Michel MC. A comprehensive review of the pharmacodynamics, pharmacokinetics, and clinical effects of the neutral endopeptidase inhibitor racecadotril. Front Pharmacol 2012; 3: 93

80 Gallelli L, Colosimo M, Tolotta GA et al. Prospective randomized doubleblind trial of racecadotril compared with loperamide in elderly people with gastroenteritis living in nursing homes. Eur J Clin Pharmacol 2010; 66 (2): 137-144

81 Prado D. Global Adult Racecadotril Study Group. A multinational comparison of racecadotril and loperamide in the treatment of acute watery diarrhoea in adults. Scand J Gastroenterol 2002; 37 (6): 656-661

82 Etienney I, Beaugerie L, Viboud C et al. Non-steroidal anti-inflammatory drugs as a risk factor for acute diarrhoea: a case crossover study. Gut 2003; 52 (2): 260-263

83 Nonsteroidal anti-inflammatory drugs: add an anti-ulcer drug for patients at high risk only. Always limit the dose and duration of treatment with NSAIDs. Prescrire Int 2011; 20 (119): 216-219

84 Fedorowicz Z, Jagannath VA, Carter B. Antiemetics for reducing vomiting related to acute gastroenteritis in children and adolescents. Cochrane Database Syst Rev 2011, (9): CD005506

85 Passariello A, Agricole P, Malfertheiner P. A critical appraisal of probiotics (as drugs or food supplements) in gastrointestinal diseases. Curr Med Res Opin 2014; 30 (6): 1055 - 1064

86 Allen SJ, Martinez EG, Gregorio GV et al. Probiotics for treating acute infectious diarrhoea. Cochrane Database Syst Rev 2010, (11): CD003048 
87 McFarland LV. Systematic review and meta-analysis of Saccharomyces boulardii in adult patients. World J Gastroenterol 2010; 16 (18): $2202-2222$

88 Pichler H, Diridl G, Wolf D. Ciprofloxacin in the treatment of acute bacterial diarrhea: a double blind study. Eur J Clin Microbiol 1986; 5 (2): $241-243$

89 Pichler HE, Diridl G, Stickler K et al. Clinical efficacy of ciprofloxacin compared with placebo in bacterial diarrhea. Am J Med 1987; 82 (4): $329-332$

90 Dryden MS, Gabb RJ, Wright SK. Empirical treatment of severe acute community-acquired gastroenteritis with ciprofloxacin. Clin Infect Dis 1996; 22 (6): 1019-1025

91 Goodman LJ, Trenholme GM, Kaplan RL et al. Empiric antimicrobial therapy of domestically acquired acute diarrhea in urban adults. Arch Intern Med 1990; 150 (3): 541 - 546

92 Robert Koch-Institut. Infektionsepidemiologisches Jahrbuch meldepflichtiger Krankheiten für 2013; 2014, Available at: http://www.rki. de/DE/Content/Infekt/Jahrbuch/Jahrbuch_2013.pdf?_blob=publicationFile Accessed October 27, 2014

93 Robert Koch-Institut. Salmonellose (Salmonellen-Gastroenteritis): RKI-Ratgeber für Ärzte. Available at: http://www.rki.de/DE/Content/ Infekt/EpidBull/Merkblaetter/Ratgeber_Salmonellose.html

94 Olsen SJ, DeBess EE, McGivern TE et al. A nosocomial outbreak of fluoroquinolone-resistant salmonella infection. N Engl J Med 2001; 344 (21): $1572-1579$

95 Buchwald DS, Blaser MJ. A review of human salmonellosis: II. Duration of excretion following infection with nontyphi Salmonella . Rev Infect Dis $1984 ; 6$ (3): $345-356$

96 Saphra I, Winter JW. Clinical manifestations of salmonellosis in man; an evaluation of 7779 human infections identified at the New York Salmonella Center. N Engl J Med 1957; 256 (24): 1128-1134

97 Helms M, Simonsen J, Molbak K. Quinolone resistance is associated with increased risk of invasive illness or death during infection with Salmonella serotype Typhimurium. J Infect Dis 2004; 190 (9): 1652 - 1654

98 Onwuezobe IA, Oshun PO, Odigwe CC. Antimicrobials for treating symptomatic non-typhoidal Salmonella infection. Cochrane Database Syst Rev 2012; 11 CD001167

99 Cohen PS, O'Brien TF, Schoenbaum SC et al. The risk of endothelial infection in adults with salmonella bacteremia. Ann Intern Med 1978; 89 (6): 931 - 932

100 Day LJ, Qayyum QJ, Kauffman CA. Salmonella prosthetic joint septic arthritis. Clin Microbiol Infect 2002; 8 (7): 427-430

101 Guerrant RL, Van Gilder T, Steiner TS et al. Practice guidelines for the management of infectious diarrhea. Clin Infect Dis 2001; 32 (3): $331-351$

102 Hohmann EL. Nontyphoidal salmonellosis. Clin Infect Dis 2001; 32 (2): $263-269$

103 Gotuzzo E, Guerra JG, Benavente L et al. Use of norfloxacin to treat chronic typhoid carriers. J Infect Dis 1988; 157 (6): 1221 - 1225

104 Zavala TI, Quiroz C, Gutierrez MA et al. Fluoroquinolones in the treatment of typhoid fever and the carrier state. Eur J Clin Microbiol Infect Dis 1991; 10 (4): 334-341

105 Gonzalez-Escobedo G, Marshall JM, Gunn JS. Chronic and acute infection of the gall bladder by Salmonella Typhi: understanding the carrier state. Nat Rev Microbiol 2011; 9 (1): 9-14

106 Robert Koch-Institut. Shigellose: Ratgeber für Ärzte. Available at: http://www.rki.de/DE/Content/Infekt/EpidBull/Merkblaetter/Ratgeber_Shigellose.html

107 Kosek M, Yori PP, Olortegui MP. Shigellosis update: advancing antibiotic resistance, investment empowered vaccine development, and green bananas. Curr Opin Infect Dis 2010; 23 (5): 475 - 480

108 Butler T. Haemolytic uraemic syndrome during shigellosis. Trans $\mathrm{R}$ Soc Trop Med Hyg 2012; 106 (7): 395 - 399

109 Carter JD, Hudson AP. Reactive arthritis: clinical aspects and medical management. Rheum Dis Clin North Am 2009; 35 (1): 21 - 44

110 Christopher PR, David KV, John SM et al. Antibiotic therapy for Shigella dysentery. Cochrane Database Syst Rev 2010, (8): CD006784

111 Haltalin $K C$, Nelson JD, Ring $R$ et al. Double-blind treatment study of shigellosis comparing ampicillin, sulfadiazine, and placebo. J Pediatr 1967; 70 (6): 970 - 981

112 Hoffmann C, Sahly H, Jessen A et al. High rates of quinolone-resistant strains of Shigella sonnei in HIV-infected MSM. Infection 2013; 41 (5): 999-1003

$113 \mathrm{Gu}$ B, Cao Y, Pan S et al. Comparison of the prevalence and changing resistance to nalidixic acid and ciprofloxacin of Shigella between Eu-
rope-America and Asia-Africa from 1998 to 2009. Int J Antimicrob Agents 2012; 40 (1): 9-17

114 Khan WA, Seas C, Dhar U et al. Treatment of shigellosis: V. Comparison of azithromycin and ciprofloxacin. A double-blind, randomized, controlled trial. Ann Intern Med 1997; 126 (9): 697-703

115 Bennish ML, Salam MA, Khan WA et al. Treatment of shigellosis: III. Comparison of one- or two-dose ciprofloxacin with standard 5-day therapy. A randomized, blinded trial. Ann Intern Med 1992; 117 (9): $727-734$

116 Bassily S, Hyams KC, el-Masry NA et al. Short-course norfloxacin and trimethoprim-sulfamethoxazole treatment of shigellosis and salmonellosis in Egypt. Am J Trop Med Hyg 1994; 51 (2): 219-223

117 Robert Koch-Institut. Campylobacter: Ratgeber für Ärzte. Available at: http://www.rki.de/DE/Content/Infekt/EpidBull/Merkblaetter/Ratgeber_Campylobacter.html

118 Kapperud G, Lassen J, Ostroff SM et al. Clinical features of sporadic Campylobacter infections in Norway. Scand J Infect Dis 1992; 24 (6): $741-749$

119 Molina J, Casin I, Hausfater P et al. Campylobacter infections in HIVinfected patients: clinical and bacteriological features. AIDS 1995; 9 (8): $881-885$

120 Nielsen H, Hansen KK, Gradel KO et al. Bacteraemia as a result of Campylobacter species: a population-based study of epidemiology and clinical risk factors. Clin Microbiol Infect 2010; 16 (1): 57-61

121 Pacanowski J, Lalande V, Lacombe K et al. Campylobacter bacteremia: clinical features and factors associated with fatal outcome. Clin Infect Dis 2008; 47 (6): $790-796$

122 Vukelic D, Trkulja V, Salkovic-Petrisic M. Single oral dose of azithromycin versus 5 days of oral erythromycin or no antibiotic in treatment of campylobacter enterocolitis in children: a prospective randomized assessor-blind study. J Pediatr Gastroenterol Nutr 2010; 50 (4): 404-410

123 Lariviere LA, Gaudreau CL, Turgeon FF. Susceptibility of clinical isolates of Campylobacter jejuni to twenty-five antimicrobial agents. J Antimicrob Chemother 1986; 18 (6): 681 - 685

124 Ostroff SM, Kapperud G, Lassen J et al. Clinical features of sporadic Yersinia enterocolitica infections in Norway. J Infect Dis 1992; 166 (4): $812-817$

125 Robert Koch-Institut. Yersiniose: Risikofaktoren in Deutschland 2012, (Nr. 6). Available at: http://www.rki.de/DE/Content/Infekt/ EpidBull/Archiv/2012/Ausgaben/06_12.pdf?_blob=publicationFile

126 Bottone EJ. Yersinia enterocolitica: overview and epidemiologic correlates. Microbes Infect 1999; 1 (4): 323-333

127 Press N, Fyfe M, Bowie W et al. Clinical and microbiological follow-up of an outbreak of Yersinia pseudotuberculosis serotype Ib. Scand J Infect Dis 2001; 33 (7): $523-526$

128 Frank C, Werber D, Cramer JP et al. Epidemic profile of Shiga-toxinproducing Escherichia coli 0104:H4 outbreak in Germany. N Engl J Med 2011; 365 (19): 1771 - 1780

129 Smith KE, Wilker PR, Reiter PL et al. Antibiotic treatment of Escherichia coli 0157 infection and the risk of hemolytic uremic syndrome, Minnesota. Pediatr Infect Dis J 2012; 31 (1): 37-41

130 Menne J, Nitschke M, Stingele R et al. Validation of treatment strategies for enterohaemorrhagic Escherichia coli 0104:H4 induced haemolytic uraemic syndrome: case-control study. BMJ 2012: 345

131 Geerdes-Fenge HF, Löbermann $M$, Nürnberg $M$ et al. Ciprofloxacin reduces the risk of hemolytic uremic syndrome in patients with Escherichia coli 0104:H4-associated diarrhea. Infection 2013; 41 (3): 669 673

132 Nitschke M, Sayk F, Härtel C et al. Association between azithromycin therapy and duration of bacterial shedding among patients with Shiga toxin-producing enteroaggregative Escherichia coli 0104:H4. JAMA 2012; 307 (10): 1046-1052

133 Lima NL, Guerrant RL, Kaiser DL et al. A retrospective cohort study of nosocomial diarrhea as a risk factor for nosocomial infection. J Infect Dis 1990; 161 (5): $948-952$

134 Polage CR, Solnick JV, Cohen SH. Nosocomial diarrhea: evaluation and treatment of causes other than Clostridium difficile. J Infect Dis 2012; 55 (7): $982-989$

135 Magill SS, Edwards JR, Bamberg W et al. Multistate point-prevalence survey of health care-associated infections. N Engl J Med 2014; 370 (13): $1198-1208$

136 Meyer E, Gastmeier P, Weizel-Kage D et al. Associations between nosocomial meticillin-resistant Staphylococcus aureus and nosocomial 
Clostridium difficile-associated diarrhoea in 89 German hospitals. J Hosp Infect 2012; 82 (3): 181-186

137 Hensgens MP, Goorhuis A, Dekkers OM et al. All-cause and diseasespecific mortality in hospitalized patients with Clostridium difficile infection: a multicenter cohort study. Clin Infect Dis 2013; 56 (8): $1108-1116$

138 Vonberg RP, Reichardt C, Behnke M et al. Costs of nosocomial Clostridium difficile-associated diarrhoea. J Hosp Infect 2008; 70 (1): 15-20

139 Robert Koch-Institut. Clostridium difficile: RKI-Ratgeber für Ärzte. Available at: http://www.rki.de/DE/Content/Infekt/EpidBull/Merkblaetter/Ratgeber_Clostridium.html?nn=2393714

140 Gorkiewicz G. Nosocomial and antibiotic-associated diarrhoea caused by organisms other than Clostridium difficile. Int J Antimicrob Agents 2009; 33 (Suppl 1): $37-41$

141 Loo VG, Bourgault AM, Poirier $L$ et al. Host and pathogen factors for Clostridium difficile infection and colonization. N Engl J Med 2011; 365 (18): $1693-1703$

142 Rea MC, O'Sullivan O, Shanahan F et al. Clostridium difficile carriage in elderly subjects and associated changes in the intestinal microbiota. J Clin Microbiol 2012; 50 (3): 867-875

143 Howell MD, Novack V, Grgurich P et al. Iatrogenic gastric acid suppression and the risk of nosocomial Clostridium difficile infection. Arch Intern Med 2010; 170 (9): $784-790$

144 McFarland LV, Mulligan ME, Kwok RY et al. Nosocomial acquisition of Clostridium difficile infection. N Engl J Med 1989; 320 (4): 204-210

145 Bundesamt für Verbraucherschutz und Lebensmittelsicherheit. GERMAP 2012-Bericht über den Antibiotikaverbrauch und die Verbreitung von Antibiotikaresistenzen in der Human- und Veterinärmedizin in Deutschland. Available at: http://www.bvl.bund.de/ SharedDocs/Downloads/05_Tierarzneimittel/germap2012.pdf? _blob=publicationFile $\& \mathrm{~V}=4$

146 Chitnis AS, Holzbauer SM, Belflower RM et al. Epidemiology of community-associated Clostridium difficile infection, 2009 through 2011. JAMA Intern Med 2013; 173 (14): 1359-1367

147 Allen SJ, Wareham K, Wang $D$ et al. Lactobacilli and bifidobacteria in the prevention of antibiotic-associated diarrhoea and Clostridium difficile diarrhoea in older inpatients (PLACIDE): a randomised, double-blind, placebo-controlled, multicentre trial. Lancet 2013; 382 (9900): 1249-1257

148 Bauer TM, Lalvani A, Fehrenbach J et al. Derivation and validation of guidelines for stool cultures for enteropathogenic bacteria other than Clostridium difficile in hospitalized adults. JAMA 2001; 285 (3): $313-319$

149 Epple HJ, Zeitz M. Infectious enteritis. Internist (Berl) 2011; 52 (9): 1038, 1040-1044, 1046

150 Bernard H, Hohne M, Niendorf S et al. Epidemiology of norovirus gastroenteritis in Germany 2001-2009: eight seasons of routine surveillance. Epidemiol Infect 2014; 142 (1): 63 - 74

151 Robert Koch-Institut. Noroviren-Infektionen: RKI-Ratgeber für Ärzte. Available at: http://www.rki.de/DE/Content/Infekt/EpidBull/Merkblaetter/Ratgeber_Noroviren.html

152 Cohen SH, Gerding DN, Johnson S et al. Clinical practice guidelines for Clostridium difficile infection in adults: 2010 update by the society for healthcare epidemiology of America (SHEA) and the infectious diseases society of America (IDSA). Infect Control Hosp Epidemiol 2010; 31 (5): 431-455

153 Debast SB, Bauer MP, Kuijper EJ et al. European Society of Clinical Microbiology and Infectious Diseases: update of the treatment guidance document for Clostridium difficile infection. Clin Microbiol Infect 2014; 20 (Suppl 2): 1-26

154 Johnson S. Recurrent Clostridium difficile infection: a review of risk factors, treatments, and outcomes. J Infect 2009; 58 (6): 403-410

155 Garey KW, Sethi S, Yadav Y et al. Meta-analysis to assess risk factors for recurrent Clostridium difficile infection. J Hosp Infect 2008; 70 (4): $298-304$

156 McFarland LV, Surawicz CM, Rubin M et al. Recurrent Clostridium difficile disease: epidemiology and clinical characteristics. Infect Control Hosp Epidemiol 1999; 20 (1): $43-50$

157 Pepin J, Alary ME, Valiquette L et al. Increasing risk of relapse after treatment of Clostridium difficile colitis in Quebec, Canada. Clin Infect Dis 2005; 40 (11): $1591-1597$

158 Johnson S, Louie TJ, Gerding DN et al. Vancomycin, Metronidazole, or Tolevamer for Clostridium difficile Infection: Results From Two Multinational, Randomized, Controlled Trials. Clin Infect Dis 2014; 59 (3): $345-354$
159 Nelson RL, Kelsey P, Leeman $\mathrm{H}$ et al. Antibiotic treatment for Clostridium difficile-associated diarrhea in adults. Cochrane Database Syst Rev 2011, (9): CD004610

160 Zar FA, Bakkanagari SR, Moorthi KM et al. A comparison of vancomycin and metronidazole for the treatment of Clostridium difficile-associated diarrhea, stratified by disease severity. Clin Infect Dis 2007; 45 (3): $302-307$

161 Surawicz CM, Brandt LJ, Binion DG et al. Guidelines for diagnosis, treatment, and prevention of Clostridium difficile infections. Am J Gastroenterol 2013; 108 (4): 478 - 498; quiz 499

162 Gonzales M, Pepin J, Frost EH et al. Faecal pharmacokinetics of orally administered vancomycin in patients with suspected Clostridium difficile infection. BMC Infect Dis 2010; 10: 363

163 Fekety R, Silva J, Kauffman C et al. Treatment of antibiotic-associated Clostridium difficile colitis with oral vancomycin: comparison of two dosage regimens. Am J Med 1989; 86 (1): 15-19

164 Lam SW, Bass SN, Neuner EA et al. Effect of vancomycin dose on treatment outcomes in severe Clostridium difficile infection. Int J Antimicrob Agents 2013; 42 (6): 553-558

165 Nerandzic MM, Mullane K, Miller MA et al. Reduced acquisition and overgrowth of vancomycin-resistant enterococci and Candida species in patients treated with fidaxomicin versus vancomycin for Clostridium difficile infection. Clin Infect Dis 2012; 55 (Suppl 2): S121 -S126

166 Cheah AL, Peel T, Howden BP et al. Case-case-control study on factors associated with vanB vancomycin-resistant and vancomycin-susceptible enterococcal bacteraemia. BMC Infect Dis 2014; 14 (1): 353

167 Sethi AK, Al-Nassir WN, Nerandzic MM et al. Skin and environmental contamination with vancomycin-resistant Enterococci in patients receiving oral metronidazole or oral vancomycin treatment for Clostridium difficile-associated disease. Infect Control Hosp Epidemiol 2009; 30 (1): $13-17$

168 Donskey CJ, Chowdhry TK, Hecker MT et al. Effect of antibiotic therapy on the density of vancomycin-resistant enterococci in the stool of colonized patients. N Engl J Med 2000; 343 (26): 1925-1932

169 Cornely OA, Miller MA, Louie TJ et al. Treatment of first recurrence of Clostridium difficile infection: fidaxomicin versus vancomycin. Clin Infect Dis 2012; 55 (Suppl 2): S154-S161

170 Louie TJ, Miller MA, Mullane KM et al. Fidaxomicin versus vancomycin for Clostridium difficile infection. N Engl J Med 2011; 364 (5): 422 431

171 Friedenberg F, Fernandez A, Kaul $V$ et al. Intravenous metronidazole for the treatment of Clostridium difficile colitis. Dis Colon Rectum 2001; 44 (8): $1176-1180$

172 Apisarnthanarak A, Razavi B, Mundy LM. Adjunctive intracolonic vancomycin for severe Clostridium difficile colitis: case series and review of the literature. Clin Infect Dis 2002; 35 (6): 690-696

$173 \mathrm{Kim}$ PK, Huh HC, Cohen HW et al. Intracolonic vancomycin for severe Clostridium difficile colitis. Surg Infect (Larchmt) 2013; 14 (6): 532 539

174 Musgrave CR, Bookstaver PB, Sutton SS et al. Use of alternative or adjuvant pharmacologic treatment strategies in the prevention and treatment of Clostridium difficile infection. Int J Infect Dis 2011; 15 (7): e438-e448

175 Neal MD, Alverdy JC, Hall DE et al. Diverting loop ileostomy and colonic lavage: an alternative to total abdominal colectomy for the treatment of severe, complicated Clostridium difficile associated disease. Ann Surg 2011; 254 (3): 423-427; discussion 427-429

176 Pepin J, Routhier S, Gagnon S et al. Management and outcomes of a first recurrence of Clostridium difficile-associated disease in Quebec, Canada. Clin Infect Dis 2006; 42 (6): $758-764$

177 Kapoor K, Chandra M, Nag D et al. Evaluation of metronidazole toxicity: a prospective study. Int J Clin Pharmacol Res 1999; 19 (3): 83-88

178 McFarland LV, Elmer GW, Surawicz CM. Breaking the cycle: treatment strategies for 163 cases of recurrent Clostridium difficile disease. Am J Gastroenterol 2002; 97 (7): 1769-1775

179 Eiseman AJ, Silen B, Bascom $W$ et al. Fecal enema as an adjunct in the treatment of pseudomembranous enterocolitis. Surgery 1958; 44 (5): $854-859$

180 Brandt LJ, Aroniadis OC, Mellow M et al. Long-term follow-up of colonoscopic fecal microbiota transplant for recurrent Clostridium difficile infection. Am J Gastroenterol 2012; 107 (7): 1079-1087

181 van Nood E, Vrieze A, Nieuwdorp $M$ et al. Duodenal infusion of donor feces for recurrent Clostridium difficile. N Engl J Med 2013; 368 (5): 407-415 
182 KRINKO. Personelle und organisatorische Voraussetzungen zur Prävention nosokomialer Infektionen. 52: 2009: 951 -962

183 Valiquette L, Cossette B, Garant MP et al. Impact of a reduction in the use of high-risk antibiotics on the course of an epidemic of Clostridium difficile-associated disease caused by the hypervirulent NAP1/027 strain. Clin Infect Dis 2007; 45 (Suppl 2): S112 - S121

184 Talpaert MJ, Gopal RG, Cooper BS et al. Impact of guidelines and enhanced antibiotic stewardship on reducing broad-spectrum antibiotic usage and its effect on incidence of Clostridium difficile infection. J Antimicrob Chemother 2011; 66 (9): 2168-2174

185 Siegel JD, Rhinehart E, Jackson M et al. 2007 Guideline for Isolation Precautions: Preventing Transmission of Infectious Agents in Health Care Settings. Am J Infect Control 2007; 35 (10): 65 - 164

186 Jabbar U, Leischner J, Kasper D et al. Effectiveness of alcohol-based hand rubs for removal of Clostridium difficile spores from hands. Infect Control Hosp Epidemiol 2010; 31 (6): 565 - 570

187 Boyce JM, Ligi C, Kohan C et al. Lack of association between the increased incidence of Clostridium difficile-associated disease and the increasing use of alcohol-based hand rubs. Infect Control Hosp Epidemiol 2006; 27 (5): 479-483

188 Kaier K, Hagist C, Frank U et al. Two time-series analyses of the impact of antibiotic consumption and alcohol-based hand disinfection on the incidences of nosocomial methicillin-resistant Staphylococcus aureus infection and Clostridium difficile infection. Infect Control Hosp Epidemiol 2009; 30 (4): 346 - 353

189 Rupp ME, Fitzgerald T, Puumala S et al. Prospective, controlled, crossover trial of alcohol-based hand gel in critical care units. Infect Control Hosp Epidemiol 2008; 29 (1): 8-15

190 Rutala WA, Gergen MF, Weber DJ. Efficacy of different cleaning and disinfection methods against Clostridium difficile spores: importance of physical removal versus sporicidal inactivation. Infect Control Hosp Epidemiol 2012; 33 (12): $1255-1258$

191 Dubberke ER, Carling P, Carrico R et al. Strategies to prevent Clostridium difficile infections in acute care hospitals: 2014 Update. Infect Control Hosp Epidemiol 2014; 35 (6): 628 - 645

192 MacCannell T, Umscheid CA, Agarwal RK et al. Guideline for the prevention and control of norovirus gastroenteritis outbreaks in healthcare settings. Infect Control Hosp Epidemiol 2011; 32 (10): 939-969

193 Sattar SA, Ali M, Tetro JA. In vivo comparison of two human norovirus surrogates for testing ethanol-based handrubs: the mouse chasing the cat! PLoS One 2011; 6 (2): e17340

194 Goldenberg JZ, Ma SS, Saxton JD et al. Probiotics for the prevention of Clostridium difficile-associated diarrhea in adults and children. Cochrane Database Syst Rev 2013; 5 CD006095

195 Kobrynski LJ, Mayer L. Diagnosis and treatment of primary immunodeficiency disease in patients with gastrointestinal symptoms. Clin Immunol 2011; 139 (3): $238-248$

196 Krones E, Högenauer C. Diarrhea in the immunocompromised patient. Gastroenterol Clin North Am 2012; 41 (3): 677 - 701

197 Vaiyavatjamai $P$, Boitano JJ, Techasintana $P$ et al. Immunocompromised group differences in the presentation of intestinal strongyloidiasis. Jpn J Infect Dis 2008; 61 (1): 5-8

198 Fishman JA. Infections in immunocompromised hosts and organ transplant recipients: essentials. Liver Transpl 2011; 17 (Suppl 3): $34-37$

199 Ghosh K, Weiss LM. Molecular diagnostic tests for microsporidia. Interdiscip Perspect Infect Dis 2009; 2009: 926521

200 Kulkarni SV, Kairon R, Sane SS et al. Opportunistic parasitic infections in HIV/AIDS patients presenting with diarrhoea by the level of immunesuppression. Indian J Med Res 2009; 130 (1): 63-66

201 Yakoob J, Jafri W, Beg MA et al. Blastocystis hominis and Dientamoeba fragilis in patients fulfilling irritable bowel syndrome criteria. Parasitol Res 2010; 107 (3): 679-684

202 Matthes-Martin S, Feuchtinger T, Shaw PJ et al. European guidelines for diagnosis and treatment of adenovirus infection in leukemia and stem cell transplantation: summary of ECIL-4 (2011). Transpl Infect Dis 2012; 14 (6): $555-563$

203 Karakousis PC, Moore RD, Chaisson RE. Mycobacterium avium complex in patients with HIV infection in the era of highly active antiretroviral therapy. Lancet Infect Dis 2004; 4 (9): 557-565

204 Cello JP, Day LW. Idiopathic AIDS enteropathy and treatment of gastrointestinal opportunistic pathogens. Gastroenterology 2009; 136 (6): $1952-1965$

205 Donoghue HD, Holton J. Intestinal tuberculosis. Curr Opin Infect Dis 2009; 22 (5): $490-496$
206 Assi M, McKinsey DS, Driks MR et al. Gastrointestinal histoplasmosis in the acquired immunodeficiency syndrome: report of 18 cases and literature review. Diagn Microbiol Infect Dis 2006; 55 (3): 195-201

207 Fine $K D$, Seidel $R H$, Do $K$. The prevalence, anatomic distribution, and diagnosis of colonic causes of chronic diarrhea. Gastrointest Endosc 2000; 51 (3): $318-326$

208 Guarner J, Brandt ME. Histopathologic Diagnosis of Fungal Infections in the 21st Century. Clin Microbiol Rev 2011; 24 (2): 247 - 280

209 Hommes DW, Sterringa G, van Deventer SJH et al. The pathogenicity of cytomegalovirus in inflammatory bowel disease: a systematic review and evidence-based recommendations for future research. Inflamm Bowel Dis 2004; 10 (3): 245-250

210 Kojima T, Watanabe T, Hata K et al. Cytomegalovirus infection in ulcerative colitis. Scand J Gastroenterol 2006; 41 (6): 706-711

211 Aapro MS, Bohlius J, Cameron DA et al. 2010 update of EORTC guidelines for the use of granulocyte-colony stimulating factor to reduce the incidence of chemotherapy-induced febrile neutropenia in adult patients with lymphoproliferative disorders and solid tumours. Eur J Cancer 2011; 47 (1): 8-32

212 Torres-Madriz G, Boucher HW. Immunocompromised hosts: perspectives in the treatment and prophylaxis of cytomegalovirus disease in solid-organ transplant recipients. Clin Infect Dis 2008; 47 (5): $702-711$

213 Sukhrie FHA, Siebenga JJ, Beersma MFC et al. Chronic shedders as reservoir for nosocomial transmission of norovirus. J Clin Microbiol 2010; 48 (11): $4303-4305$

214 Sandkovsky U, Vargas L, Florescu DF. Adenovirus: current epidemiology and emerging approaches to prevention and treatment. Curr Infect Dis Rep 2014; 16 (8): 416

215 Gellad ZF, Alexander BD, Liu JK et al. Severity of Clostridium difficileassociated diarrhea in solid organ transplant patients. Transpl Infect Dis 2007; 9 (4): 276-280

216 Gil L, Styczynski J, Komarnicki M. Infectious complication in 314 patients after high-dose therapy and autologous hematopoietic stem cell transplantation: risk factors analysis and outcome. Infection 2007; 35 (6): $421-427$

217 Krishna SG, Zhao W, Apewokin SK et al. Risk factors, preemptive therapy, and antiperistaltic agents for Clostridium difficile infection in cancer patients. Transpl Infect Dis 2013; 15 (5): 493-501

218 Escobedo AA, Hanevik K, Almirall P et al. Management of chronic Giardia infection. Expert Rev Anti Infect Ther 2014; 12 (9): 1143-1157

219 Burchard GD, Hentschke M, Weinke T et al. Travelers' diarrhea. Dtsch Med Wochenschr 2013; 138 (33): 1673-1683; quiz 1684-1686

220 Steffen R. Epidemiology of traveler's diarrhea. Clin Infect Dis 2005; 41 (Suppl 8): $536-540$

221 Swaminathan A, Torresi J, Schlagenhauf $P$ et al. A global study of pathogens and host risk factors associated with infectious gastrointestinal disease in returned international travellers. J Infect 2009; 59 (1): $19-27$

222 Flores J, DuPont HL, Lee SA et al. Influence of host interleukin-10 polymorphisms on development of traveler's diarrhea due to heat-labile enterotoxin-producing Escherichia coli in travelers from the United States who are visiting Mexico. Clin Vaccine Immunol 2008; 15 (8): $1194-1198$

223 Mohamed JA, DuPont HL, Flores J et al. Single nucleotide polymorphisms in the promoter of the gene encoding the lipopolysaccharide receptor CD14 are associated with bacterial diarrhea in US and Canadian travelers to Mexico. Clin Infect Dis 2011; 52 (11): 1332 - 1341

224 DuPont HL, Ericsson CD, Farthing MJG et al. Expert review of the evidence base for self-therapy of travelers' diarrhea. J Travel Med 2009; 16 (3): $161-171$

225 Al-Abri SS, Beeching NJ, Nye FJ. Traveller's diarrhoea. Lancet Infect Dis 2005; 5 (6): 349-360

226 McGregor AC, Whitty CIM, Wright SG. Geographic, symptomatic and laboratory predictors of parasitic and bacterial causes of diarrhoea in travellers. Trans R Soc Trop Med Hyg 2012; 106 (9): 549 - 553

227 von Sonnenburg F, Tornieporth $N$, Waiyaki P et al. Risk and aetiology of diarrhoea at various tourist destinations. Lancet 2000; 356 (9224): $133-134$

228 Shah N, DuPont HL, Ramsey DJ. Global etiology of travelers' diarrhea: systematic review from 1973 to the present. Am J Trop Med Hyg 2009; 80 (4): $609-614$

229 Neuberger A, Saadi T, Shetern A et al. Clostridium difficile Infection in travelers - a neglected pathogen? J Travel Med 2013; 20 (1): 37-43 
230 Jiang ZD, Dupont HL, Brown EL et al. Microbial etiology of travelers' diarrhea in Mexico, Guatemala, and India: importance of enterotoxigenic Bacteroides fragilis and Arcobacter species. J Clin Microbiol 2010; 48 (4): 1417-1419

231 Pandey P, Bodhidatta L, Lewis $M$ et al. Travelers' diarrhea in Nepal: an update on the pathogens and antibiotic resistance. J Travel Med 2011; 18 (2): $102-108$

232 Deutsche Gesellschaft für Tropenmedizin und Internationale Gesundheit (DTG). Leitlinie: Diagnostik und Therapie der Malaria; 2013, Available at: www.dtg.org/fileadmin/user_upload/PDF/LL-Malaria_2013. pdf

233 Weinke T, Liebold I. Intestinal protozoa infections. Dtsch Med Wochenschr 2013; 138 (14): 709-711

234 Taneja N, Mewara A, Kumar A et al. Cephalosporin-resistant Shigella flexneri over 9 years (2001-2009) in India. J Antimicrob Chemother 2012; 67 (6): 1347-1353

235 González-Hein G, Cordero N, García P et al. Molecular analysis of fluoroquinolones and macrolides resistance in Campylobacter jejuni isolates from humans, bovine and chicken meat. Rev Chilena Infectol 2013; 30 (2): 135-139

236 DuPont $H L$, Jiang $Z D$, Ericsson $C D$ et al. Rifaximin versus ciprofloxacin for the treatment of traveler's diarrhea: a randomized, double-blind clinical trial. Clin Infect Dis 2001; 33 (11): 1807-1815

237 Riddle MS, Arnold S, Tribble DR. Effect of adjunctive loperamide in combination with antibiotics on treatment outcomes in traveler's diarrhea: a systematic review and meta-analysis. Clin Infect Dis 2008; 47 (8): $1007-1014$

238 McFarland $L V$. Meta-analysis of probiotics for the prevention of traveler's diarrhea. Travel Med Infect Dis 2007; 5 (2): 97-105

239 Takahashi O, Noguchi Y, Omata F et al. Probiotics in the prevention of traveler's diarrhea: meta-analysis. J Clin Gastroenterol 2007; 41 (3): 336-337

240 Adachi JA, Mathewson JJ, Jiang ZD et al. Enteric pathogens in Mexican sauces of popular restaurants in Guadalajara, Mexico, and Houston, Texas. Ann Intern Med 2002; 136 (12): 884-887

241 Kendall ME, Mody RK, Mahon BE et al. Emergence of salsa and guacamole as frequent vehicles of foodborne disease outbreaks in the United States, 1973-2008. Foodborne Pathog Dis 2013; 10 (4): 316-322

242 Alajbegovic S, Sanders JW, Atherly DE et al. Effectiveness of rifaximin and fluoroquinolones in preventing travelers' diarrhea (TD): a systematic review and meta-analysis. Syst Rev 2012; 1: 39

243 DuPont HL, Ericsson CD, Farthing MJG et al. Expert review of the evidence base for prevention of travelers' diarrhea. J Travel Med 2009; 16 (3): $149-160$

244 López-Gigosos R, Campins M, Calvo MJ et al. Effectiveness of the WC/ rBS oral cholera vaccine in the prevention of traveler's diarrhea: a prospective cohort study. Hum Vaccin Immunother 2013; 9 (3): $692-698$

245 Weinke T, Liebold I, Burchard GD et al. Prophylactic immunisation against traveller's diarrhoea caused by enterotoxin-forming strains of Escherichia coli and against cholera: does it make sense and for whom? Travel Med Infect Dis 2008; 6 (6): $362-367$

246 Dobbins W. Whipple`s disease. In: Springfield, IL: Charles C. Thomas

247 Feurle GE, Junga NS, Marth T. Efficacy of ceftriaxone or meropenem as initial therapies in Whipple's disease. Gastroenterology 2010; 138 (2): 478-486; quiz 11-12

248 Feurle GE, Moos V, Bläker H et al. Intravenous ceftriaxone, followed by 12 or three months of oral treatment with trimethoprim-sulfamethoxazole in Whipple's disease. J Infect 2013; 66 (3): 263-270

249 Schneider T, Moos V, Loddenkemper $C$ et al. Whipple's disease: new aspects of pathogenesis and treatment. Lancet Infect Dis 2008; 8 (3): $179-190$

250 Marth T, Raoult D. Whipple's disease. Lancet 2003; 361 (9353): 239 246

251 Lagier JC, Lepidi H, Raoult D et al. Systemic Tropheryma whipplei: clinical presentation of 142 patients with infections diagnosed or confirmed in a reference center. Medicine (Baltimore) 2010; 89 (5): $337-345$
252 Geelhaar A, Moos V, Schinnerling $K$ et al. Specific and nonspecific Bcell function in the small intestines of patients with Whipple's disease. Infect Immun 2010; 78 (11): 4589-4592

253 Fenollar F, Lepidi $H$, Raoult $D$. Whipple's endocarditis: review of the literature and comparisons with Q fever, Bartonella infection, and blood culture-positive endocarditis. Clin Infect Dis 2001; 33 (8): $1309-1316$

254 Geissdörfer W, Moos V, Moter A et al. High frequency of Tropheryma whipplei in culture-negative endocarditis. J Clin Microbiol 2012; 50 (2): $216-222$

255 Lepidi H, Fenollar F, Dumler JS et al. Cardiac valves in patients with Whipple endocarditis: microbiological, molecular, quantitative histologic, and immunohistochemical studies of 5 patients. J Infect Dis 2004; 190 (5): $935-945$

256 von Herbay A. Whipple's disease. Histologic diagnosis after the discovery of Tropheryma whippelii. Pathologe 2001; 22 (1): 82-88

257 von Herbay A, Maiwald M, Ditton HJ et al. Histology of intestinal Whipple's disease revisited. A study of 48 patients. Virchows Arch 1996; 429 (6): 335 - 343

258 Edouard S, Fenollar F, Raoult D. The rise of Tropheryma whipplei: a 12-year retrospective study of PCR diagnoses in our reference center. J Clin Microbiol 2012; 50 (12): 3917-3920

259 Fenollar F, Fournier PE, Robert C et al. Use of genome selected repeated sequences increases the sensitivity of PCR detection of Tropheryma whipplei. J Clin Microbiol 2004; 42 (1): 401 -403

260 Fenollar F, Raoult D. Molecular techniques in Whipple's disease. Expert Rev Mol Diagn 2001; 1 (3): 299-309

261 Moter A, Schmiedel D, Petrich A et al. Validation of an rpoB gene PCR assay for detection of Tropheryma whipplei: 10 years' experience in a National Reference Laboratory. J Clin Microbiol 2013; 51 (11): 3858 3861

262 Raoult D, Fenollar F, Rolain JM et al. Tropheryma whipplei in children with gastroenteritis. Emerging Infect Dis 2010; 16 (5): 776 - 782

263 Keita AK, Brouqui P, Badiaga S et al. Tropheryma whipplei prevalence strongly suggests human transmission in homeless shelters. Int J Infect Dis 2013; 17 (1): e67-e68

264 Fenollar F, Trani M, Davoust B et al. Prevalence of asymptomatic Tropheryma whipplei carriage among humans and nonhuman primates. J Infect Dis 2008; 197 (6): 880-887

265 Panegyres PK. Diagnosis and management of Whipple's disease of the brain. Pract Neurol 2008; 8 (5): 311 - 317

266 Touitou V, Fenollar F, Cassoux N et al. Ocular Whipple's disease: therapeutic strategy and long-term follow-up. Ophthalmology 2012; 119 (7): $1465-1469$

267 Lagier JC, Fenollar F, Lepidi $H$ et al. Treatment of classic Whipple's disease: from in vitro results to clinical outcome. J Antimicrob Chemother 2014; 69 (1): 219-227

268 Feurle GE, Marth T. An evaluation of antimicrobial treatment for Whipple's Disease. Tetracycline versus trimethoprim-sulfamethoxazole. Dig Dis Sci 1994; 39 (8): $1642-1648$

269 Fleming JL, Wiesner $R H$, Shorter RG. Whipple's disease: clinical, biochemical, and histopathologic features and assessment of treatment in 29 patients. Mayo Clin Proc 1988; 63 (6): 539-551270

270 Feurle GE, Moos V, Schneider T et al. The combination of chloroquine and minocycline, a therapeutic option in cerebrospinal infection of Whipple's disease refractory to treatment with ceftriaxone, meropenem and co-trimoxazole. J Antimicrob Chemother 2012; 67 (5): $1295-1296$

271 Fenollar F, Rolain JM, Alric L et al. Resistance to trimethoprim/sulfamethoxazole and Tropheryma whipplei. Int J Antimicrob Agents 2009; 34 (3): 255-259

272 Lagier JC, Fenollar F, Lepidi $H$ et al. Evidence of lifetime susceptibility to Tropheryma whipplei in patients with Whipple's disease. J Antimicrob Chemother 2011; 66 (5): 1188-1189

273 Fenollar F, Lepidi H, Gérolami R et al. Whipple disease associated with giardiasis. J Infect Dis 2003; 188 (6): 828-834

274 Feurle GE, Moos V, Schinnerling K et al. The immune reconstitution inflammatory syndrome in whipple disease: a cohort study. Ann Intern Med 2010; 153 (11): 710-717 